\title{
UMA ABORDAGEM HISTÓRICA SOBRE A TEORIA DA ESTABILIDADE NA ANÁLISE DO EQUILÍBRIO COMPETITIVO
}

\author{
TÁCITO AUGUSTO FARIAS
}

Economista/Matemático

Orientador: Prof. Dr. ELEUTÉRIO FERNANDO DA SILVA PRADO

\footnotetext{
Tese apresentada à Escola Superior de Agricultura "Luiz de Queiroz", Universidade de São Paulo, para obtençāo do título de Doutor em Ciências, Área de Concentração: Economia Aplicada.
}

\author{
PIRACICABA \\ Estado de São Paulo - Brasil \\ Janeiro - 1999
}


Dados Internacionais de Catalogação na Publicação (CIP) DIVISÃo DE BIBLIOTECA E DOCUMENTAÇÃO - Campus "Luiz de Queiroz"/USP

\section{Farias, Tácito Augusto}

Uma abordagem histórica sobre a teoria da estabilidade na análise do equilibrio competitivo / Tácito Augusto Farias. - Piracicaba, 1999.

$151 \mathrm{p}$.

Tese (doutorado) - - Escola Superior de Agricultura Luiz de Queiroz, 1999.

Bibliografia.

1. Competição 2. Demanda 3. Economia matemática 4. Equibrio econômico 5. Establilização de mercado 6. Teoria econòmica l. Título 


\section{UMA ABORDAGEM HISTÓRICA SOBRE A TEORIA DA ESTABILIDADE NA ANÁLISE DO EQUILÍBRIO COMPETITIVO}

TÁCITO AUGUSTO FARIAS 


\section{DEDICATÓRIA}

Enquanto esforço e desprendimento dedico este trabalho a GUIOMAR DE AQUINO FARIAS (1907-1989), LINDINALVA FARIAS e ADENIZIIA SERAFIM DOS SANTOS. 


\section{AGRADECIMENTOS}

Para a execução de qualquer tarefa ordinária tanto na vida pessoal como profissional um grupo de pessoas nos cercam com o propósito único de orientar e facilitar a elaboração, organização, planejamento e eficiência, daquela. Com efeito, expresso gratidão ao Professor Eleutério Fernando da Silva Prado pela paciência e interesse na orientação da tese doutoral; ao Professor Manoel Cabral de Castro pelo zelo e confiança em meu desempenho acadêmico; ao Professor Joaquim Martins Guilhoto que através de seu excelente desempenho na disciplina de doutorado, MICROECONOMIA III, despertou o interesse pelo tema na área de equilíbrio geral; ao Professor Paulo do Amaral Costa pelo empenho na execução dos serviços de informática; a Maria Aparecida Maielli Travalini e Luciane Cipriano funcionárias atentas a servir com zelo e cortesia aos alunos da Pós-Graduação. 


\section{SUMÁRIO}

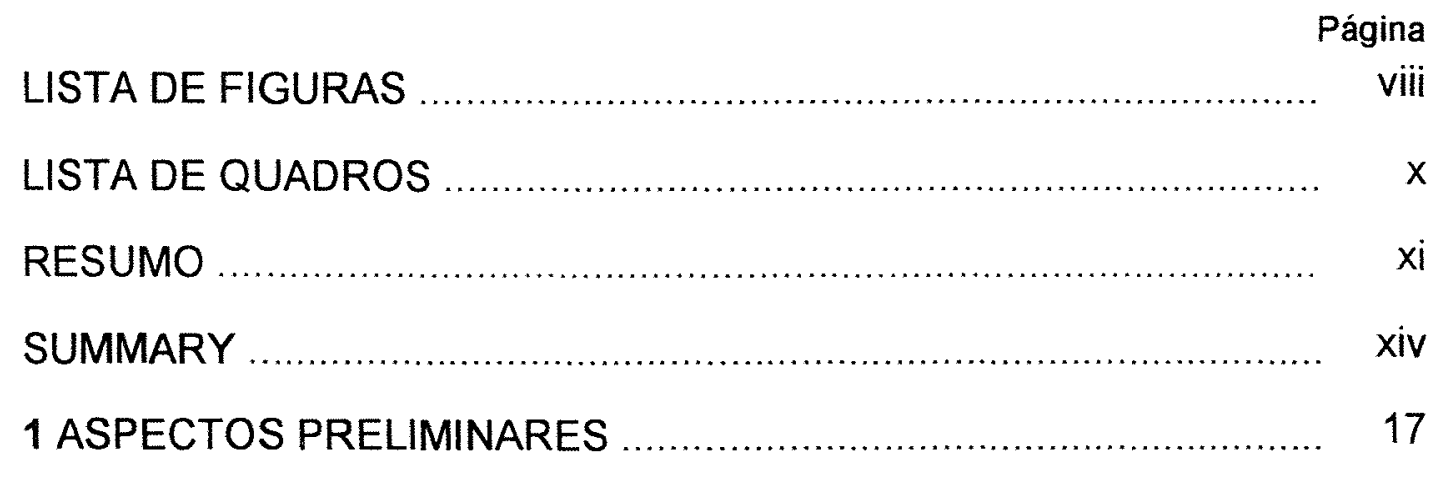

1.1 Definição do problema e sua delimitação ................................. 17

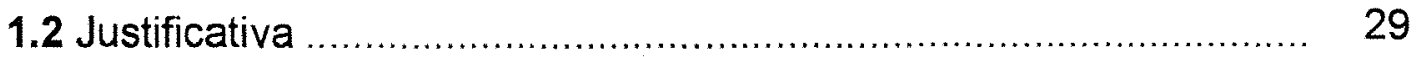

1.3 Objetivos ..................................................................... 34

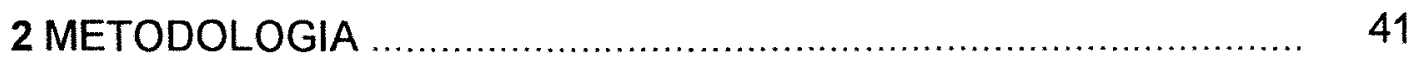

2.1 Fundamentos analíticos ................................................ 41

2.2 Enfoque histórico e as fontes de pesquisas ............................ 44

3 AS RAIZZES DA TEORIA DA ESTABILIDADE DO EQUILÍBRIO COMPETITIVO …................................................... 48

3.1 A estabilidade do equilíbrio em mercado único ......................... 49

3.1.1 Cenário sócio-econômico e a influência de Antoine Augustin

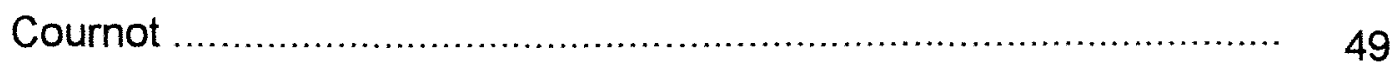

3.1.2 A contribuição de Walras ................................................... 53

3.1.3 Considerações adicionais ................................................. 64

3.2 A estabilidade do equilibrio em mercados múltiplos .................. 66 
3.2.1 Panorama institucional e características gerais

3.2.2 John Richard Hicks ................................................... 72

3.2.3 Paul Anthony Samuelson ............................................... 79

3.2.4 Oscar Lange ...................................................................... 84

3.2.5 Lloyd Metzler ................................................................. 87

3.2.6 O modelo de expectativas adaptativas ................................. 92

4 A TEORIA DA ESTABILIDADE DO EQUILÍBRIO COMPETITIVO EM MERCADO MÚLTIPLO BASEADA NUMA ECONOMIA

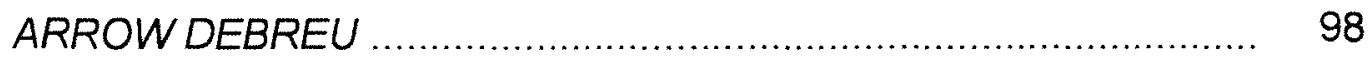

4.1 Ambiente econômico e cenário analítico ................................ 98

4.2 Fundamentos da teoria da estabilidade do equilíbrio competitivo O processo de ajustamento de preços no sistema econômico: Tâtonnement

4.3 Scarf e o ataque frontal ao Tâtonnement

4.4 A teoria da estabilidade no sistema econômico após o ataque frontal de Scarf

4.4.1 Fundamentos do processo de ajustamento de preços no sistema econômico: Non-Tâtonnement

4.4.2 Análise global: Stephen Smale

5 CONSIDERAÇÕES FINAIS

REFERÊNCIAS BIBLIOGRÁFICAS 


\section{LISTA DE FIGURAS}

Página

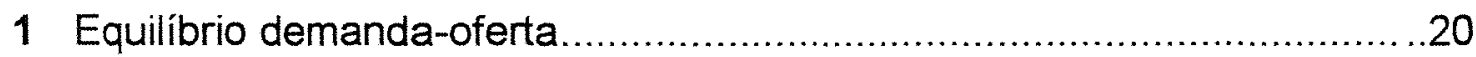

2 Equilibrio demanda-oferta e função excesso da demanda ....................22

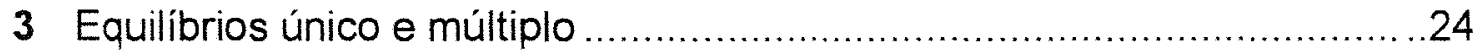

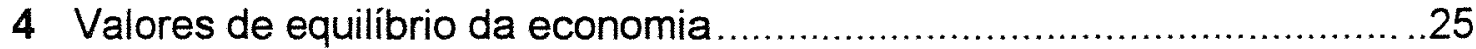

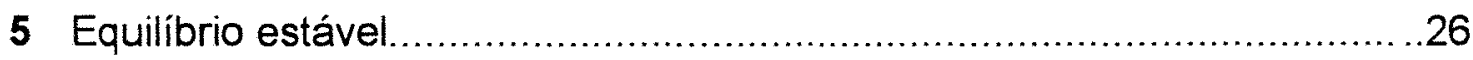

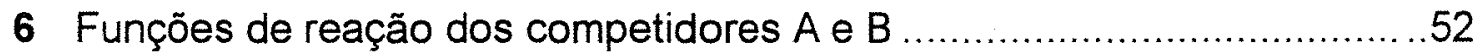

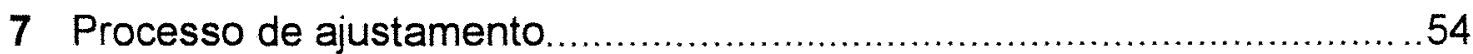

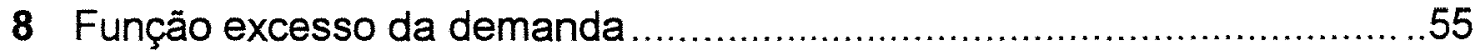

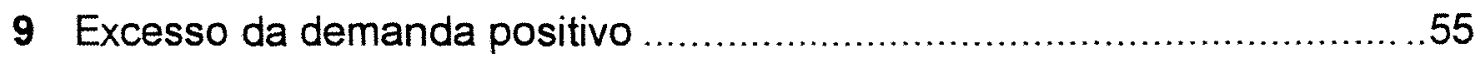

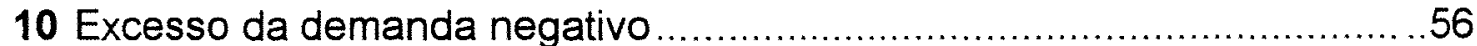

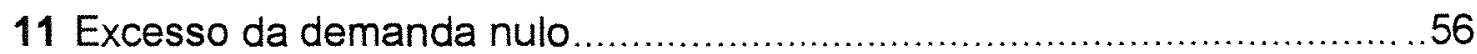

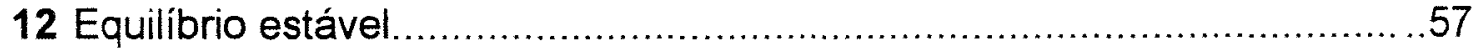

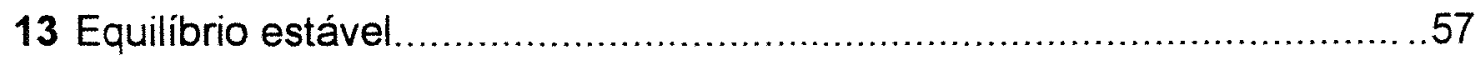

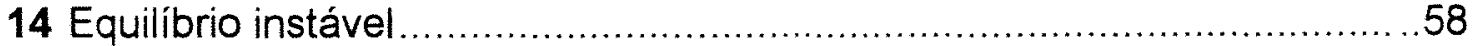

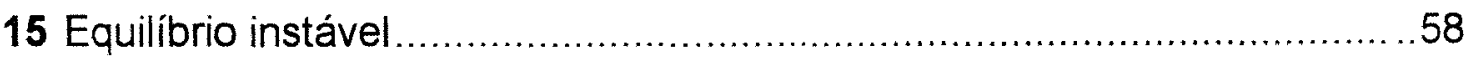

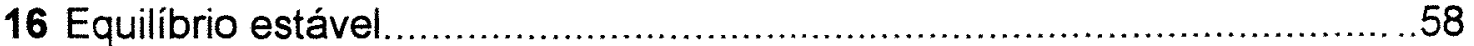

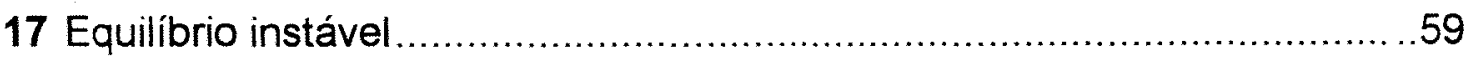

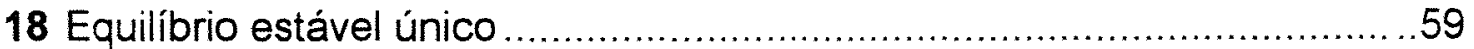

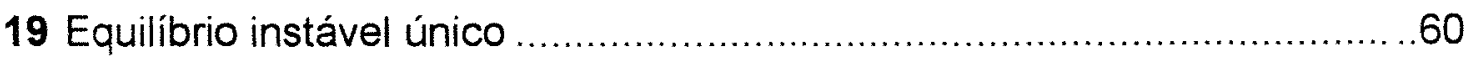

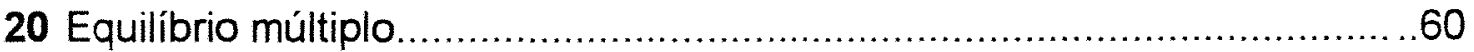

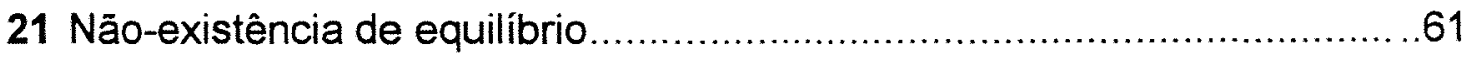

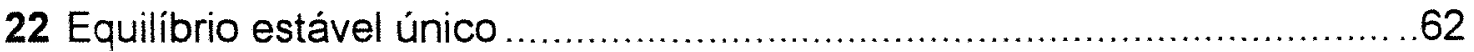




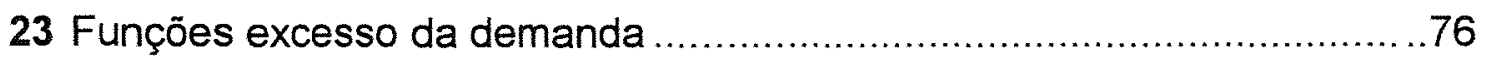

24 Curvas de indiferenças ............................................... 115

25 Equilibrio Cournot-Nash........................................................ 135 


\section{LISTA DE QUADROS}

Página

1 Seqüência de construção do modelo abstrato. 43

2 Construção da teoria da estabilidade do equilíbrio competitivo 47 


\title{
UMA ABORDAGEM HISTÓRICA SOBRE A TEORIA DA ESTABILIDADE NA ANÁLISE DO EQUILIB́RIO COMPETITIVO
}

\author{
Autor: TÁCITO AUGUSTO FARIAS \\ Orientador: Prof. ELEUTÉRIO FERNANDO DA SILVA PRADO
}

\section{Resumo}

Com o objetivo de compreender a evolução da teoria da estabilidade do equilibrio competitivo - Tâtonnement e seu desdobramento - no período 1874 1990, identifica-se os quadros histórico-institucional e analítico sob o qual a teoria avançou. As identificações são realizadas através da literatura corrente sobre a história econômico-social e eventos importantes em escala mundial, estado da arte da matemática, teoria do equilíbrio geral e avaliação minuciosa dos artigos e livros clássicos originais sobre a teoria da estabilidade do equilibrio competitivo e seu desdobramento.

A exposição ao longo da tese é realizada através da identificação das contribuições principais na teoria da estabilidade e obedece uma ordem cronológica no sentido do aprofundamento cada vez maior sobre a teoria da estabilidade do equilíbrio competitivo.

Todo corpo teórico sistemático-lógico tem seu princípio na obra magistral do eminente Professor Leon Walras denominada Elements of Pure Economics (1874), que conduz sua análise sobre a teoria da estabilidade do equilíbrio competitivo através da apreciação do ente abstrato, função excesso 
da demanda, e enuncia a condição Walrasiana fundamental: um mercado é estável se uma elevação do preço reduz o excesso da demanda. O uso da condição da estabilidade do sistema econômico competitivo associado a novos instrumentos de análise quais sejam, estabilidade perfeita e imperfeita estabelecidas por J.R. Hicks em seu livro clássico Value and Capital (1939), estabilidade de $1^{a}$ espécie descrita por Samuelson em Foundations of Economic Analysis (1947), aspectos normativos da teoria da estabilidade do equilíbriocompetitivo destacado por Lange em Price Flexibility and Employement (1944), substitutos brutos e velocidades de ajustamentos de preços apreciados por Metzler em Econometrica (13, 1945, p.277-292) nas décadas dos 30 e 40 acarretam a apreciação de teoremas fundamentais que revelam o comportamento dos fenômenos existentes no sistema econômico.

No fim dos anos 50 e início dos 60 os Professores Arrow, Hahn e Block, desenvolvem trabalhos que definem o método de análise na teoria do equilíbrio, ao qual a ênfase principal ocorre sobre a teoria da estabilidade dos mercados sob regime competitivo. Usam intensivamente os conceitos de estabilidade local, estabilidade global, substitutos brutos, substitutos líquidos, expectativa adaptativa, o método de Lyapunov e o axioma da preferência revelada (Fraco) que quando relacionados convenientemente, geraram inúmeros teoremas fundamentais que preservam a consistência lógica do funcionamento dos mercados sob regime competitivo. Porém, no inicio da década dos 60 , Scarf (1960) e Gale (1960) levantam questionamentos sobre a validade da teoria da estabilidade baseada na hipótese de substitutibilidade bruta focalizando contraexemplos que apresentam um sistema econômico que é considerado instável: a substitutibilidade falha.

A partir daí, anos 60, 70 e 80, inúmeros estudos direcionam em óticas distintas para pesquisar sobre a estabilidade do sistema: Non-Tâtonnement, caos, catastrófe, teorias do crescimento e ciclos de negócios, jogos e oligopólio; além do desenvolvimento da análise global aplicada ao processo de ajustamento Tâtonnement (Stephen Smale) como linguagem alternativa à 
economia Arrow \& Debreu, destacando-se a generalização dos resultados e a reintrodução da variável tempo que fora desconsiderada no modelo de equilíbrio geral estabelecido por Arrow \& Debreu. 


\section{A HISTORICAL APPROACH UPON THE THEORY OF STABILITY RELATING TO ANALYSIS OF COMPETITIVE EQUILIBRIUM}

Author: TÁCITO AUGUSTO FARIAS

Tutor: Professor ELEUTÉRIO FERNANDO DA SILVA PRADO

\section{Summary}

In order to understanding the evolution of the theory of stability involving the comprehension of the competitive equilibrium - Tattonnement and its fully development _ throughout the period 1874-1990, one can identify that one - the historic-institutional events and analytic data - under which the cited theory has advanced along the time up-to-date. Such identifications have been held throughout the current literature (bibliography) over the economic-social history and other most important worldwide events such as the status of the art of mathematic science, including even though the general equilibrium theory and a careful and accurate evaluation of published articles and edition of original classic books in which are widely discussed the quoted subject, i.e. the theory of stability before the challenge of the competitive equilibrium and its fully development.

Therefore, the explanation along the present thesis is held throughout the identification of the main contributions for the stability of such theory and in this manner must obey a chronological order of itemized propositions in order to 
make a profound study on the structure of the theory of stability in the field of competitive equilibrium.

Basically, all theoretical and sistematic-logical structure has kept its origin in the masterpiece written by the eminent Professor Leon Walras named Elements of Pure Economics (1874) that leads his analysis upon the cited theory to the valuation of the abstract referencial element and the excess function in demand, announcing the Walrasian basic condition, i.e.: a market will only be stable whether the increase of price decreases the excess in demand. And the use of such condition of stability on the economic competitive system associated to a new instruments of analysis such as perfect and perfect elements of stability established by J.R. Hicks in his classic book Value and Capital (1939) in which the stability of first rank described by P.A Samuelson in Foundations of Economic Analysis (1947), and some other normative aspects of the theory of stability competitive equilibrium emphasized by $O$. Lange in Price Flexibility and Employment (1944), gross substitutes and speed of price adjustments valued by L. Metzler in Econometrica( 13, 1945, p. 277-292) in the decades of 30's and 40's have caused the evaluation of basic theorems that embodying the behavior of phenomena that have already existed in the economic structure..

At the end of 50's and earlier in the 60's, the Professors Arrow, Hahn and Block developed analitical studies that defined the method of analysis on the theory of equilibrium in which the principal emphasis occurs upon the theory of stability and the market research under competitive model. Concepts of local stability, concepts of global stability, gross substitutes, net substitutes, adaptive expectation, the classical Lyapunov's second method and the weak axiom of the revealed preference that when properly related are intensively used and have created several basic theorems that have preserved the logical structure of work of such markets under competitive model. However, in the earlier decade of 60's, Scarf (1960) and Gale (1960) made some inquiries about the validate of the theory of stability based on hypothesis of gross 
substitutes pointing out contra-examples that demonstrate a type of economic system which is basically considered instable: the condition of substitutibility is failured.

Since then, a lot of studies are conducted to distinct angles in order to accomplish the research about the stability of such system. Non-Tâtonnement, chaos, catastrophe, the growth theory business cicles, theory of games and oligopolistic structures, and more the description of global analysis applied to the Tâtonnement process of adjustment (Stephen Smale) as an alternative language to the economic system Arrow \& Debreu, emphasizing the results in general and the reintroduction of the variable "time" which was disregarded on the model of general equilibrium established by Arrow \& Debreu. 


\section{ASPECTOS PRELIMINARES}

O Capítulo introdutório está dividido em três Seções. Na primeira, coloca-se o problema e sua delimitação, deixando claro, qual a indagação que é respondida ao longo da tese. Na segunda, é estabelecida a justificativa da realização do tema proposto. Na terceira, revela-se com clareza os objetivos a serem alcançados, qual seja, explicar sob a ótica histórica, a construção da teoria da estabilidade do equilíbrio competitivo através de seus elementos influenciadores: panorama histórico-institucional, cenário analítico e eventos importantes.

\subsection{Definição do problema e sua delimitação}

Atualmente, distingue-se três niveis do conhecimento científico. Primeiro, o inorgânico, estudado pela Ciências Exatas e da Natureza. Segundo, o orgânico, estudado pelas Ciências Biológicas. Terceiro, o superorgânico, estudado pelas Ciências Sociais. Com efeito, o dominio de ação das Ciências Sociais ocorre somente quando as investigações física e biológica do homem e seu universo terminam. $\mathrm{Na}$ verdade, os três niveis inter-relacionam-se de modo que a transição de um para outro é gradativa. O superorgânico é observado no domínio dos individuos em interação e nos resultados dessa interação: linguagem, filosofia, ciência, tecnologia, ética, usos e costumes; e em outros elementos essenciais, presentes no domínio cultural e da organização social. Significa dizer que ao estudar o superorgânico, as Ciências Sociais têm o seu interesse voltado para o homem em sociedade. 
Inúmeras são aquelas maneiras possíveis de classificação das Ciências Sociais, contudo, para o propósito da análise, no momento, importa apresentar aquela que julga-se mais conveniente sem entrar em detalhes na escolha, pois fugiria ao propósito do tema a ser adequadamente abordado. Aquela classificase em Antropologia Cultural, Direito, Economia, Política, Psicologia Social e Sociologia. Portanto, observa-se que a Economia impõe-se como uma disciplina incluída no âmbito das Ciência Sociais . Economia investiga as ações humanas no domínio do planejamento, organização e controle dos recursos da sociedade. Sua esfera de ação projeta-se sobre produção, circulação, distribuição e consumo de mercadorias e serviços. Significa dizer que a Economia trata com a ação humana, individual e coletiva, objetivando a apropriação dos bens materiais e usos dos serviços dos fatores de modo a atingir a satisfação das necessidades humanas. À Economia, num leque de atividades humanas, cabe apenas, a atividade econômica.

A Economia como corpo de ciência que estuda a organização dos recursos econômicos possui sua própria divisão para efeito de investigação científica. Domínios de investigação são distinguidos. Primeiro, a Macroeconomia, que estuda as atividades econômicas no agregado, tratando especificamente da Teoria clássica, Teoria keynesiana, Teoria novo-clássica e Teoria novo-keynesiana. As variáveis relevantes no contexto macroeconômico são renda agregada, produto agregado, poupança agregada, desemprego, inflação, taxa de juros e investimento agregado (bruto e líquido). Segundo, a Microeconomia, que estuda as atividades econômicas dos agentes individuais tratando especificamente da Teoria da demanda do comportamento do consumidor (versões: cardinal, ordinal, preferência revelada e escolha envolvendo risco), Teoria da firma (produção e custo), Estrutura de mercado (produto e fatores), Teoria do equilíbrio geral, Teoria do Bem-Estar e Economia da informação. Terceiro, o Desenvolvimento econômico, que estuda os elementos essenciais para o alcance e manutenção da qualidade de vida da sociedade, tratando especificamente com a teoria do crescimento econômico e 
os principais indicadores do desenvolvimento econômico e social de uma nação. Quarto, a Economia internacional, que estuda as relações efetuadas entre residentes e não-residentes de um país, tratando especificamente da Teoria pura do comércio internacional (Teoria da Troca), Teoria monetária do comércio internacional, Balança de pagamento e Política comercial.

Neste ponto, identifica-se como relevante para o estudo a ser realizado, o corpo teórico da microeconomia onde encontra-se o objeto da análise: teoria do equilibrio geral. Neste contexto, e para propósito de análise, a microeconomia identifica-se como a economia neoclássica. Significa dizer que os pilares da microeconomia confunde-se com os pilares da doutrina neoclássica: princípios de otimização e equilibrio. Formalmente, a economia neoclássica vincula-se à presença de três elementos: (1) utilização do reducionismo no sentido de focalizar as explicações para os fenômenos econômicos a partir da ação de agentes individuais; (2) utilização das normas de racionalidade; (3) crença de que a noção do equilibrio é exigida e que o estudo dos estados de equilibrio é útil.

O conceito de equilíbrio está presente em todo modelo microeconômico e representa o referencial definicional principal da teoria do equilibrio geral, qual seja, balanceamento de forças. Toda a argumentação explicativa e conclusiva que está presente naquela teoria baseia-se na presença do conceito do equilibrio. Tal conceito desempenha basicamente três funções: (1) é um recurso heurístico e como tal busca organizar em torno de um eixo comum, fenômenos econômicos, que em principio mostram-se independentes e revelam-se parte de um sistema ordenado; (2) é uma norma teórica, e como tal, se constitui em uma medida abstrata que os economistas podem comparar o estado de uma economia real em um dado momento do tempo; (3) é um sistema de lógica, pois serve como paradigma do método científico. Portanto, a teoria do equilíbrio geral apresenta-se sob o rigor e a precisão matemática, o que impõe à economia neoclássica o caráter científico.

Após a identificação da teoria do equilíbrio no corpo da teoria 
econômica neoclássica, precisamente na microeconomia, cumpre estabelecer que tipos de problemas relevantes revelam-se: (1) existência do equilibrio do sistema econômico; (2) unicidade do equilíbrio do sistema econômico;

estabilidade do equilíbrio do sistema econômico.

Primeiro, a formulação abstrata relevante da idéia do equilíbrio em uma economia simples é aquela na qual observa-se a ocorrência dos desejos dos consumidores em adquirir uma quantidade de uma determinada mercadoria que coincida com as intenções dos produtores em produzirem e venderem aquela mesma quantidade demandada pelos consumidores. Significa dizer que oferta $e$ demanda devem coincidir a um certo preço positivo e o ponto declarado é denominado ponto de equilíbrio. Veja a Figura 1 :

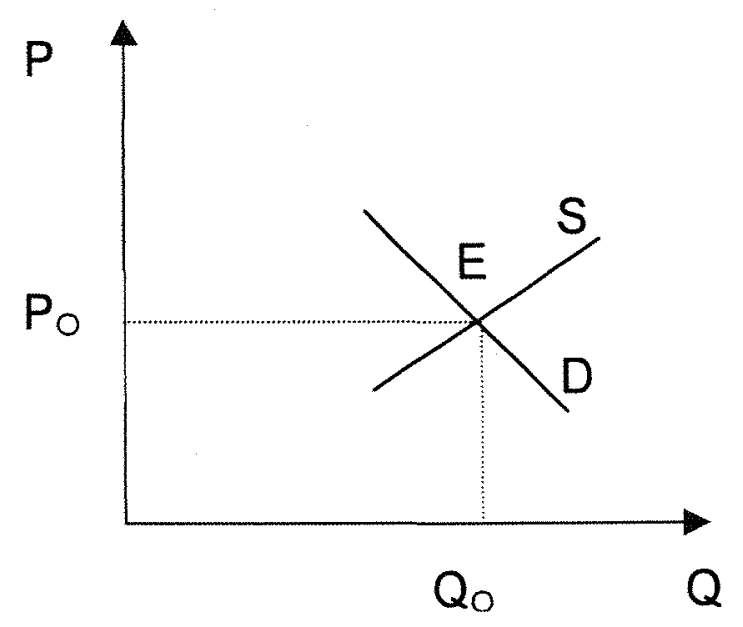

Figura 1 - Equilibrio demanda-oferta

Um exercicio simples é resolvido em detalhe. Imagine uma economia simples descrita pelas funções de demanda e oferta:

$$
\left\{\begin{array}{l}
D=100-5 P \\
S=50+5 P
\end{array}\right.
$$


e determina-se o par ordenado de equilíbrio $\left(Q_{e}, P_{e}\right)$, função excesso da demanda e a representação gráfica:

$\mathrm{D}=\mathrm{S} \quad \rightarrow \quad$ condição de equilibrio

$100-5 P=50+5 P$

$100-50=10 P$

$50=10 P$

$P_{e}=5 \rightarrow$ preço de equilibrio

$S=D=Q_{e} \rightarrow$ condição de equilíbrio

$Q_{\mathrm{e}}=50+5 \times 5$

$Q_{e}=50+25$

$\mathrm{Q}_{\mathrm{e}}=75 \quad \rightarrow \quad$ quantidade de equilibrio

$E(P)=D(P)-S(P)$

$E(P)=100-5 P-(50+5 P)$

$E(P)=100-50-5 P-5 P$

$E(P)=50-10 P \rightarrow$ função excesso da demanda

$\frac{d E(P)}{d P}=-10<0 \rightarrow$ inclinação da curva de excesso da demanda 


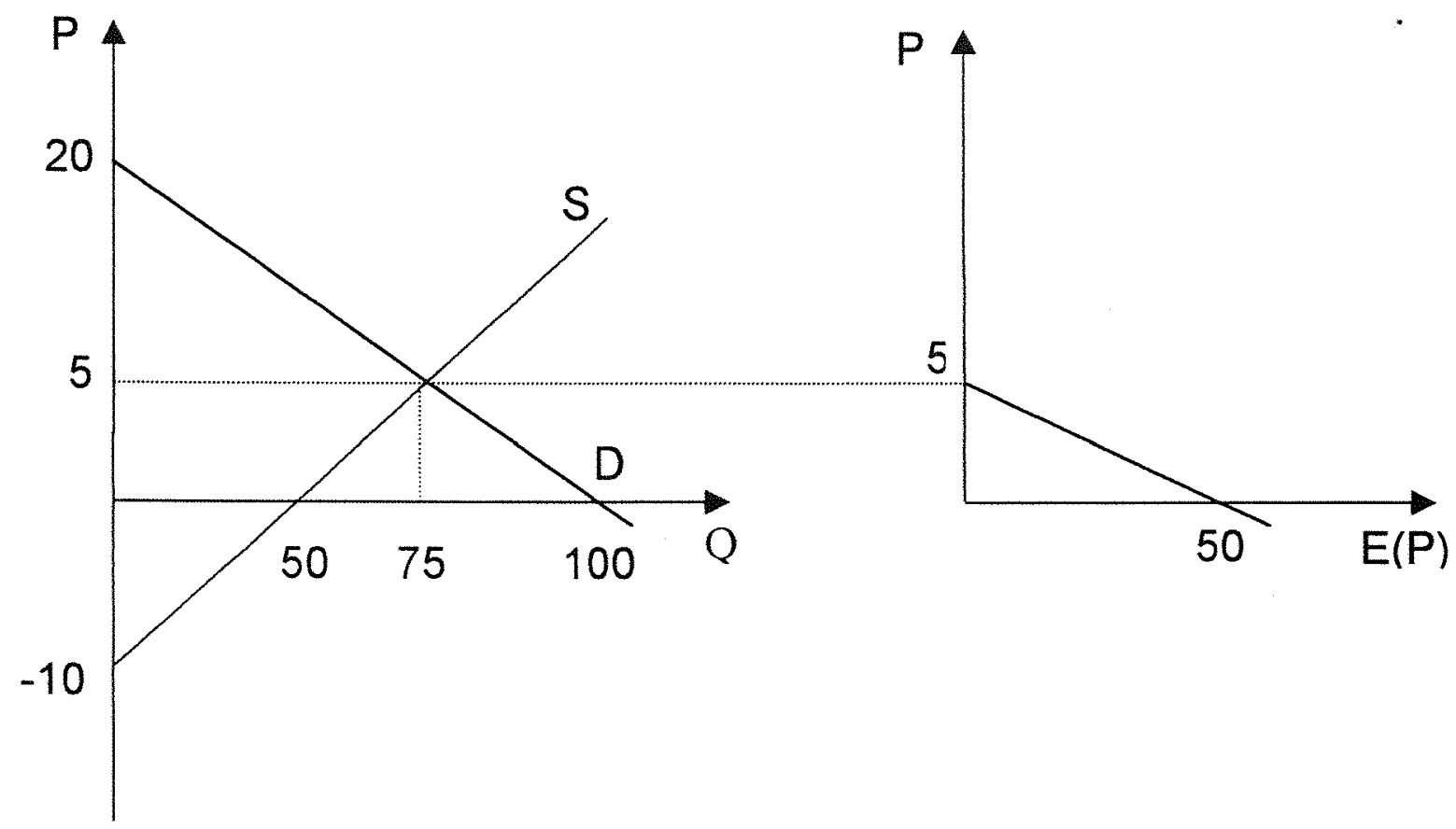

(a) Equilibrio demanda-oferta

(b) Função excesso da demanda

Figura 2 - Equilíbrio demanda-oferta e função excesso da demanda

Numa economia mais complexa com um número finito de consumidores e produtores e, também, um número finito de mercadorias, os desejos dos agentes econômicos, consumidores e produtores, devem coincidir em todos os mercados individualmente e para cada mercadoria. Significa dizer que a oferta e a demanda em cada mercado são iguais e o ponto declarado é denominado ponto de equilibrio, porém não mais de um mercado especifico, e sim do conjunto de todos os mercados (cada mercado em particular deve estar em equilíbrio para que haja equilibrio geral). E está estabelecido o problema da existência do equilibrio geral no mercado na literatura corrente através de Debreu, Arrow e McKenzie. Novamente, um exercício simples é resolvido em detalhe. Suponha que exista uma economia que seja descrita pelas funções 
excesso da demanda abaixo:

$$
\begin{cases}E_{1}=-P_{1}+3 P_{2}-7 & \text { excesso da demanda para a mercadoria } 1 \\ E_{2}=P_{1}-2 P_{2}+4 & \text { excesso da demanda para a mercadoria } 2\end{cases}
$$

A condição de existência do vetor de preços de equilíbrio é que a função excesso da demanda para cada mercadoria seja zero:

$$
\begin{aligned}
& E_{1}=0 \quad \therefore \quad-P_{1}+3 P_{2}-7=0 \\
& \left\{\begin{array}{l}
-P_{1}+3 P_{2}=7 \\
P_{1}-2 P_{2}=-4
\end{array}\right.
\end{aligned}
$$

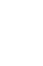


único?. Nem sempre, pois pode existir situações na qual a multiplicidade dos pontos de equilibrio pode ocorrer. Depende tal fato do formato das curvas de oferta e demanda das mercadorias. Veja a Figura 3 :

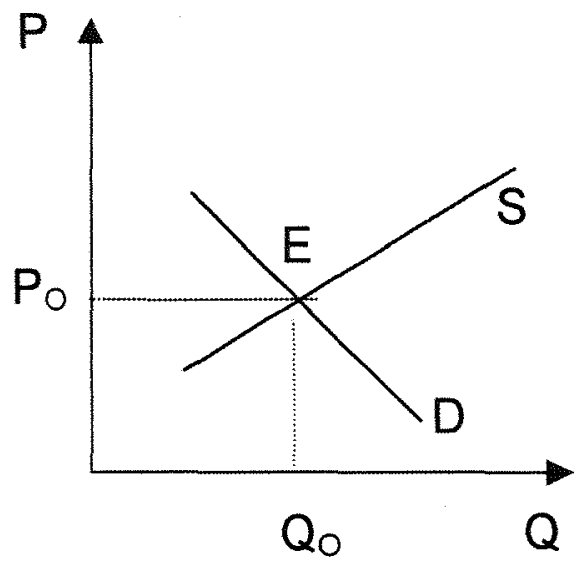

(a) Equilíbrio único

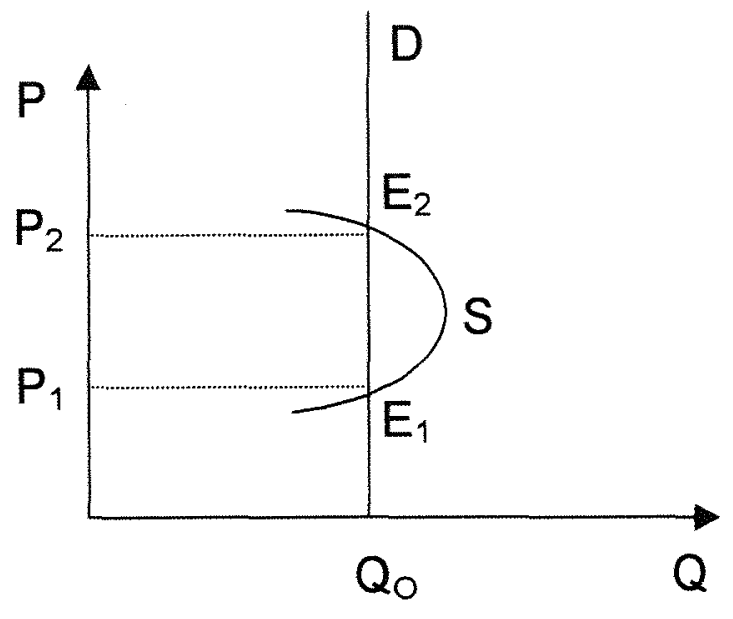

(b) Equilíbrio múltiplo

Figura 3 - Equilíbrios único e múltiplo.

Em geral, se as curvas da oferta e da demanda apresentam formatos suaves e convencionais, a ocorrência da unicidade fica estabelecida (veja a Figura 3(a)). Aplica-se um exercício numérico em detalhe. Imagine uma economia representada pelas funções da demanda e da oferta:

$$
\left\{\begin{array}{l}
D=100-5 P \\
S=20+5 P
\end{array}\right.
$$

$D(P)=S(P) \quad \rightarrow \quad$ condição de equilibrio

$100-5 P=20+5 P$

$100-20=10 P$

$80=10 \mathrm{P}$

$\mathrm{P}_{\mathrm{e}}=8 \rightarrow$ preço de equilíbrio

$D=S=Q_{e}$ 
$Q_{e}=20+5 \times 8$

$Q_{e}=20+40$

$Q_{e}=60 \quad \rightarrow \quad$ quantidade de equilibrio

$E(P)=D(P)-S(P)$

$E(P)=100-5 P-20-5 P$

$E(P)=80-10 P \quad \rightarrow \quad$ função excesso da demanda

$\frac{\mathrm{dE}(\mathrm{P})}{\mathrm{dP}}=-10<0 \quad \rightarrow \quad$ inclinação da curva de excesso da demanda

$|E(P)|=\frac{d E(P)}{d P} \quad \therefore \quad|E(P)|=-10<0 \rightarrow$ condição de unicidade do vetor de preços de equilíbrio,

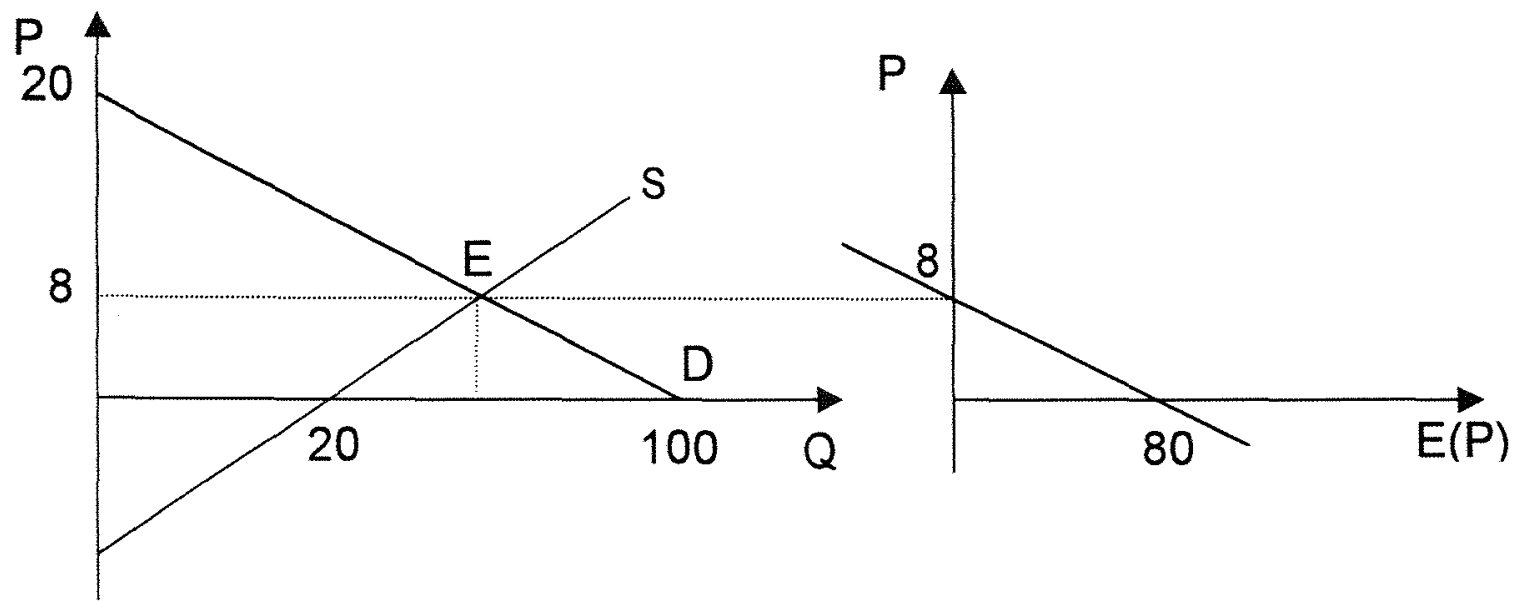

(a) Equilibrio demanda-oferta

(b) Função excesso da demanda

Figura 4 - Valores de equilíbrio da economia.

Caso contrário, observa-se a multiplicidade dos pontos de equilíbrio (veja a Figura 3(b)). E, aplica-se um exercício simples em detalhes. Suponha uma economia que possua duas mercadorias (sistema normalizado) e que é 
representada pelas funções excesso da demanda descritas como segue:

$$
\left\{\begin{array}{l}
E_{2}=P_{2}^{2}+22 P_{2}-13 P_{2} P_{3}-64 P_{3}+20 P_{3}^{2}+48 \\
E_{3}=P_{2}-2 P_{3}+3
\end{array}\right.
$$

Substituindo a segunda equação na primeira tem-se:

$$
P_{3}^{2}-5 P_{3}+6=0
$$

com raízes

$$
\begin{array}{ll}
\mathrm{P}_{3}^{\prime}=3 & \mathrm{P}_{3}^{\prime \prime}=2 \\
\mathrm{P}_{2}^{\prime}=4 & \mathrm{P}_{2}^{\prime \prime}=2
\end{array}
$$

cujos vetores de equilíbrio são $A_{1}=(1,4,3)$ e $A_{2}=(1,2,2)$.

É estabelecido o problema da unicidade do ponto de equilíbrio na literatura corrente por Debreu e Arrow (1954) e McKenzie (1959).

Terceiro, a idéia da estabilidade do ponto de equilíbrio no esquema oferta-demanda depende rigorosamente dos formatos das curvas de oferta e demanda. Daí, diz-se que o equilíbrio é estável se a curva da demanda intercepta a curva da oferta a partir de cima. Caso contrário, o ponto é considerado instável. Veja a Figura 5:

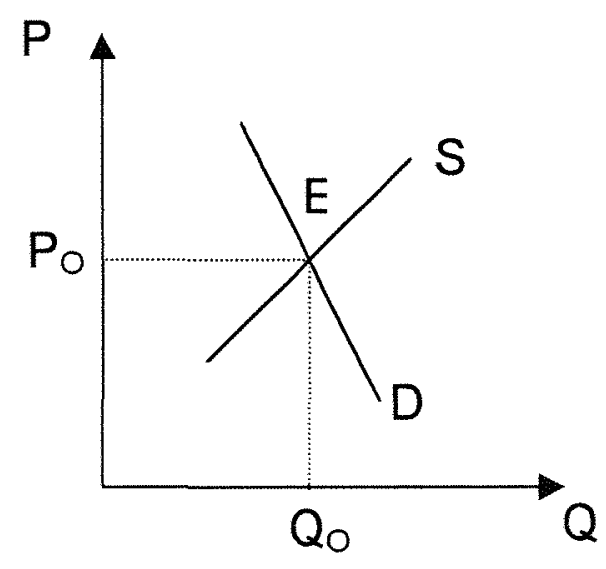

Figura 5 - Equilibrio estável 
Aplica-se, em seguida, um exercício numérico simples. Imagine uma economia que possui duas mercadorias e que é representada por funções excesso da demanda descritas abaixo:

$$
\left\{\begin{array}{l}
E_{1}=-P_{1}-P_{2}+7 \\
E_{2}=P_{1}-P_{2}+1
\end{array}\right.
$$

As condições matemáticas da estabilidade do sistema são descritas como segue:

$1 \operatorname{Tr} A<0$

$A=E(P)=\left[\begin{array}{cc}-1 & -1 \\ 1 & -1\end{array}\right] \quad \therefore \quad \operatorname{Tr} A=(-1)+(-1) \quad \therefore \quad \operatorname{Tr} A=-2<0$

$\underline{2}|E(P)|>0$

$E(P)=\left[\begin{array}{cc}-1 & -1 \\ 1 & -1\end{array}\right] \quad \therefore|E(P)|=\left|\begin{array}{cc}-1 & -1 \\ 1 & -1\end{array}\right| \quad \therefore|E(P)|=1-(-1)$

$|E(P)|=1+1 \therefore|E(P)|=2>0$

Satisfeitas as duas condições, afirma-se que o vetor de preços de equilibrio $\left(P_{1}, P_{2}\right)=(3,4)$ é estável.

No domínio da teoria do equilíbrio econômico geral, o problema da estabilidade do equilibrio impõe-se segundo considerações relevantes. Primeira, o sistema quando é estável garante a unicidade de sua solução. Segunda, a economia pode ser representada por um sistema dinâmico gerado por sistemas de equações diferenciais ou sistema de equações a diferenças que implicam o mecanismo de ajustamento do preço ou produto da economia. Terceira, a trajetória do preço ou produto da economia pode ser estudada 
através do instrumento gráfico denominado plano de fase. Quarta, estabilidades local e global são estudadas para saber o comportamento local ou global do ponto de equilibrio, ou seja, se numa vizinhança ou distante do ponto de equilíbrio normal, após uma perturbação daquele ponto.

Delimita-se o raio de ação do estudo do problema sobre a teoria matemática da estabilidade aplicada ao equilíbrio competitivo sob dois aspectos: espacial e temporal.

Espacialmente, leva-se em consideração somente as contribuições dos economistas matemáticos que militam nas escolas avançadas que contribuíram de forma decisiva para a solução do problema sobre a estabilidade do equilíbrio competitivo sob o processo de ajustamento Tâtonnement e seu desdobramento. Alguns desses economistas matemáticos trabalharam (alguns ainda trabalham) em institutos de pesquisas avançadas nos Estados Unidos, Europa e Ásia (Japão). Destaques para Arrow, Green, McKenzie, Lange, Metzler, Scarf, Fisher, Smale e Gale nos Estados Unidos; Hahn e Hicks, na Inglaterra; Negishi, Nikaidô e Uzawa, no Japão.

Temporalmente, considera-se o período de 1874 - 1990 porque compreende o período de fertilidade no tocante à contribuição para 0 desenvolvimento, aperfeiçoamento e solução de alguns problemas essenciais sobre a estabilidade do equilibrio competitivo. Fases do desenvolvimento da teoria da estabilidade do equilibrio competitivo são estabelecidas: (1) 1874 1958, uso intensivo do cálculo diferencial e integral na construção e desdobramento dos modelos de equilíbrio geral, inclusive, estabilidade do equilibrio competitivo; (2) 1958 - 1976, axiomatização verificada pelo uso intensivo da topologia geral, análise convexa e análise no $R^{\text {n. }}$ (3) 1976 - ?, análise global (cálculo e axiomatização).

Estabelecido os três problemas chaves na teoria do equilíbrio competitivo, existência, unicidade e estabilidade $e$ as respectivas fases do desenvolvimento da teoria da estabilidade do equilíbrio competitivo, cumpre destacar qual o problema a considerar como relevante, qual seja, a teoria da 
estabilidade do equilíbrio competitivo é abordada sob a ótica histórica de forma a responder a seguinte pergunta: É possível elaborar ou construir a história da teoria da estabilidade do equilibrio competitivo e suas respectivas soluções através da seqüência de modelos sem romper com o paradigma prevalecente da economia neoclássica? Sim, e o esforço ao longo do texto é traçar a trajetória histórico-comparativa dos respectivos modelos, mantendo-se os princípios da economia-neoclássica: determinância, otimização e equilíbrio.

As maneiras possiveis para a realização da tarefa proposta consta nos métodos de procedimento apriorístico e de abordagem histórica, conjugadas. A forma da pesquisa estabelecida na tese segue de perto Schumpeter, Blaug, Weintraub e Samuelson, porém a forma de abordagem é própria, pois apresenta elementos influenciadores da análise, tais como história da matemática, aspectos institucionais e cenário analítico relevantes.

\subsection{Justificativa}

Embora exista uma vasta literatura de língua inglêsa, disponível, sobre equilibrio geral, em sua maioria, apresenta-se como inacessivel ao estudante médio, isto é, aquele não treinado no campo da matemática universitária avançada que inclui tópicos sobre Análise real, Topologia geral, Topologia algébrica ${ }_{2}$ Topologia diferencial, Equações diferenciais ordinárias e parciais Sistemas dinâmicos, Teoria das probabilidades, Teoria da medida e integração, Processos estocásticos (integração estocásitica, equações diferenciais estocásticas, equações à diferenças estocásticas). Com efeito, a fim de facilitar a compreensão e uso do instrumental matemático envolvido nos livros e periódicos nacionais e internacionais busca-se desenvolver na forma de tese o tema que compreende especificamente a estabilidade do equilíbrio geral numa economia competitiva usando uma metodologia diferenciada (Capítulo 2, Seção 2.2).

A tese elaborada sobre o problema da estabilidade do equilíbrio 
competitivo importa em novidade como conteúdo na forma estabelecida, abordagem histórica e de forma seqüencial dos modelos, pois permite alcançar um grupo maior de economistas que por ventura venham a se interessar pelo tema proposto e assim, utilizar o texto como orientação para seus estudos posteriores. Ademais, a literatura corrente não apresenta nenhum estudo histórico sobre o tema, na medida do meu conhecimento, após levantar a literatura nacional e internacional através dos seus periódicos e livros textos didáticos e técnicos, apesar de existirem alguns levantamentos na forma de livros e artigos que utilizam outras linhas de argumentação: Samuelson (1947), Schumpeter (1964), Quirk (1968), Arrow-Hahn (1971), Negishi (1962, 1972), Blaug (1984), Fisher (1990), Ingrao (1990), Eatwell (1990), Takayama (1996).

Inexistência na literatura corrente de explicação do problema da teoria da estabilidade do equilíbrio competitivo fazendo uso simultâneo dos eventos institucionais, história da matemática e cenário analítico, através de uma abordagem histórica tradicional (método de abordagem) e tendo como suporte o método de procedimento apriorístico associado à seqüência dos modelos (Koopmans) conduziu a uma pesquisa que resulta na constituição da tese em pauta. Com efeito, busca-se atingir objetivamente os pontos essenciais à compreensão do problema (eventos matemáticos, institucionais e formação intelectual) relacionado à teoria do equilibrio sob a ótica Walrasiana e seu desdobramento. Desenvolve-se o encadeamento lógico do problema a partir das idéias concebidas por Leon Walras, origem do problema, o qual se prende exatamente em explicar o funcionamento do sistema econômico como um todo. Porém, devido ao instrumental matemático ao qual possivelmente ele não teve acesso (que é discutido no Capítulo 3) àquela época, impede que realize com sucesso suas intenções: estudar 0 problema da existência, unicidade e estabilidade do equilíbrio para o caso de mercados múltiplos. Para o problema da existência, o máximo que Walras consegue é identificar que em seu sistema o número de equações corresponde exatamente ao número de incógnitas. Os problemas da unicidade e estabilidade se mostram analiticamente amarrados, 
isto é não se pode levantar qualquer questão sobre unicidade dos pontos de equilibrio sem que se tenha informações seguras sobre a estabilidade daquele ponto. Contudo, Walras realiza com sucesso o seu propósito para mercado único, ao definir um ente abstrato que se presta fielmente à análise: a função excesso da demanda. Formalmente,

$$
E(P)=D(P)-S(P)
$$

Com efeito, estabelece a condição Walrasiana fundamental: um mercado é estável se uma elevação do preço reduz o excesso da demanda. Formalmente,

$$
\frac{d E(P)}{d P}=D^{\prime}(P)-S^{\prime}(P)<0
$$

Sob a ótica geométrica elabora-se o trabalho de Walras (1954) relativo à teoria do equilibrio, no caso específico do mercado único, destacando o problema sobre estabilidade do mercado único, o qual realizou com sucesso. Busca-se ser exaustivo no sentido de construir não somente os casos comuns, como aqueles teoricamente possíveis, estendendo-se assim 0 raciocinio Walrasiano.

Em seguida incursiona-se através da obra do Professor Hicks (1939) que complementa o trabalho de Leon Walras, realizando com relativo sucesso 0 problema da estabilidade do equilibrio competitivo no caso dos mercados múltiplos. O Professor Hicks procura definir alguns entes abstratos: estabilidade perfeita e imperfeita. Com efeito, desenvolve as condições necessárias e suficientes para existência da estabilidade perfeita, que possibilita questionar que, se cada mercado único é estável, o sistema econômico inteiro é dinamicamente estável. Neste ponto a discussão sobre o trabalho de Hicks se desenvolve especificamente do ponto de vista algébrico. Além disso, tece-se comentários sobre o significado econômico de suas idéias e exemplos aplicativos da teoria é trabalhado em detalhe no texto como material de apoio à compreensão dos conceitos e resultados estabelecidos pela literatura Hicksiana (Capítulo 3, Seção 3.2.2). 
Com o propósito de desenvolver de maneira consistente as condições da estabilidade do equilibrio competitivo, o Professor Metzler (1945) estabelece a condição necessária e suficiente para estabilidade dinâmica impondo que tal condição se concretiza somente quando as mercadorias existentes naquele sistema de mercado são substitutos brutos, ente abstrato definido em seu trabalho. Apresenta-se dois teoremas que são demonstrados pelo Professor Metzler e procura-se estabelecer seu valor aplicacional à teoria do equilíbrio tecendo alguns comentários que julga-se pertinentes. Exemplo numérico detalhado é elaborado como material de apoio à compreensão dos conceitos e teoremas estabelecidos na literatura Metzleriana (Capitulo 3, Seção 3.2.5).

O Professor Samuelson $(1941,1942,1947)$ incorpora à teoria da estabilidade dois resultados: (1) um sistema pode ser estável mas não ser perfeita ou imperfeitamente estável (Capítulo 3, Seção 3.2.3), (2) um sistema pode ser imperfeitamente estável, porém afastar-se indefinidamente do equilibrio. Para alcançar tais resultados apresenta-se exemplos. No texto, Samuelson (1947), cita exemplo em nota de rodapé, deixando a cargo do leitor a verificação dos resultados por ele obtido de acordo com as conhecidas condições de estabilidade perfeita e imperfeita, enquanto que na tese resolvese estes exemplos por completo. Inclusive impõe-se comentários relevantes sobre a contribuição de Samuelson à literatura corrente.

Em vista dos resultados obtidos por Samuelson em seu trabalho denominado Foundations of Economic Analysis (1947), que consegue sistematizar as idéias teóricas referentes à teoria do equilibrio, em particular, estabilidade, somando às contribuições de Lange (1944) e Metzler (1945), surgiram vários trabalhos sobre o tema destacando-se aqueles apresentados por Arrow \& Hurwicz (1958, 1959, 1960). Suas contribuições se revestem de importância pois incorporam, como instrumento de análise na teoria da estabilidade o segundo método de Lyapunov que associado ao instrumental desenvolvimento por Samuelson, axioma da preferência relevada, têm o propósito de demonstrar teoremas que revelam o comportamento do sistema 
econômico. Além disso, apresenta-se na íntegra o teorema que trata sobre estabilidade global e que utiliza os instrumentos citados: axioma da preferência revelada e o método de Lyapunov. Quando possível, apresentam-se exemplos algébricos em detalhe, como material de apoio à compreensão dos conceitos e proposições estabelecidos na literatura corrente.

A tese é escrita sob o enfoque da seqüência de modelos, não perdendo de vista assim o raciocínio lógico derivado das idéias anteriormente concebidas e as explicações realizadas, mostrando desta forma a ampliação elou a correção dos resultados anteriormente obtidos, diferindo em forma e conteúdo daqueles trabalhos citados no início desta Seção (segundo parágrafo), porque no discurso da tese exemplos numéricos detalhados, cenário analítico, eventos importantes e história da matemática são apresentados e discutidos conforme a ligação direta dentro do conteúdo no domínio espacial e temporal ao construir a narrativa e a explicação do conteúdo em estudo. Ademais, a tese em pauta constitui um trabalho científico porque responde aos seguintes requisitos: (1) é um estudo que versa sobre um objeto reconhecível, a teoria da estabilidade do equilibrio competitivo, e definido de tal maneira que seja reconhecivel pelos outros pesquisadores; (2) é um estudo que diz do objeto algo sob uma forma diferente o que já se disse (abordagem histórica sob a forma de seqüência de modelos); (3) é um estudo útil aos demais pesquisadores porque serve de material de referência analítica; (4) é um estudo que fornece elementos que verificam a hipótese apresentada: possibilidade em construir a história da teoria da estabilidade do equilibrio competitivo usando elementos influenciadores, tais como, eventos importantes, panorama sócio-econômico e história da matemática.

Em vista do supra estabelecido, os resultados esperados compreendem que a pesquisa sobre a teoria da estabilidade do equilíbrio competitivo tem obtido sucesso na conjugação dos esforços ao explicar o mecanismo de funcionamento da economia sob a ótica Tâtonnement quando algumas hipóteses chaves são estabelecidas: substitutos brutos e líquidos, 
homogeneidade, Lei de Walras e complementares brutos e líquidos. Porém, demonstra fragilidade quando tais hipóteses são descartadas atingindo em cheio o mecanismo Tâtonnement, redirecionando a pesquisa para áreas NonTâtonnement, ainda assim dentro do contexto analítico neoclássico e construindo-se linhas de pesquisa em mecanismo Tâtonnement com hipóteses modificadas sobre o funcionamento do sistema econômico.

\subsection{Objetivos}

A teoria do equilíbrio tomou impulso a partir das obras de economistas célebres no ultimo quartel do século XIX: Carl Menger (1840-1921) na Áustria; William Stanley Jevons (1835-1882), Francis Ysidro Edgeworth (1845-1926) e Alfred Marshall (1842-1924) na Inglaterra; Marie Espirit Léon Walras (18351926) na Suiça; Vilfredo Pareto (1884-1923) na Itália; Irving Fisher (1867-1927) nos Estados Unidos; Knut Wicksell (1851-1926) na Suécia.

O ponto de partida na construção da teoria do equilibrio origina-se no trabalho de Leon Walras. O problema que Walras idealiza é que dada uma quantidade fixa inicial de recursos produtivos que detém cada um dos agentes econômicos; dada uma certa tecnologia de produção; dado o sistema de preferências dos agentes econômicos; cabe determinar a quantidade de bens produzidos e trocados e os preços aos quais se realizam as trocas, na configuração do equilíbrio geral no qual se procedem simultaneamente as posições do equilíbrio para as quais convergem os vários agentes econômicos.

Para a compreensão do plano traçado por Walras em seu esquema analítico cumpre destacar os conceitos fundamentais por ele idealizado. $O$ primeiro conceito fundamental constante em sua obra é aquele de riqueza social. Diz-se que riqueza social é o conjunto das coisas materiais ou imateriais que são escassas, ou seja, que por um lado nos são úteis e, por outro, não estão disponíveis a não ser em quantidades limitadas. Significa dizer que existem duas condições necessárias e suficientes para que qualquer objeto 
possa ser considerado como riqueza: deve possuir a capacidade de satisfazer alguma necessidade do agente econômico $e$, deve estar disponível em quantidade limitada relativo a essa necessidade. Por conseguinte, a dupla qualidade de ser útil e limitada impõem à riqueza três propriedade: ser apropriável, ser objetivo de troca e ser objeto da atividade produtiva.

O passo seguinte no procedimento do esquema teórico de Walras objetivando à determinação dos preços e quantidades de equilíbrio se coloca à base da classificação dos elementos constituintes da riqueza social. Com efeito, duas categorias são consagradas: os capitais, que são os bens usados diretamente no processo de produção e que possuem vida útil decerto duradoura e que são divididos em três categorias: as terras, o capital humano e os bens de produção; os rendimentos, que são bens utilizados uma única vez no processo de produção e que são divididos em duas categorias: bens de consumo não duráveis e os serviços dos bens de capital.

Com base nos conceitos e classificação expostos, Walras estabelece um esquema analítico para a teoria do equilibrio constituído de quatro etapas: (1) teoria da troca, cuja preocupação é a determinação das quantidades trocadas e dos preços dos bens de consumo; (2) teoria da produção, cuja preocupação é a determinação das quantidades trocadas e dos preços dos serviços dos capitais, ou dos bens intermediários; (3) teoria da capitalização, cuja preocupação é a determinação dos capitais propriamente ditos e dos seus preços; (4) teoria do capital circulante, cuja preocupação centra-se no fato que a distribuição no tempo, seja do aprovisionamento dos bens intermediários, seja na venda dos produtos finais pode vir a requerer a necessidade de antecipações financeiras.

É claro, que existe o encaixe de cada etapa constituindo do sistema, pois o mesmo se utiliza para a determinação do equilibrio geral. Consequentemente, o equilibrio no sistema ocorre quando duas ordens de condições são satisfeitas: condição subjetiva, que consiste na busca de uma posição de máximo por parte de cada um dos agentes econômicos isolados, e 
condição objetiva, que consiste no equilíbrio entre oferta e demanda para cada mercado que garante a posição de máximo atingido por todo agente e que é compatível com a alcançada por qualquer outro.

O esquema analítico Walrasiano pode ser traduzido de maneira explícita na linguagem matemática: sistema de equações algébricas, as quais exprimem as condições subjetivas ditas anteriormente. $\mathrm{Na}$ verdade, este sistema não é concebido por Walras como um sistema a ser efetivamente resolvido no sentido de se poder calcular os valores numéricos das quantidades e dos preços de equilíbrio, mas é escrito essencialmente para colocar em evidência a lógica do sistema e para ter, mediante resultados do raciocínio matemático, a conformação da amplitude e suficiência do discurso econômico.

Walras não se manifesta satisfeito apenas em efetivamente apresentar as condições de equilíbrio do sistema econômico como um todo. Ele consegue produzir mais que isso e introduz um modo de restabelecer o equilibrio do sistema econômico abstrato quando por ventura o mesmo se encontrasse em desequilibrio. Operacionalmente diz-nos, que quando uma excesso de demanda é positivo, alguns compradores empurram para cima a oferta ao se dispor a pagar preços elevados, e que inversamente, os vendedores diminuem seus preço quando o excesso da demanda é negativa.

Nota-se que Walras inclui um elemento que caracteriza o estudo sobre a estabilidade do sistema econômico como um todo: a função excesso da demanda. É definida como a diferença entre as funções demanda e oferta. A partir daí se estabelece a condição Walrasiana fundamental relativa à estabilidade do equilíbrio do sistema econômico como um todo: um mercado é estável se um elevação do preço reduz o excesso da demanda.

O Professor John R. Hicks seguindo a tradição Walrasiana, busca em seu livro clássico, Value and Capital (1939), estabelecer de modo explícito, determinados conceitos referentes à estabilidade do equilibrio competitivo (estabilidade perfeita e imperfeita) e apresentar condições gerais da estabilidade do sistema. Particularmente, expõe pela primeira vez um estudo 
sobre a teoria da estabilidade para uma economia sob regime de troca múltipla. Para facilitar a elaboração do quadro analítico de uma economia com trocas múltiplas apresenta duas definições básicas: estabilidade perfeita - ocorre num sistema em que todas as condições de estabilidade estejam satisfeitas; estabilidade imperfeita - ocorre num sistema onde algumas condições de estabilidade não estejam satisfeitas, contudo a oferta supera a demanda quando houver aumento de preço e todas as repercussões desse aumento são consideradas.

Os conceitos $e$ as extensões das idéias fundamentais são desenvolvidas ao longo da tese, incluindo não só a contribuição de Hicks, como a de outros autores: Paul Anthony Samuelson, Allan Metzler, Oskar Lange e Kenneth Arrow associado com cientistas da Comissão Cowles.

O Professor Samuelson $(1941,1942,1947)$ promove algumas correções no trabalho embrionário de Hicks (1939) e a partir dai sedimentam-se os conceitos e condições gerais de estabilidade do equilíbrio econômico geral. Tais correções realizadas por Paul Anthony Samuelson, passam pela redefinição de estabilidade perfeita e imperfeita. Diz-se que uma posição de equilibrio possui estabilidade perfeita da primeira espécie se a partir de condições iniciais quaisquer, todas as variáveis se aproximarem de seus valores de equilíbrio no limite, à medida que o tempo se torna infinito.

De posse da definição de estabilidade perfeita de primeira espécie, Samuelson passa a relacioná-la às definições da estabilidade perfeita e imperfeita à moda de Hicks. E conclui: (1) um sistema pode ser estável, mas não ser perfeita ou imperfeitamente estável (exercício numérico é estabelecido no Capítulo 3, Seção 3.2.3) e, (2) um sistema pode ser imperfeitamente estável mas não ser estável (exercicio numérico é estabelecido no Capítulo 3 , Seção 3.2.3).

No final dos anos 50, Arrow et al (1956; 1958; 1959; 1960) estabelecem resultados fundamentais para o mecanismo de ajustamento Tâtonnement na forma de teoremas que lançam luz sobre a relação entre 
estabilidade dinâmica e expectativa adaptativa, estabilidade dinâmica local e global que utiliza a noção de preferência revelada e o segundo método de Lyapunov.

No inicio dos anos 60, Scarf (1960) em seu artigo relâmpago, apresenta alguns exemplos que implica na limitação do processo de ajustamento Tâtonnement em uma economia competitiva. Segundo Scarf, a lei da demanda era contrariada, ou seja, um aumento de preço de um bem (ceteris paribus) não levaria a uma queda na quantidade demandada do bem de Giffen. Em outro exemplo, considera a complementariedade perfeita nas funções utilidade dos consumidores no espaço de mercadorias. Conseqüência de tais resultados é a sustentação do novo mecanismo de ajustamento denominado NonTâtonnement, onde a troca é realizada a cada vetor de preço anunciado à medida que as dotações dos participantes se modificam continuamente como resultado da mudança nos preços. Ainda nos anos 60, Hahn (1962) enuncia teorema fundamental sobre o mecanismo de ajustamento Non-Tâtonnement. a troca ocorre quando o nível do excesso da demanda para qualquer mercadoria individual for o mesmo como no sinal do excesso de demanda para aquela mercadoria no agregado. É incluído um exercício de apoio à compreensão do enunciado do teorema (Capitulo 4, Seção 4.4.1).

Ao longo dos anos 70 , e 80 , firmam-se os estudos sobre o mecanismo de ajustamento Non-Tâtonnement através de artigo protagonizado por Smale (1976) onde apresenta modelo de equilíbrio geral como extensão do modelo de Hahn \& Negishi. Quirk (1970) e Tarr (1978) apresentam modelos com mercadorias complementares. As técnicas utilizadas nos modelos destas duas décadas sofisticaram-se ainda mais: topologia diferencial, análise global e sistemas dinâmicos (Debreu 1976, 1984; Smale 1976; Murata 1977).

O propósito da tese consiste à luz da teoria do equilíbrio e dos elementos influenciadores de sua construção alcançar quatro objetivos.

Primeiro, levantando as raízes da teoria da estabilidade do equilibrio competitivo, (1) construir à luz dos panoramas histórico-institucional e analítico 
sob a ótica geométrica a contribuição de Walras sobre a estabilidade do equilibrio em mercado único usando o elemento instrumental fundamental, a função excesso da demanda, incluindo exercício algébrico resolvido em detalhes e comentários sobre sua obra referente a estabilidade do equilibrio competitivo; (2) estabelecer à luz dos cenários histórico-institucional e analítico as condições de estabilidade em mercados múltiplos (local) focalizando especificamente as contribuições fundamentais de Hicks, incluindo exemplos numéricos e comentários críticos pertinentes sobre a sua contribuição à estabilidade do equilibrio competitivo; (3) estabelecer as condições de estabilidade em mercados múltiplo focalizando as contribuições fundamentais de Samuelson (1941, 1942, 1947), Lange (1944), Metzler (1945), na década de 40 , incluindo exemplos algébricos resolvidos em detalhes e comentários pertinentes sobre suas contribuições ao problema da estabilidade do equilíbrio competitivo; (4) construir e discutir a relação entre a estabilidade dinâmica e uma função expectativa sugerida pela definição de elasticidade expectativa de Hicks e a relação fundamental entre estabilidade dinâmica e expectativa adaptativa; esforço é realizado para apresentar exemplo algébrico resolvido em detalhe como material de apoio a compreensão dos conceitos e proposições estabelecidas.

Segundo, levanta-se o problema da estabilidade do equilíbrio competitivo sob uma estrutura matemática precisa de modo que seja possível estabelecer as condições em mercados múltiplos focalizando especificamente as contribuições fundamentais dos cientistas Arrow, Hurwicks, Block, MacManus, Uzawa, Negishi, Hahn e Smale. Sob a estrutura matemática de uma economia Arrow \& Debreu é discutido a solução do problema da estabilidade sob certas condições e, como material de apoio incluem-se exemplos algébricos resolvidos em detalhes e comentários pertinentes.

Terceiro, sob os cenários histórico-institucional e analítico é introduzido e discutido detalhadamente as contribuições de Scarf, Hahn \& Negishi e Uzawa, como extensão do modelo neoclássico, o processo de ajustamento 
Non-Tâtonnement, fazendo referência aos modelos de Green (1974), Fisher (1974), Smale (1976), Tarr (1978), incluindo exemplos numéricos como material de apoio.

Quarto, realiza-se o fechamento da tese ao focalizar-se sobre que linhas de pesquisas futuras realmente são estabelecidas nos trabalhos que estão em pauta nos anos noventa como consequência dos resultados anteriormente estabelecidos, e que o problema da estabilidade ainda se mantém aberto pois soluções definitivas sobre o mesmo não são possíveis porque para cada conjunto de premissas é possível construir uma nova economia e para a mesma determinar soluções para a questão da estabilidade (Capítulo 5). 


\section{METODOLOGIA}

\subsection{Fundamentos analíticos}

De certo modo, o propósito em elaborar qualquer trabalho de caráter cientifico impõe como base para análise teórica a linha de raciocínio estabelecido no método a ser utilizado. Consequentemente, a exposição clara e concreta do método se faz necessário, pois o mesmo norteará com autoridade - pesquisador no sentido de alcançar seu objetivo desejado, embora seja conhecida as dificuldades enfrentadas por aquele no que concerne a compreensão do aparato teórico existente no cerne da própria ciência, em particular, a ciência econômica, face principalmente aos diversos métodos de análise utilizados pelos economistas profissionais. Significa dizer que utiliza-se - método de modo particular, ou, então realiza-se a combinação de dois ou mais método na elaboração dos trabalhos com rigor científico.

O objetivo do método científico consiste em capacitar o pesquisador a relacionar de maneira clara e razoavelmente precisa, no âmbito da ciência econômica, o corpo teórico e os fatos observados no mundo real. Consequentemente, a idealização de um modelo abstrato surge como de imediato. Porém, para que a elaboração de tal modelo se torne possível, necessário se torna a classificação dos instrumentos chaves de análise: dados, variáveis e suposições comportamentais. Por conseguinte, dentro do contexto analítico que serve de cenário na tese, tem-se:

1) análise do consumidor individual

dados- função utilidade, renda e preço de todos os bens 
variáveis- quantidade de bens que o consumidor compra e consome. suposição comportamental - desejo de maximizar utilidade.

2) análise do produtor individual dados- função produção, os preço de todos os insumos. variáveis- quantidades produzidas $e$ vendidas dos produtos $e$ quantidade comprada de insumo.

suposição comportamental - desejo de maximizar lucros.

3) análise do equilíbrio num mercado de bens finais

dados- função utilidade de todos os consumidores e produtores, as rendas de todos os consumidores, os preço de todos os fatores e bens inclusive aqueles que está analisando.

variáveis- preço do bem em análise, quantidade comprada de bens por parte de cada consumidor, quantidade vendida apenas de bens por cada produtor e quantidade comprada de fatores por cada produtor.

suposição comportamental - desejo de maximizar utilidade e lucro por parte de todos os consumidores e produtores $e$, demanda agregada igual á oferta agregada.

4) análise do equilíbrio em mercados múltiplos

dados- função utilidade e produção de todos os fatores, quantidade de fatores compradas pelos produtor.

variáveis- preços de todos os bens, preços de todos os fatores, quantidade de fatores compradas pelos produtores.

suposição comportamental - maximização de utilidade e lucro e, demanda agregada igual á agregada.

Saber o que compreende-se por teoria econômica, neste ponto da exposição do método científico que norteia a tese, impõem-se como fundamental para as conclusão futuras que surgem dentro do escopo da ciência econômica. Portanto, entende-se que:

"Teoria econômica é uma conjunto de proposições organizadas em um 
modo característico e, designado para servir como premissas parciais para explicar tão bem como predizer uma variada classe indeterminada de fenômenos econômicos" (Nagel,1953, p.20).

Geralmente, a elaboração de um modelo abstrato está condicionada pelos passos seguintes: (1) impõe abstração do mundo real em modelo lógico simplificado; (2) requer o uso de argumentação lógica para alcançar a uma conclusão abstrata; (3) retornar ao mundo real através de uma interpretação que fornece conclusões em termos do mundo palpável, concreto, da realidade física.

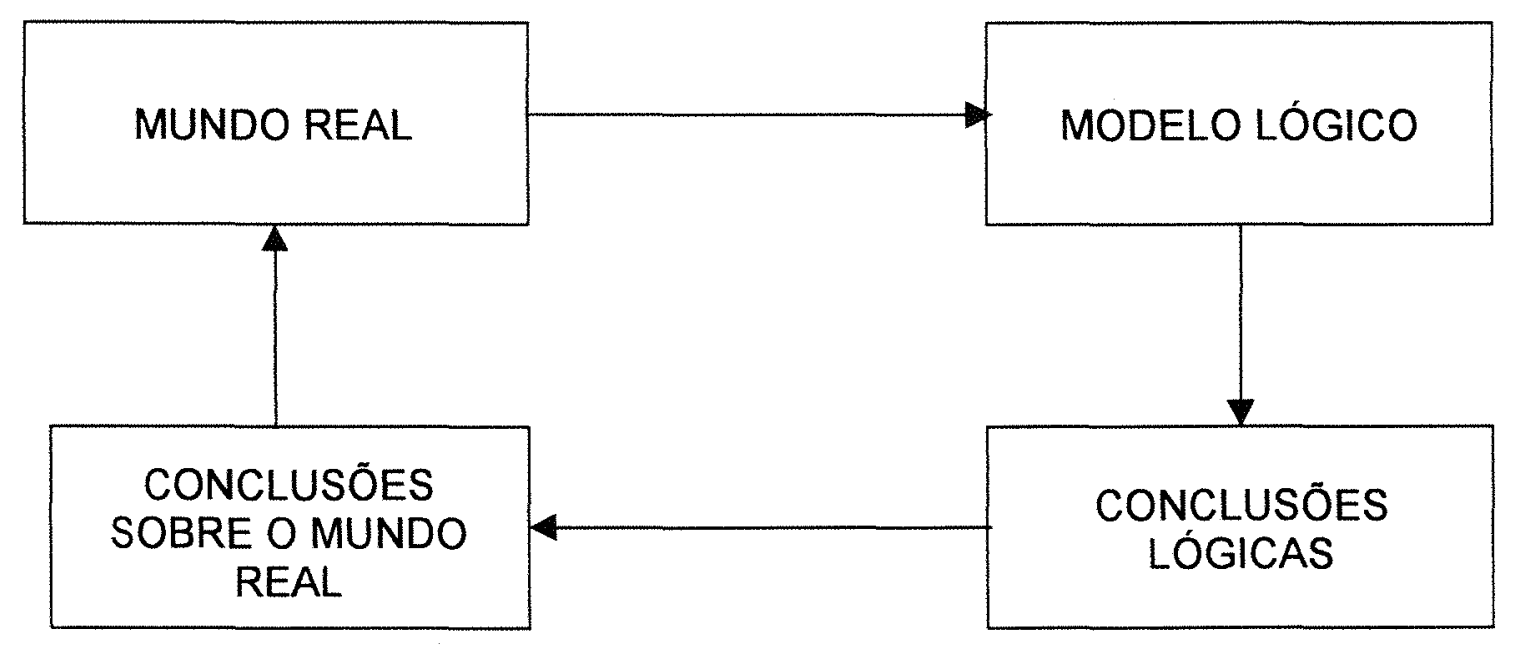

Quadro 1 - Seqüência de construção do modelo abstrato.

A argumentação sobre 0 método científico até o momento presente propicia meios para o estabelecimento do apriorismo extremo, que consiste no método de análise que conduz o estudo em pauta (método de procedimento) no campo da estabilidade do equilíbrio. Com efeito, o apriorista extremo acredita que: (1) as premissas e axiomas fundamentais da ciência são absolutamente verdadeiros; (2) os teoremas e conclusões derivados dos conjuntos de axiomas fundamentais pelas leis da lógica são, por conseguinte, absolutamente verdadeiros; (3) com efeito, não há necessidade de testes empíricos, seja dos axiomas fundamentais ou dos teoremas; (4) os teoremas deduzidos não 
poderiam ser testados mesmo que fosse desejável.

Em suma, os aprioristas extremos acreditam firmemente que "a ciência econômica é um sistema de verdades a priori, um produto da razão pura... um sistema de dedução pura a partir de uma série de postulados" (Ferguson,1966, p.358). Deste modo, o apriorista acredita plenamente na introspecção e na lógica para a elaboração de maneira completa do corpo de princípios econômicos. Compreende-se, então que o exame que faz alguém dos próprios pensamentos e sentimentos, segundo um princípios anterior a experiência $e$, que se utiliza da lógica dedutiva como parte central do corpo analítico, fá-lo seguro e capaz para elaborar abstratos que produzem respostas convincentes face aos fenômenos econômicos considerados na ciência pura.

O propósito é utilizar na elaboração da tese o método de procedimento apriorista por considerá-lo mais convincente no sentido de atingir aos objetivos estabelecidos (abordagem histórica na forma de seqüência de modelos), qual seja, expor de maneira detalhada a partir de conceituação precisa a propriedade da estabilidade do equilíbrio competitivo colocando em relevo as contribuições dos principais arquitetos da teoria matemática da estabilidade aplicada ao contexto do equilíbrio geral.

\subsection{O enfoque histórico e as fontes de pesquisas}

Existem ao menos três enfoques possiveis para elaboração da história do pensamento econômico. No primeiro enfoque, o passado é examinado através de seus precursores, e as teorias correntes são localizadas nas realizações do passado. Ligando elementos de compreensão analítica atual com o trabalho passado, é possível a um pesquisador traçar linhas de argumentação que produzam narrativas que sejam claras, distintas e cumulativas. Tais procedimentos são úteis à medida que possam ser realizados por pesquisadores experientes, quando eles podem identificar linhas principais de influências ou ao menos aquelas que tornam possíveis as explicações do 
passado com o instrumento corrente. No segundo enfoque, a história do pensamento econômico é elaborado sob a ótica da metodologia. $O$ pesquisador, na categoria de filósofo da ciência pode tratar o passado como um caso de estudos e dados modernos à medida que ele elabora e verifica explicações da mudança no contexto disciplinar. Imagine que o pesquisador procura defender a idéia de que o conhecimento econômico progrida descontinuadamente, ele poderia usar o passado para identificar revoluções significativas. Por conseguinte, o pesquisador desenvolverá o material histórico de modo que a hipótese possa ser falsificada. Exemplo, a revolução Keynesiana considerada como uma revolução no sentido de Kuhn, é uma proposição potencialmente falseável. No terceiro enfoque, mantém-se a tradição histórica na construção do pensamento econômico. Produz-se uma narrativa coerente na qual a explicação da evidência histórica acontece através do exame minucioso dos materiais, dos autores e do contexto. Constrói-se o tecido histórico na crença de que o ambiente social (eventos institucionais e históricos) e analítico, alimentam o trabalho intelectual de um período e que este facilita construir a narrativa de modo a enfatizar elementos da história social e intelectual. Significa uma procura hoje por justificativas da evolução da ciência econômica.

A reflexão sobre o trabalho da tese é conduzido através da atitude de pesquisa estabelecida pelo terceiro enfoque. Tal atitude consiste em utilizar elementos influenciadores da análise com o propósito de construção analítica da teoria matemática da estabilidade do equilíbrio competitivo e o seu desdobramento: (1) história da matemática da $2^{\text {a }}$ metade do século XIX até os nossos dias; (2) eventos institucionais importantes, tais como criação da Econometric Society e do próprio jornal técnico-científico denominado Econometrica e o Colóquio de Viena na Áustria; (3) panorama sócio-intelectual estabelecido por eventos históricos importantes, tais como $1^{\underline{a}}$ e $2^{\underline{a}}$ guerras mundiais e o nazismo provocando a fuga dos principais cientistas da Europa para os Estados Unidos e o advento de novas tecnologias. 
Para realizar a tarefa supra estabelecida é necessário conhecer as fontes materiais de pesquisa. Existem duas fontes: primária e secundária. A fonte primária compreende os artigos e livros originais dos principais representantes da teoria do equilíbrio geral: Walras (1874), Hicks (1939), Samuelson (1941, 1942, 1947, 1998), Lang (1944), Metzler (1945), Arrow (1958, 1959, 1960), Hahn (1960), Debreu (1959), Uzawa (1960, 1961, 1962), Negishi (1962), Green (1974), Fisher (1974), Smale (1976) e Grandmont (1977). A fonte secundária inclui artigos e livros que produzem críticas sobre os livros e artigos originais: Schumpeter (1964), Morgenstern (1977), Hunt (1980), Weintraub (1983), Blaug (1984), Ingrao (1992), Boyer (1996), Eves (1990, 1997) e Struik (1997).

Apresenta-se, na página seguinte, um quadro analítico sobre a construção da teoria da estabilidade do equilibrio competitivo e o seu desdobramento. 

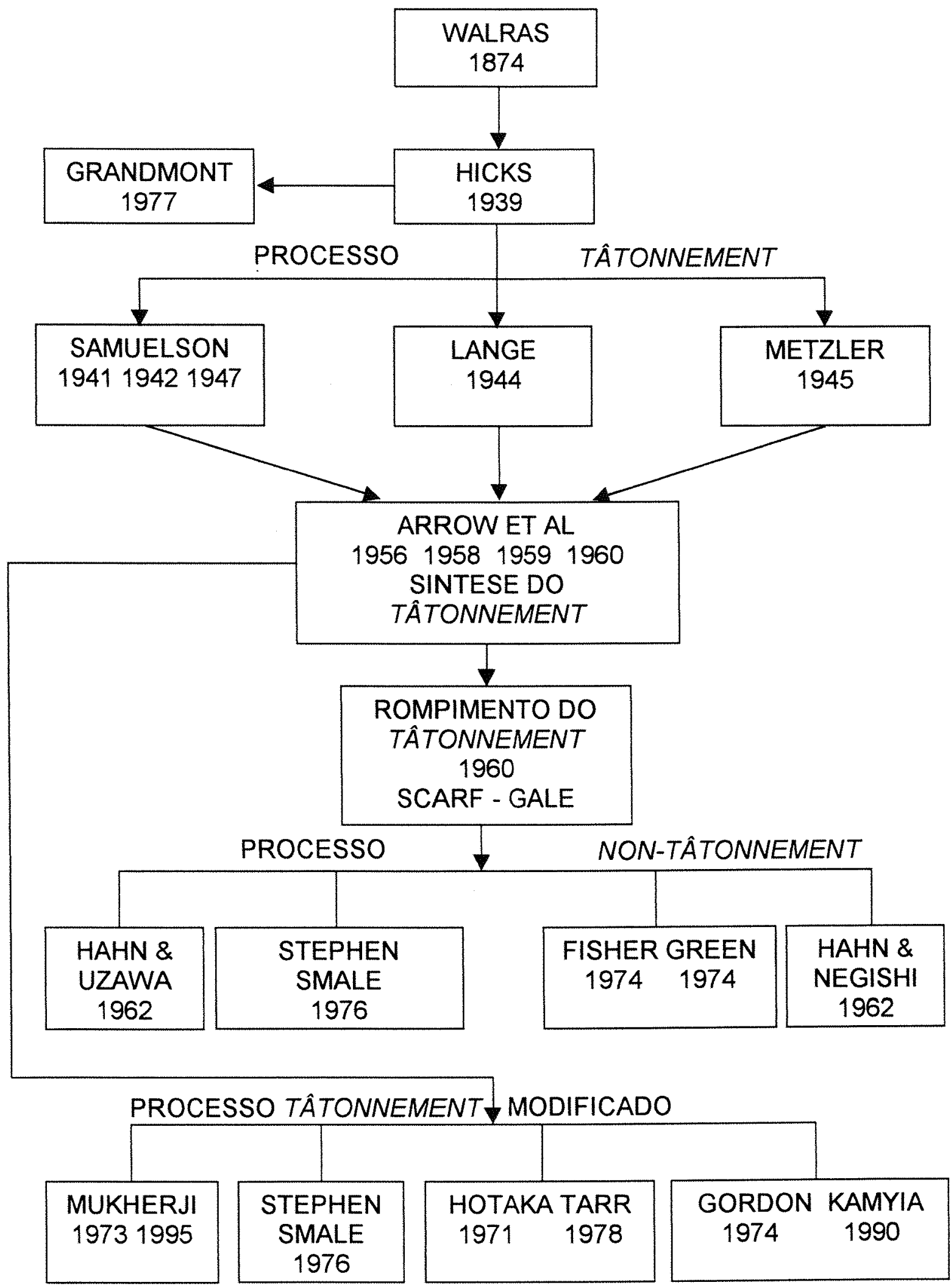

Quadro 2 - Construção da teoria da estabilidade do equilíbrio competitivo. 


\section{AS RAÍZES DA TEORIA DA ESTABILIDADE DO EQUILÍBRIO COMPETITIVO}

Neste Capítulo propõe-se realizar de maneira clara e sucinta três pontos. Primeiro, traçar os panoramas histórico-institucional e analítico do período de elaboração e publicação das obras dos principais representantes da teoria da estabilidade do equilibrio competitivo. Tal tarefa é realizada no início de cada Seção da seguinte maneira: mercado único e mercado múltiplo. Segundo, construir a teoria da estabilidade do equilíbrio competitivo em mercado único, estabelecido em Walras (1874), usando como elemento de análise a geometria analítica, o cálculo diferencial e exemplo numérico que facilita a compreensão dos pontos teóricos e dá-se o fechamento da Seção com comentários pertinentes. Terceiro, elaborar a teoria da estabilidade do equilíbrio competitivo em mercado múltiplo e sua solução estabelecida em Hicks (1939), Lange (1944), Metzler (1945) e Samuelson (1941, 1942, 1947) expondo suas contribuições principais tais como conceitos, proposições e teoremas, e usando exemplos numéricos como material de apoio aplicativo e encerrando as Seções com comentários pertinentes. 


\subsection{A estabilidade do equilíbrio em mercado único}

\subsubsection{Cenário sócio-econômico e a influência de Antoine Augustin Cournot}

Antes da tarefa de construção do edificio Walrasiano relativo a teoria da estabilidade, é necessário motivar tal empreendimento ao explicitar o que estava efetivamente acontecendo no periodo imediatamente anterior á publicação da obra principal de Leon Walras. Que elementos institucionais e teóricos são importantes na condução de sua atitude de expressar o conteúdo analítico da economia pura.

Leon Walras (1834-1910), estabelecido num ambiente de filosofia cartesiana na Suiça, é considerado o expoente da escola neoclássica, mais precisamente, um dos pilares da escola marginalista, juntamente com Carl Menger (1840-1921), que respirava num ambiente Neokantiano da Áustria e William Stanley Jevons (1835-1882), que vivia sob a tradição empírica e utilitarista da filosofia britânica .

Os primeiros quarentas anos da vida de Leon Walras estavam situadas territorialmente em um mundo que passava por um período de prosperidade econômica. Estava presente, de forma marcante, a industrialização, tanto no continente europeu, como na América do Norte, precisamente os Estados Unidos da América do Norte.

A industrialização era marcada pela concentração de capital em pequenos grupos de firmas gigantescas e, como conseqüência, aumentava a força da concorrência e reduzia o número de concorrentes, dando a ocorrência de fusões e falências.

Concomitantemente a industrialização, aconteceram mudanças 
estruturais nos setores de transportes e comunicações Conseqüência disso: (1) aceleração da concentração industrial; (2) atendimento em maior escala aos mercados de maneira mais eficiente. As firmas passam do domínio familiar para o domínio das sociedades anônimas, o que facilita a captação e emprego de maior volume de capital financeiro associado a plantas industriais cada vez maiores e mais eficientes no uso das inovações tecnológicas.

Estruturação de um mercado financeiro eficiente com a função maior de financiar as atividades produtivas atendia cada vez mais aos reclamos da sociedade contemporânea ao final do segundo quartel do século XIX. Por conseguinte, quando a década dos 70 , no século $X I X$, se inicia, o capitalismo estabelecido no continente europeu e nos Estados Unidos se caracterizava por um sistema econômico dotado de empresas gigantes nas áreas industrial, financeira, transportes e comércio.

Que tipo de relações sociais surgem a reboque dessa nova configuração do sistema econômico? Duas se destacam. Primeira, nos conglomerados de empresas, as relações sociais são estabelecidas de uma forma hierárquica e burocrática. Surge a idéia da hierarquia piramidal. Significa dizer que na base da pirâmide concentram-se os individuos que executam as ordens advindas dos comandos imediatamente superiores da pirâmide. Segunda, elites de gerenciamento e administração são estabelecidos: sistemas de contabilidade de custos, controle da qualidade e administração cientifica. Contudo, o objetivo central do capitalista permanecia o mesmo: maximização do lucro e fortalecimento da poupança empresarial. É neste contexto históricoinstitucional que surge a revolução marginalista e, precisamente a obra principal de Leon Walras, publicada em 1874, denominada Elements of Pure Economics (1926).

Sob o espectro do panorama histórico-institucional, um elemento influenciador da conduta analítica de Walras traduz-se na obra de Antoine Augustin Cournot, denominada Researches into the Mathematical Principles 
of the Theory of Wealth, publicada em 1838, quatro anos após o nascimento de Walras. As contribuições de Cournot que marcam sua obra são estabelecidas em cinco partes: geométrica, conceitual, monopólio puro, duopólio e estudo comparativo da concorrência perfeita e as estruturas de monopólio e duopólio.

Cournot foi o primeiro escritor em teoria econômica a definir e traçar uma curva da demanda. Inclusive estabelece que a curva da demanda de mercado possui representação geométrica e que apresenta declividade negativa, que expressa a relação entre as quantidades efetivas que os consumidores compram a cada ano a um preço médio anual; a curva da demanda é uma relação empírica entre vendas e preços.

Monopólio puro é uma estrutura do mercado de produto onde existe um único produto que não possui substituto próximo. As funções da demanda, receita total, receita marginal e custo marginal são estabelecidas por Cournot com o propósito de esclarecer a condição de maximização de lucro: (1) condição de primeira ordem na qual a derivada do lucro em relação ao preço iguala a zero o que implica, receita marginal igual a custo marginal, (2) condição de segunda ordem, mostra que receita marginal é menor do que o custo marginal no campo de definição do equilíbrio na estrutura monopolística.

Na construção de Cournot, a teoria do duopólio repousa na hipótese concorrencial segundo a qual os compradores anunciam os preços e os vendedores ajustam a sua produção aos preços dados. Estabelece a estratégia de ação do duopolista. Significa dizer que cada duopolista avalia a função da demanda do produto, mantendo fixa as quantidades do produto que interessa negociar tomando como hipótese que a produção do seu competidor permanece inalterada. Apesar de que cada duopolista venha a ajustar sua produção simultaneamente á produção do seu competidor, supõe sempre que a produção do competidor permanece inalterada e uma solução determinada é estabelecida. É possivel caracterizar tal estratégia de ação graficamente 
através do uso das curvas de reação dos competidores:

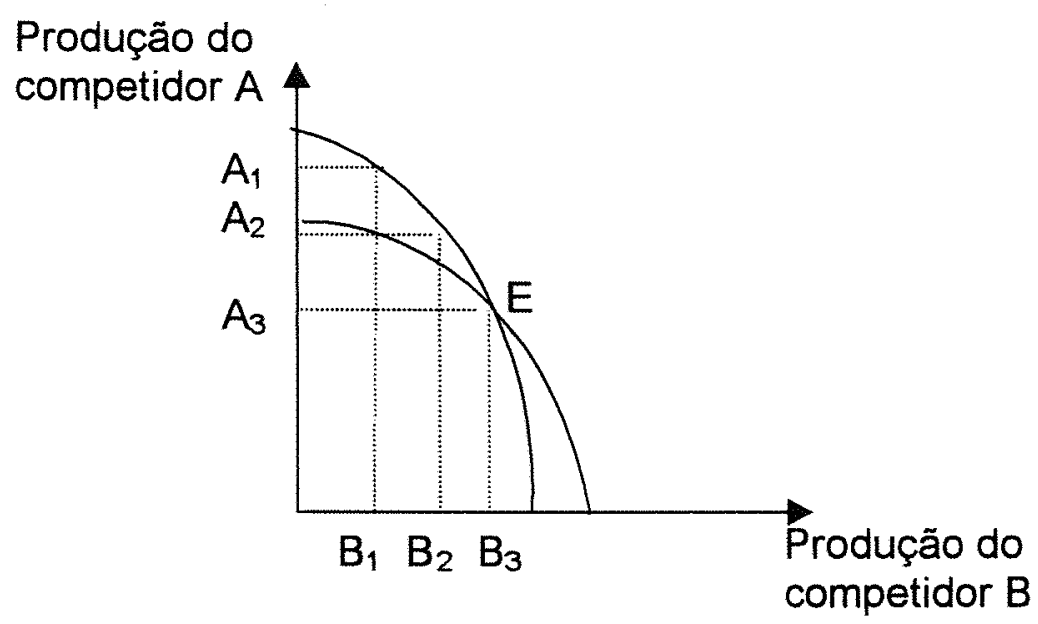

Figura 6 - Funções de reação dos competidores A e B

Cournot estabelece comparações dos níveis de preço e produção entre as estruturas de mercado: concorrência perfeita, duopólio e monopólio. Constata que a nivel de preços, a concorrência perfeita apresenta níveis inferiores àquele alcançado pelo duopólio e este inferior ao monopólio; enquanto que a nivel de produção, constata que os niveis de produção em concorrência perfeita são superiores àqueles alcançados pelo duopólio e monopólio, onde o monopólio apresenta o menor dos níveis de produção.

Portanto, é possível constatar que Walras se utiliza dos elementos chaves na construção de sua teoria devido a Cournot: (1) função excesso da demanda que usa como parte integrante a função da demanda; (2) a noção de equilibrio, otimização e determinância; (3) uso do aparato algébrico e gráfico para representarem situações econômicas abstratas.

Como material de apoio ao supra citado, focaliza-se as principais 
contribuições de Walras na forma de conceitos e proposições e realiza-se um exercício numérico em detalhe de maneira a facilitar a compreensão das principais contribuições á teoria da estabilidade do equilíbrio competitivo, associado a configuração geométrica do problema da estabilidade, focalizando os caso possíveis .

\subsubsection{A contribuição de Walras}

Num sistema econômico Walrasiano o preço e a quantidade de equilíbrio resultam da igualdade entre oferta e demanda. Por conseguinte, o equilíbrio caracteriza-se pelo entendimento no mercado entre compradores e vendedores. Significa dizer que nenhum dos participantes no mercado está disposto a modificar seu comportamento. Porém, a simples existência de tal equilíbrio não justifica que este seja alcançado. Quando as negociações começam a se processar nada garante que o preço de equilíbrio será atingido. Também não há garantia ou mesmo razão para imaginar que o preço inicial seja aquele de equilibrio. Ademais, as curvas de oferta ou de demanda podem se alterar como resultado de mudanças nas inovações técnicas ou preferências dos consumidores. Estes fatores implicam uma mudança na situação estabelecida do equilíbrio. A mudança conduz a uma nova situação do equilíbrio e, mesmo assim não há qualquer garantia de que ele será atingido.

Num sistema econômico diz-se que uma perturbação representa uma situação na qual o preço real difere daquele de equilíbrio. No mesmo sistema, define se que um equilíbrio é estável se uma perturbação implica num retorno ao equilíbrio. Caso contrário, afirma-se que o equilíbrio é instável.

Qualquer perturbação no esquema analítico do equilíbrio Walrasiano gera um processo de ajustamento no mercado. Significa dizer que, se o preço real for superior ao preço de equilíbrio, ponto $A$ do gráfico, o ajustamento se processa no sentido do menor número de lances do consumidor, restaurando assim o equilíbrio no mercado. Caso contrário, aumenta o número de lances do 
consumidor, restaurando o equilíbrio no mercado, ponto B do gráfico.

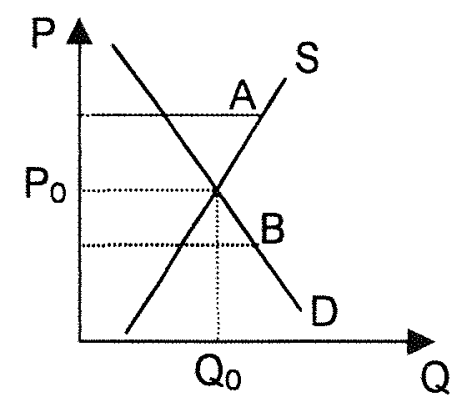

Figura 7 - Processo de ajustamento

A análise sobre estabilidade do equilíbrio Walrasiano procede-se segundo a ótica estática. Significa dizer que não é considerado o tempo necessário para o processo de ajustamento, examina-se única e especificamente a natureza da mudança. Tecnicamente, a análise estática é um método de tratar fenômenos econômicos que procura estabelecer relações entre elementos do sistema econômico - preço e quantidade de bens - que se referem ao mesmo período de tempo.

Walras inclui um elemento de análise que caracteriza seu estudo sobre a estabilidade do sistema econômico: a função excesso da demanda. É definida como a diferença entre as funções demanda e oferta. $\mathrm{Na}$ representação matemática:

$$
E(P)=D(P)-S(P), \quad P>0
$$

onde

$E(P)$ : função excesso da demanda ao preço $P$

$E(P)$ : função da demanda ao preço $P$

$S(P)$ : função da oferta ao preço $P$ 
Considerando-se que as curvas da demanda e da oferta apresentam inclinações convencionais e que tais curvas sejam descritas graficamente no plano cartesiano, a curva do excesso da demanda é descrita num plano cartesiano, também, e tem inclinação negativa. Caso particular em que as curvas da demanda e da oferta são lineares, a curva do excesso da demanda tem o formato abaixo:

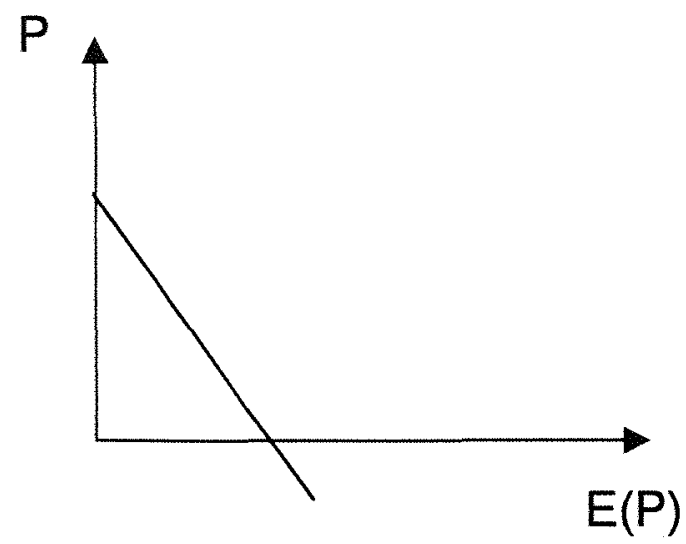

Figura 8 - Função excesso da demanda

Geometricamente é possivel imaginar três situações:

Situação $1-E\left(P_{0}\right)>0$, pois $D\left(P_{0}\right)>S\left(P_{0}\right)$

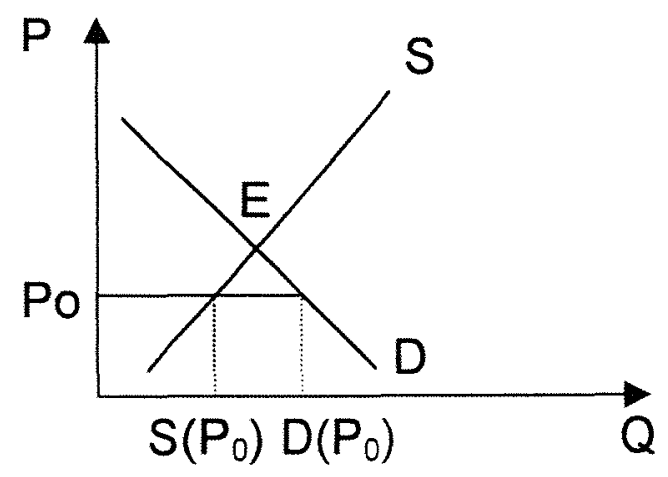

Figura 9 - Excesso da demanda positivo 
Situação $2-E\left(P_{0}\right)<0$, pois $D\left(P_{0}\right)<S\left(P_{0}\right)$

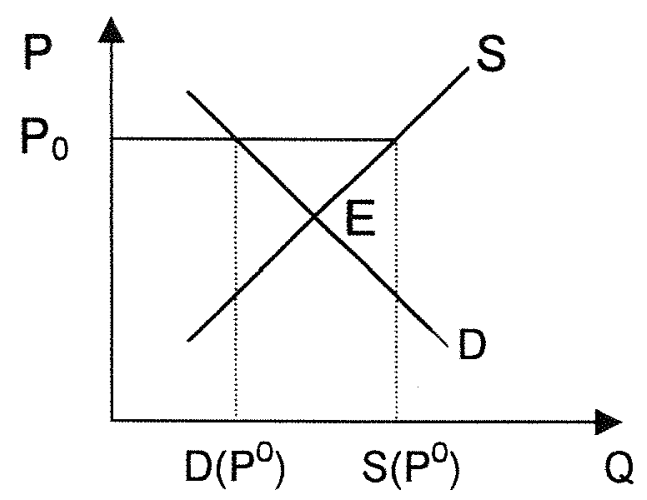

Figura 10 - Excesso da demanda negativo

Situação $3-E\left(P_{e}\right)=0$, pois $D\left(P_{e}\right)=S\left(P_{e}\right)$

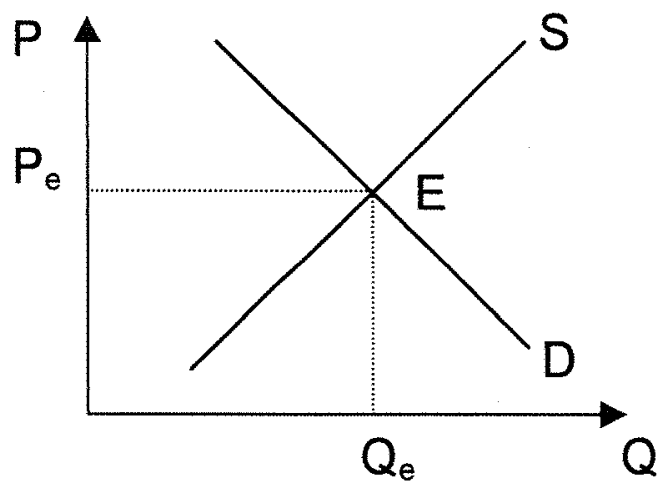

Figura 11 - Excesso da demanda nulo.

É a partir da definição da função excesso da demanda que Walras estabelece a condição fundamental relativa a estabilidade do equilíbrio 
competitivo: um mercado é estável se uma elevação do preço reduz o excesso da demanda. Formalmente representa-se em notação atual esta condição de estabilidade como segue:

$$
\frac{d E(P)}{d P}=E^{\prime}(P)=D^{\prime}(P)-S^{\prime}(P)<0
$$

É, geometricamente possivel, ilustrar-se situações em que a eq. (4) pode ou não ser satisfeita:

Situação $1-D^{\prime}(P)<0$ e $S^{\prime}(P)>0$

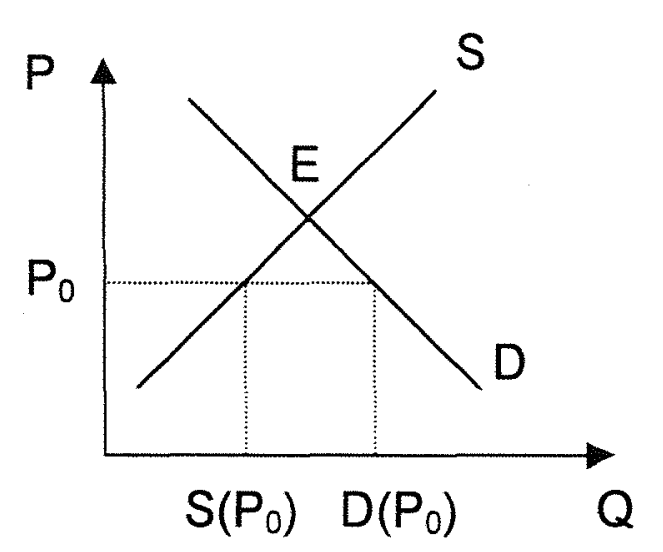

(a) $E(P)>0$

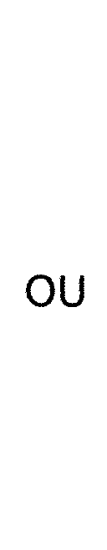

OU

Figura 12 - Equilibrio estável

Situação 2 - $D^{\prime}(P)<0$ e $S^{\prime}(P)<0$ onde $S^{\prime}(P)<D^{\prime}(P)$

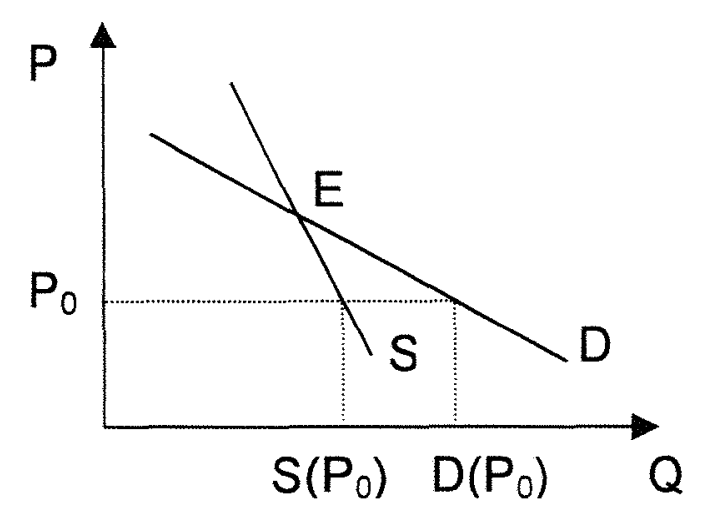

Figura 13 - Equilíbrio estável 
Situação $3-D^{\prime}(P)<0$ e $S^{\prime}(P)<0$ onde $S^{\prime}(P)<D^{\prime}(P)$

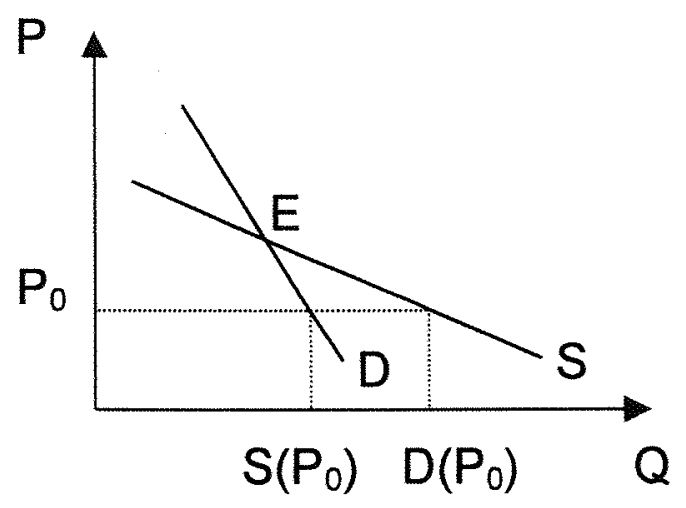

Figura 14 - Equilibrio instável

Situação $4-D^{\prime}(P)<0$ e $S^{\prime}(P)<0$ onde $S^{\prime}(P)<D^{\prime}(P)$

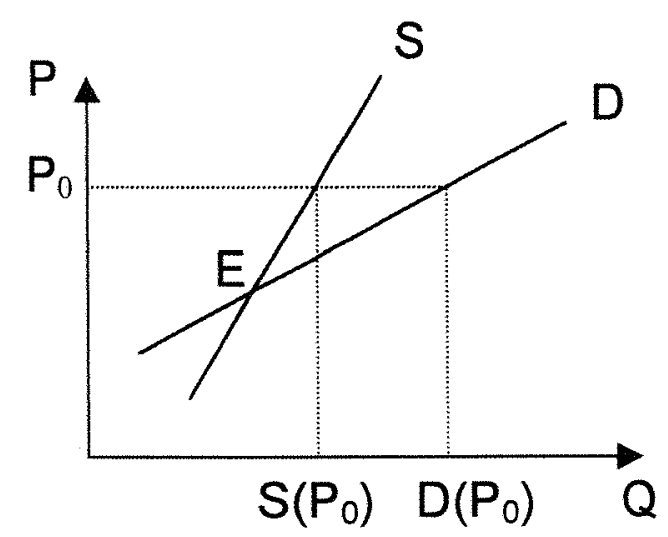

Figura 15 - Equilibrio instável

Situação 5 - $D^{\prime}(P)>0$ e $S^{\prime}(P)>0$ onde $S^{\prime}(P)<D^{\prime}(P)$

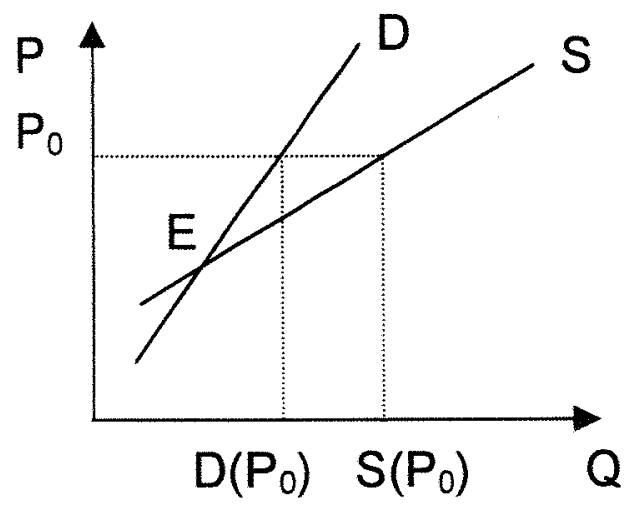

Figura 16 - Equilíbrio estável 
Situação 6 - $D^{\prime}(P)>0$ e $S^{\prime}(P)<0$

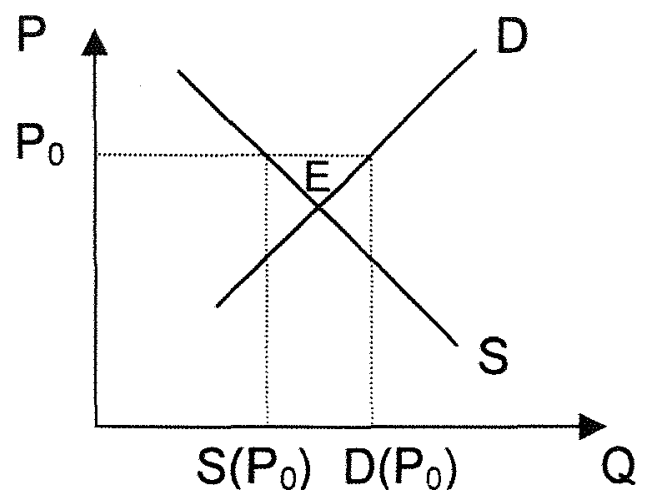

Figura 17 - Equilíbrio instável

É possível descrever geometricamente a função excesso da demanda num sistema cartesiano retangular exaustivamente os casos possíveis. Veja situações descritas a seguir:

Situação 1 - Formatos convencionais das curvas da oferta e da demanda
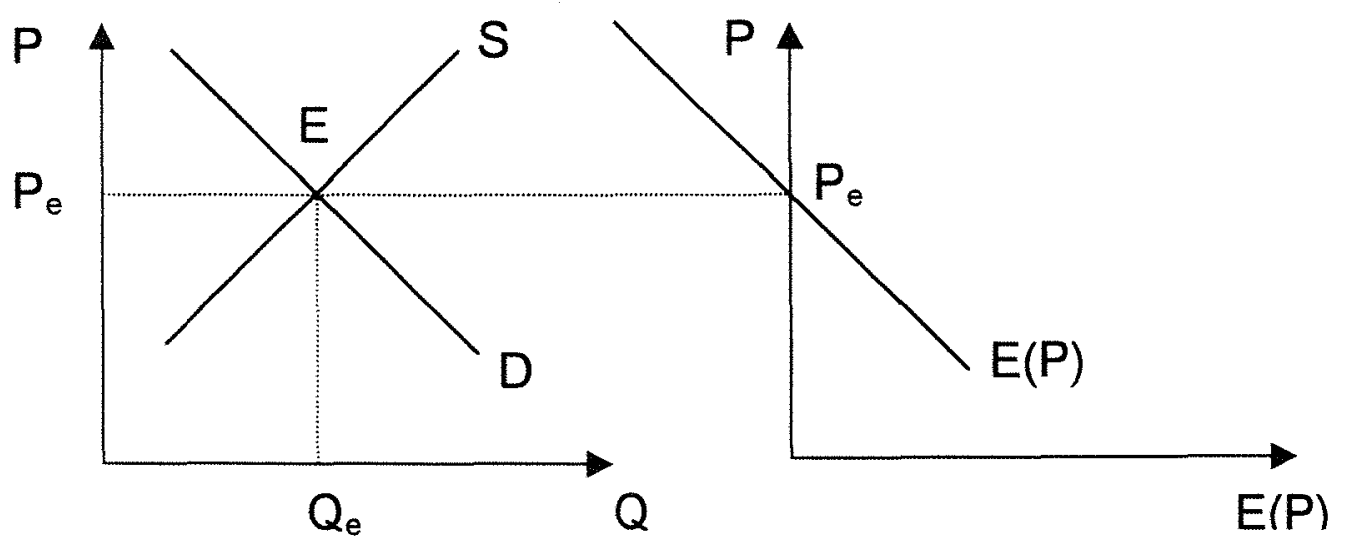

(a) $D^{\prime}(P)<0, S^{\prime}(0)>0$

(b) $E^{\prime}(P)<0$

Figura 18 - Equilibrio estável único 
Situação 2 - Formatos não convencionais das curvas da oferta e da demanda

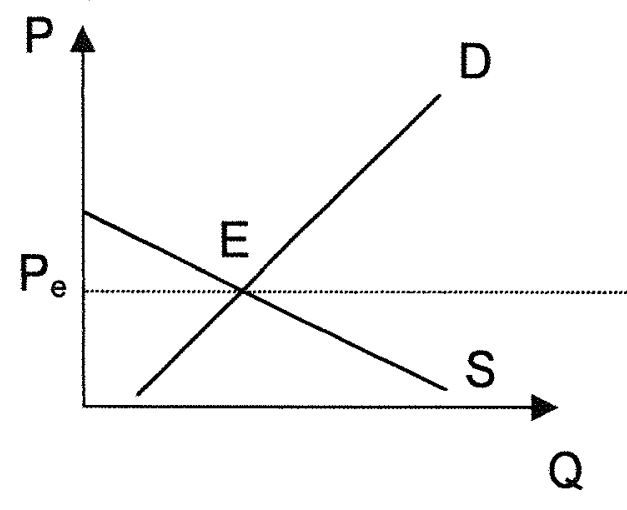

(a) $D^{\prime}(P)>0, S^{\prime}(P)<0$

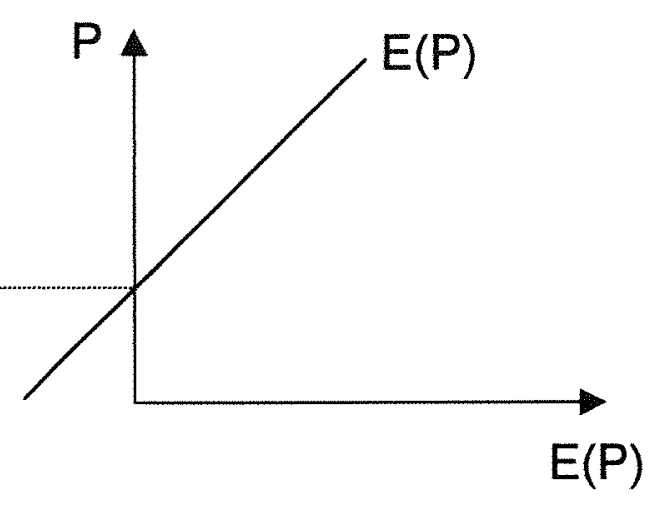

(B) $E^{\prime}(P)>0$

Figura 19 - Equilíbrio instável único

Situação 3 - Formato não convencional da curva da demanda

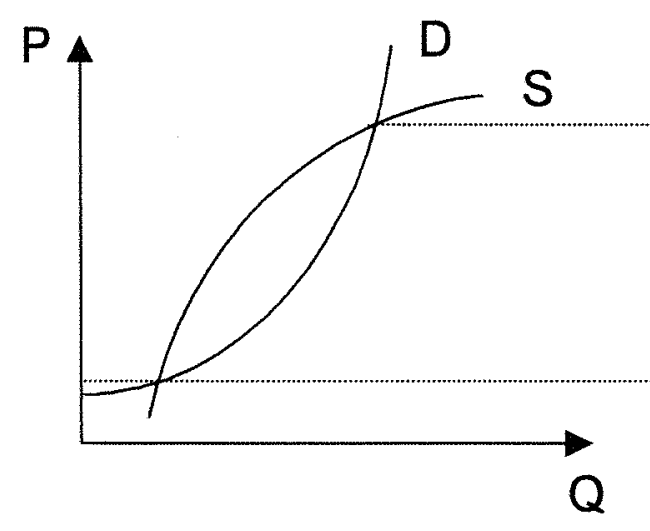

(a) $D^{\prime}(P)>0, S^{\prime}(P)>0$

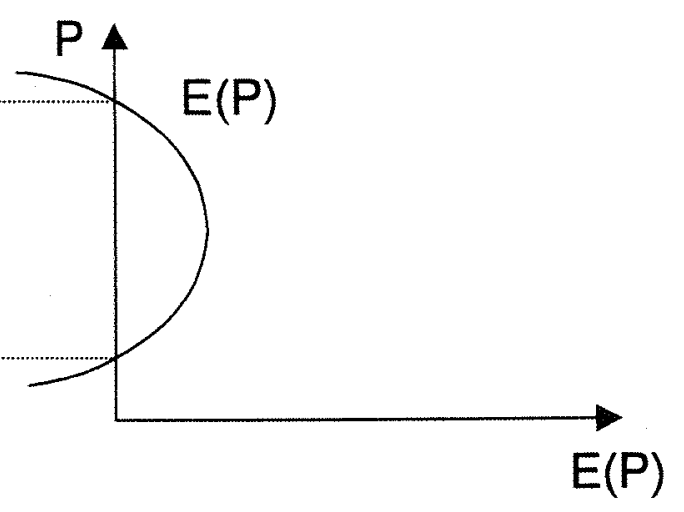

(b) $E^{\prime}(P)>0$ ou $E(P)<0$

Figura 20 - Equilíbrio múltiplo 
Situação 4 - Formatos convencionais das curvas da oferta e da demanda

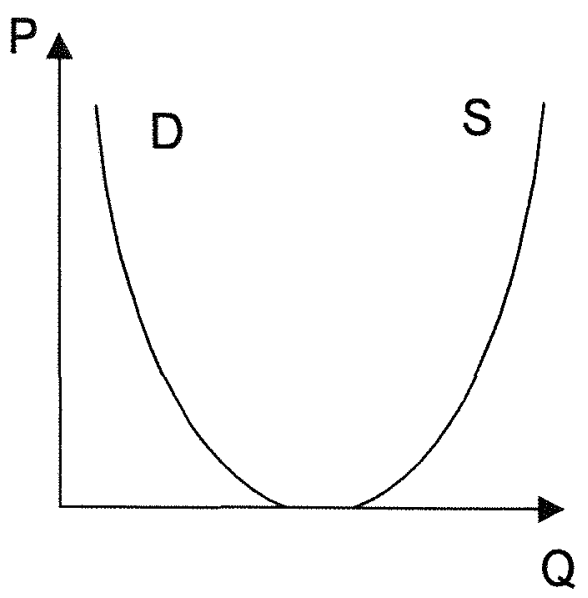

(a) $D^{\prime}(P)<0, S^{\prime}(P)>0$

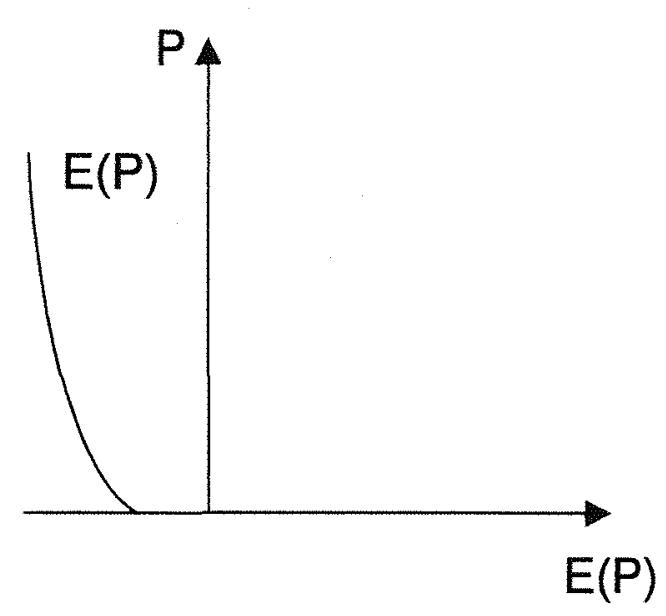

(B) $E^{\prime}(P)<0$

Figura 21 - Não existência do equilibrio

Apesar da importância dos instrumentos analíticos desenvolvidos por Walras para tratar o problema da estabilidade do equilíbrio competitivo, ele pecou em não buscar circunscrever o caso geral (mercado múltiplo) realizando com sucesso apenas o caso do mercado único. Embora não o fizesse, o caso geral, ele abre as portas para o estabelecimento da metodologia no campo da teoria do equilibrio econômico que fornece como fruto principal o desenvolvimento fecundo da dinâmica e da estática comparativa. Ainda, destaca-se que sob a ótica Walrasiana quaisquer afirmações relativas a estabilidade do equilíbrio dependem das suposição relativas ao mecanismo do mercado e do comportamento dos seus participantes. Significa dizer que numa gama de situações reais, a estabilidade do equilibrio somente pode ser avaliada mediante suficientes informações empíricas sobre o padrão de comportamento dos participantes do mercado.

Estabelecido a formulação teórica e gráfica do problema da estabilidade 
do equilíbrio competitivo segundo a concepção estática Walrasiana, cumpre apresentar um exemplo numérico detalhado. Suponha uma economia abstrata representada pelas funções demanda e oferta:

$$
\begin{aligned}
& \left\{\begin{array}{l}
D=-0,25 P+50 \\
S=-0,05 P+25
\end{array}\right. \\
& \frac{d D(P)}{d P}=D^{\prime}(P)=-0,25<0 \\
& \frac{d S(P)}{d P}=S^{\prime}(P)=-0,05<0
\end{aligned}
$$$$
E^{\prime}(P)=D^{\prime}(P)-S^{\prime}(P)=-0,25+0,05=-0,20<0 \rightarrow \text { condição de }
$$
estabilidade estática.

Graficamente,

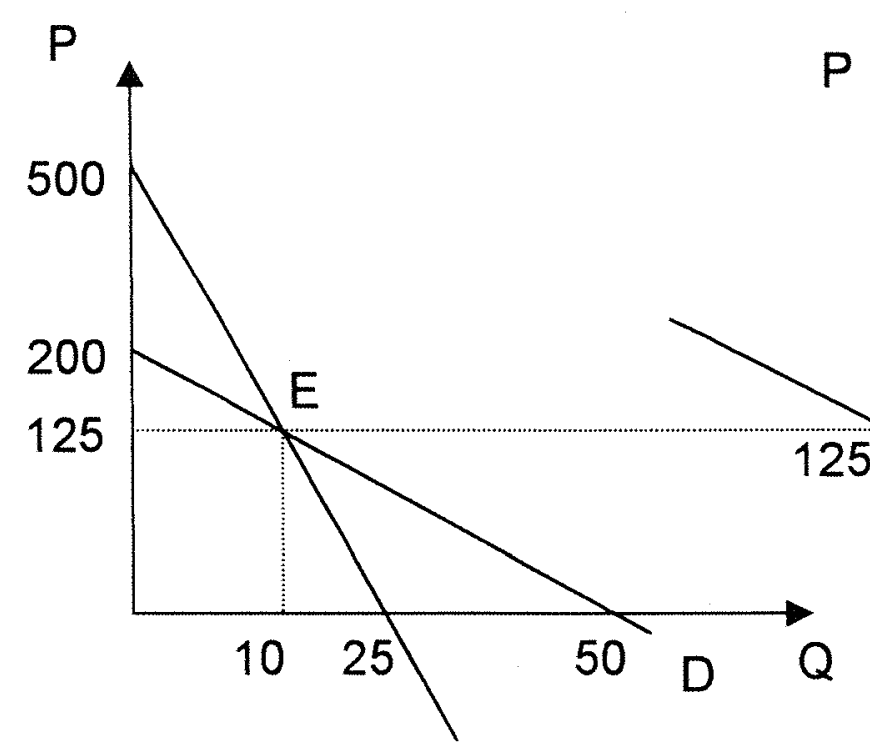

$S$

(a) Equilíbrio demanda-oferta (b) Função excesso da demanda

Figura 22 - Equilibrio estável único 
cujos cálculo são estabelecidos como segue:

$$
\begin{aligned}
& -0,25 P+50=-0,05 P+25 \\
& 50-25=-0,05 P+0,25 P \\
& 25=0,20 P \\
& P=\frac{25}{0,20} \\
& P_{e}=125 \rightarrow \quad \text { preço de equilíbrio } \\
& D=-0,25 \times 1,25+50=-31,25+50=18,75 \\
& S=0,05 \times 125+25=-6,25+25=18,75 \\
& Q_{e}=18,75 \quad \rightarrow \quad \text { quantidade de equilibrio }
\end{aligned}
$$

$$
\left.\begin{array}{l}
E(P)=D(P)-S(P)=-0,25 P+50-(-0,05 P+25) \\
E(P)=-0,25 P+0,05 P+50-25 \\
E(P)=-0,20 P+25 \rightarrow E(P)=25 \\
P=0 \rightarrow P=125
\end{array}\right\} \begin{aligned}
& \text { função excesso da demanda } \\
& E(P)=0 \rightarrow P \text { extos para construção da curva de } \\
& \text { excesso da demanda. }
\end{aligned}
$$

E conclui-se, que o equilíbrio Walrasiano é estável no sentido estático. 


\subsubsection{Considerações adicionais}

Por que a obra de Walras não produziu uma repercussão á altura da literatura de Marshall, até o seu resgate nos anos 30 do século XX? Apontamse quatro razões diretas.

Primeira, a literatura Marshaliana está escrita em linguagem mais acessivel pois pretendia atingir um público ligado á área de negócios e não ao especialista em economia pura, o que não o fez Walras em seus escritos.

Segunda, a literatura Marshaliana manteve fidelidade com a grande tradição da Economia Política Clássica cuja linhagem remontava a Adam Smith, David Ricardo e Stuart Mill, o que não fez Walras, pois alinhou-se completamente à nova visão marginalista protagonizada por ele, Jevons (Inglaterra) e Menger (Áustria), também.

Terceira, o que dificulta o avanço da literatura Walrasiana é o limitado conhecimento do próprio Walras da teoria matemática existente àquela época, quando do seu período de atividade intelectual mais intenso (1870 - 1890). 0 Professor Struik (1997) afirma que por volta de 1870, as matemáticas formavam uma estrutura enorme e complexa, dividida num grande número de campos, só conhecido dos especialistas. Mesmo os grandes matemáticos - Hermite (18221901), Weierstrass (1815-1897), Cayley (1821-1895), Beltrami (1835-1900) - só podiam ser eficientes em poucos destes domínios. Para se ter uma idéia do grau de conhecimento que a matemática produzia no período (1800 - 1910), é possivel visualizar a elaboração das geometrias não-euclideanas por Lobachevsky (1793-1856) e Boliay (1802-1860); a álgebra pura por Felix Klein (1849-1925), Sophus Lie (1842-1899), Sylvester (1814-1897), Grasmann (18091877). No domínio da análise real sobressaíram-se Riemann (1826-1866), Grasmann, Hamilton (1805-1865), Dedekind (1831-1916) e Poincaré (18541912).

Quarta, ataques frontais e muito pesado sobre o uso da matemática em 
economia, são desferidos por matemáticos eminentes, por exemplo, J.Bertrand e por economistas ilustres que obtiveram sucesso em seu empreendimento teórico sem o uso da matemática, tais como, John Bates Clark e Böhm Bawerk que alertavam para a não necessidade do uso da matemática para 0 conhecimento e aplicação do núcleo teórico estabelecido.

Como observa-se na literatura Walrasiana em seus dois livros mais conhecidos, Elements of Pure Economics e Compêndios dos elementos de economia política pura, a literatura matemática trabalhada consiste apenas em cálculo diferencial e integral elementar e geometria analítica plana elementar, o que é muito pouco para que Walras pudesse aprofundar-se em questões mais intrincadas na teoria do equilibrio geral, como por exemplo, a elaboração e solução do problema da estabilidade em mercado múltiplo. Necessitava que Walras tivesse usado ativamente os aspectos computacionais e qualitativos das equações diferenciais ordinárias e parciais inclusive o método de Lyapunov desenvolvido no último decênio do século XIX, publicado em 1892, que estavam bastante desenvolvidos àquela época de sua maior atividade intelectual (1870 -1900).

Walras demonstra muito esforço na busca cada vez mais intensa de conhecimento na literatura matemática como pôde ser constatado em suas correspondências com célebres matemáticos daquela época, tal como o francês Henri Poincaré, conforme Ingrao (1990). Falta de interesse e motivação portanto não foi, porém o ser humano tem suas limitações ponderáveis. 


\subsection{A estabilidade do equilíbrio em mercados múltiplos}

\subsubsection{Panorama institucional e características gerais}

O período que transcorre da publicação do trabalho pioneiro de Leon Walras (1874) até o início da Primeira Grande Guerra (1914) é caracterizado por fatos importantes.

Primeiro, progresso no sistema de transportes, principalmente, nos modos marítimo, ferroviário e rodoviário. Os navios são intensamente utilizados para fins de transporte de mercadorias e passageiros, tanto no circuito europeu como fora dele: África, Ásia e América do Norte. Ainda, no transporte marítimo transparece que ocorreram crescimento da frota na marinha mercante, progresso na construção naval, assim como na exploração e abertura de novas rotas marítimas. Enquanto que no modo ferroviário observava-se que as novas rotas estavam divididas em três categorias: (1) rotas de penetração de um ponto da costa em direção ao interior, (2) redes ligando as rotas de penetração por vias transversais, (3) rotas transcontinentais atravessando um continente permitindo o florescer da atividade econômica. Historicamente, o exemplo mais importante dessas categorias são os Estados Unidos da América do Norte, que desperta disputas internas muito competitivas pela posse e uso do modo ferroviário por motivos econômico e político.

Segundo, a expansão comercial da Europa desponta: (1) pelo uso intensivo da aduana como corredor de escoamento das exportações, (2) pela organização das importações de ultramar, (3) pelas concessões de ferrovias, de importância vital tanto para o escoamento das exportações como a facilitação do transporte das importações.

Terceiro, a expansão financeira da comunidade européia, onde destacam-se: (1) os paises investidores, tais a França, a Grã-Bretanha e a Alemanha; (2) as regiōes receptoras, tais como o continente Asiático onde 
figuram Japão, China, Índias Inglesas e Neerlandesas, o continente americano onde figuram Estados Unidos e Argentina, o continente africano onde figuram o Egito e a África Sul.

Quarto, a expansão demográfica resultante de motivos emigratórios, existência de focos de emigração tais como Noroeste da Europa e Europa Oriental Europa Meridional e zonas de imigração, tais como Estados Unidos, Canadá, Argentina e Brasil no continente americano, assim como, Austrália, África do Sul e África do Norte no continente não-americano.

O periodo 1874 - 1914, visto rigorosamente sob a ótica econômica, transparece a passagem do capitalismo industrial dominado pela figura do empresário-empreendedor ligado ao capital essencialmente industrial para 0 capitalismo financeiro dominado pelos grandes conglomerados financeiros atrelados ao capital essencialmente financeiro, figura do banqueiroempreendedor. $E$, é neste período que se observa que a Alemanha descreve uma trajetória de crescimento econômico invejável, denominado 'milagre alemão', cujos fatores declarados da pujança despontam: (1) bancos fortes; (2) cartéis; (3) dumping; (4) progresso acentuado no transporte modal e suas rotas; (5) papel do Estado como agente econômico nas figuras de grande consumidor de bens e serviços produzidos pela iniciativa privada, assim como grande produtor de bens e serviços. Outros países, também, tiveram prosperidade econômica acentuada no período, tais como a França e a Inglaterra.

Com o clima de confiança na capacidade de gerenciar economias prósperas, o povo europeu imaginava que pudesse suportar os custos de um conflito armado. Lêdo engano. O declínio europeu logo transparece: (1) perdas humanas irreparáveis; (2) destruição da base industrial; (3) desorganização da atividade comercial interna e externa; (4) desestruturação do sistema financeiro e (5) desarticulação dos programas dos governos, direcionados para atividades essenciais a comunidade e deslocando a massa financeira para financiar a economia de guerra. E o conflito transcorre de 1914 a 1918, deixando um rastro de destruição material e humana, desorganização econômico-financeira do 
continente europeu, destacando a crise alemã que se instalaria em 1923 e a crise americana, bolsa de Nova lorque em 1929, seguida de profunda depressão que se arrasta até 1932.

Sob os acontecimentos do período 1874-1914, da Primeira Grande Guerra ,1914 - 1918, aliado ao periodo de conseqüências do conflito e outros fatores incomodantes da economia mundial, tais como crise alemã (1923), crack da Bolsa de Nova lorque e depressão americana (1929 - 1932) acontecem importantes fatos institucionais e teórico-analíticos que têm influência na elaboração dos trabalhos científicos relevantes para a teoria econômica do equilíbrio geral, especialmente, a teoria da estabilidade.

No último quartel do século XIX, o eminente cientista Gustav Cassel (1899) apresenta seu primeiro artigo que versa sobre a teoria econômica do equilíbrio geral, que considera uma versão simplificada do modelo Walrasiano, a qual atribui idéias inovadoras, argumentando que a versão simplificada deixa de lado a teoria da utilidade embora essa apareça sob uma terminologia diferente. Apresenta seu trabalho clássico em 1918, denominado The Theory of Social Economy. Destaca-se, também, W. Launhardt (1885), autor do primeiro livro didático que procura difundir os conhecimentos da escola marginalista, em especial Walras, e produz resultados aplicacionais do modelo Walrasiano, ao aplicá-lo aos sistemas de transportes. E, Edgeworth (1881) apresenta a explicação da teoria Walrasiana simplificada através da configuração geométrica denominada posteriormente de caixa de Edgeworth com o uso das curvas de indiferenças e de contrato.

É fundada nos Estados Unidos a American Economic Associations (1885) e a Royal Economic Society na Inglaterra (1890) com o propósito de fortalecerem a profissão em economia e ao mesmo tempo na divulgação da Ciência Econômica. Em 1904, H. Cunynghame elabora um livro texto no qual divulga, através do uso intensivo e declarado da geometria, os conhecimentos já estabelecidos pelos principais representantes da escola marginalista. Outros cientistas contribuem com destaque: H.L. Moore (1905), Vilfredo Pareto (1910), 
W. Zawadski (1914), J. Moret (1915), Slutzky (1915) e Bowley (1924).

Nos anos 30 , alguns eventos institucionais marcam a decolagem ao sucesso na esteira do conhecimento da teoria econômica revelada em moldes matemáticos: a teoria do equilibrio competitivo Walrasiano.

Primeiro, a fundação da Econometric Society, em Cleveland, nos Estados Unidos, em dezembro de 1930, por um grupo de economistas: Irving Fisher, Charles Roos, Ragnar Frisch e outros. A finalidade da Econometric Society é divulgar o conhecimento da teoria econômica através de seus segmentos quantitativos: econometria e economia matemática. E para tal divulgação se utiliza da organização de encontros na forma de congressos, simpósios e palestras que consagram a discussão do que de melhor é elaborado na comunidade acadêmica sobre métodos quantitativos aplicados à economia.

Segundo, a constituição da Comissão Cowles para a Pesquisa Econômica, em 1932, sob a tutela de Alfred Cowles, cuja finalidade é fomentar - uso da Lógica, da Matemática e de métodos estatísticos na análise econômica, além de divulgar os resultados através de livros, artigos e promoção de encontros formais da comunidade para discussão do desenvolvimento e da aplicação dos métodos quantitativos à teoria econômica.

Terceiro, a criação da revista Econometrica, em 1933, sob o manto da Econometric Society, que se revela como o instrumento da publicação de estudos originais em economia pura e aplicada, tais como, Hicks (1934), Samuelson (1941-1942), Lange (1944), Metzler (1945) e outros.

Quarto, publicações de estudos econométricos valiosos elaborados por Frisch (1934), Schultz (1938) e Tinbergen (1939).

Quinto, o Colóquio de Viena, realizado em Viena, capital da Áustria, nos anos 20 e 30, representa um ambiente cultural e intelectual de intensa atividade em matemática, filosofia e economia. Representantes da nata da matemática do século XX, tais como Kurt Gödel (1906-1978), Karl Menger, Banach (1892-1945), Kuratowski, Shauder, Borsuk, Mazur, Tarski (1902-?), 
Steinhaus, Kac Lomnicki, S. M. Ulam, John von Neumann (1903-1957), Abraham Wald; representantes da filosofia tais como Ernst Mach, Otto Neurath, Rudolph Carnap, Friedrich Waisman, Hans Reichenbach, Richard Von Mises e Carl Hempes; representantes da esfera econômica tais como Karl Schlesinger, Oskar Morgenstern, Friedrich Von Hayek promovem a movimentação constante de encontros entre cientistas de diversas especialidades que resulta em contribuições importantes para o desenvolvimento da economia pura. Publicações de artigos em teoria do equilibrio geral é elaborado por Hicks (1934) e Wald (1933 - 34, 1934 - 35, 1936), o último com a primeira formulação e demonstração formal da existência do equilíbrio econômico de troca e produção na versão Walrasiana juntamente com o livro de Cassel (1932, tradução do original de 1918) que apresenta uma versão simplificada do modelo de equilibrio geral Walrasiano, enquanto que Schlesinger (1933 - 34) apresenta um modelo de equilíbrio geral em versão não-Walrasiana.

A constituição do edifício matemático no período 1870 - 1939 é de extrema importância para a condução da pesquisa econômica em linguagem simbólica. Precisão e síntese representam o esteio da linguagem matemática formal. Observa-se ao apagar das luzes do século XIX, último quartel, que a matemática estava passando por um estágio muito importante: formalização da análise matemática, construção do edifício da álgebra pura e sedimentação das geometrias não-euclideanas (Eves, 1990 e 1997). Anteriormente, o desenvolvimento da matemática em grande parte estava atrelado aos interesses da física teórica. Portanto consegue sua libertação e passa a andar sobre suas próprias pernas e disso se utilizam os economistas de inclinação quantitativista, tais como Irving Fisher, Leon Walras, Carl Menger, Edgeworth, Bowley, Marshall e Wicksell para desenvolverem suas pesquisas na área da economia pura e aplicada. De posse dos conhecimentos de análise matemática (cálculo diferencial e integral) e geometria analítica plana e no espaço constroem modelos econômicos que mantém elementos importantes como unidade de análise: equilíbrio e otimização sob condição de diferenciabilidade 
das funçōes objetivo. Aplicam estes princípios para construirem as teorias do consumidor, produção, custos e sobre estruturas de mercado (produto e fator), destacando-se Walras (1874), Edgeworth (1881), J. Bertrand (1883), Marshall (1898), Pareto (1910), Wicksell, Cassel (1918), Karl Schlesinger (1932), Joan Robinson (1933), Edward Chamberlain (1933), Stalkelberg (1934) e Wald (1934).

Problemas institucionais de natureza política, tais como, o advento do totalitarismo russo influenciando e dominando o leste europeu, a cortina de ferro, constituída pela Polônia, Hungria, Tchecoeslováquia, Romênia, Bulgária e Albânia; o surgimento das ditaduras de direita, fascismo na Itália e nazismo na Alemanha, deslocam o centro das atividades acadêmico-científicas do mundo europeu para a emergente potência mundial, Estados Unidos da América do Norte, que recebe de bom grado os principais cérebros europeus, valorizando cada vez mais o ensino e a pesquisa em ciência pura e tecnologia, nos institutos e universidades americanas. Matemáticos importantes, do quilate de John Von Neumann e Paul Halmos (Hungria), Richard Courant (1888-1972), Emmy Noether e Hermann Weil (Alemanha), Jean Diedonnée (França) se estabelecem nos Estados Unidos, traduzindo esta permanência em construção e desenvolvimento das linhas de pesquisas que favorecem diretamente à formação intelectual em métodos quantitativos dos principias agentes promotores futuros da literatura econômica do equilibrio geral, em toda a sua problemática: existência, unicidade e estabilidade. Entre aqueles, diretamente favorecidos destacam-se, Paul Anthony Samuelson, Lloyd Metzler, Oskar Lange, Kenneth Arrow, Gerard Debreu, Tjailling Koopmans, Lionel Mckenzie, Wassily Leontief, Leonid Hurwics, Maurice Allais e Haalvelmo, para citar apenas aqueles que estavam envolvidos com a pesquisa e desenvolvimento da teoria do equilíbrio geral. Pegaram carona, em face do deslocamento do centro de pesquisa e desenvolvimento, os economistas japoneses que estavam atrelados às novas linhas de pesquisas na teoria do equilíbrio competitivo: Negishi, Uzawa, Morishima e Nikadô. Do mesmo modo, cientistas ingleses de renome 
são envolvidos pela êxtase do desenvolvimento cientifico-tecnológico que se alastrou no período 30 - 50: Hicks, Allen e Hahn.

O tipo de matemática utilizada pelos economistas na pesquisa centrada na construção dos modelos de equilibrio geral, no período $30-50$, tinha como núcleo, o cálculo diferencial e integral avançado, os sistemas de equações diferenciais e a diferenças e a álgebra matricial.

Como material analítico de apoio ao supra descrito apresenta-se em detalhe as contribuições dos principais economistas no período 39 - 58 , focalizando os conceitos e proposições estabelecidas associadas a exercícios numéricos realizado em detalhe para facilitar a compreensão dos conceitos e do enunciado das principais proposições e encerra-se cada Seção com comentários pertinentes. Autores estudados: John Richard Hicks (1939), Paul Anthony Samuelson (1941, 1942, 1947), Oskar Lange (1944), Lloyd Metzler (1945) e Kenneth Arrow et al $(1956,1958,1959)$.

\subsubsection{John Richard Hicks}

Hicks trata o problema da estabilidade em mercado competitivo múltiplo num sentido muito restrito, a estabilidade local. Deste modo, não leva em consideração a necessidade de explicar que qualquer que seja o estado inicial da economia, ela tenderá ao equilíbrio, ou seja, prevalece considerações estáticas. $O$ conceito de estabilidade estática Walrasiana é generalizada para o caso de mercado múltiplos, ou seja para situações de equilíbrio por Hicks em Value and Capital (1939).

No caso do mercado único, sabe-se que a estabilidade Walrasiana procede, se, a preços acima do preço de equilíbrio, o excesso da demanda é negativo (oferta excede demanda) e a preços abaixo do preço do equilíbrio, 0 excesso da demanda é positivo (demanda excede oferta).

Para Hicks, no caso de mercados múltiplos os efeitos de uma mudança de preço de uma mercadoria sobre os preços de outras mercadorias na 
situação de equilibrio geral são levados em consideração. Assim sendo, com o propósito de desenvolver o conteúdo analítico sobre a estabilidade em mercados múltiplos em Hicks (1939) procede-se de modo a definir alguns instrumentos de análise considerados fundamentais para a compreensão das condições de estabilidade.

Primeiro, um mercado é definido como imperfeitamente estável se uma queda no preço de uma mercadoria particular gera um excesso da demanda para aquela mercadoria, depois que todos os outros preços têm se ajustado eles mesmos de modo que oferta é novamente igual a demanda em todos os mercados exceto para aquele da mercadoria particular (Hicks, 1939, p. 62). Formalmente,

$$
\frac{d E_{i}(P)}{d P_{i}}=\frac{J}{J_{i i}}<0
$$

onde $\mathrm{J}$ é o determinante jacobiano do sistema completo e $\mathrm{J}_{\mathrm{ii}}$ é cofator de $b_{\mathrm{ii}}$. Uma aplicação direta facilita a compreensão do conceito. Suponha que exista uma economia cuja representação é dada pelas equações abaixo:

$$
\begin{aligned}
& \left\{\begin{array}{l}
E_{2}=3 P_{2}+4 P_{3}-17 \\
E_{3}=P_{2}+P_{3}-5
\end{array}\right. \\
& \frac{d E_{2}}{d P_{2}}=\frac{\left|\begin{array}{ll}
3 & +4 \\
1 & +1
\end{array}\right|}{+1}=\frac{3-4}{+1}=\frac{(-1)}{1}=-1<0 \\
& \frac{d E_{3}}{d_{3}}=\frac{\left|\begin{array}{ll}
3+4 \\
1+1
\end{array}\right|}{+3}=\frac{3-4}{3}=\frac{(-1)}{3}=-\frac{1}{3}<0
\end{aligned}
$$

Segundo, um mercado é definido como perfeitamente estável se uma queda no preço abaixo do preço de equilibrio gera um excesso da demanda depois que qualquer dado subconjunto de preços em outros mercados for 
ajustado de modo que a oferta novamente iguala a demanda, com todos os outros preços restantes mantidos constantes. (Hicks, 1939, p. 62). Formalmente,

$$
\frac{d E_{j}}{d P_{j}}=b_{j j}<0
$$

onde $b_{i j}$ são coeficientes do sistema completo. Introduz-se um exemplo numérico. Imagine uma economia que possui três mercadorias representada pelas funções excesso da demanda descrita a seguir:

$$
\begin{aligned}
& \left\{\begin{array}{l}
E_{2}=-P_{2}+3 P_{3}-5 \\
E_{3}=P_{2}-P_{3}-1
\end{array}\right. \\
& \frac{\partial E_{2}}{\partial P_{2}}=-1<0 \\
& \frac{\partial E_{3}}{\partial P_{3}}=-1<0
\end{aligned}
$$

De acordo com as definições acima, fica estabelecido o resultado: se cada mercado único é estável, o sistema econômico inteiro é dinamicamente estável. A validade do teorema está ligada diretamente as condições necessárias e suficientes para a existência da estabilidade perfeita.

Satisfeitas as duas condições para estabilidade perfeita Hicksiana, eq. (5) e eq. (6), afirma-se que o sistema possui estabilidade verdadeira.

Suponha que todas as funções excesso da demanda são contínuas e diferenciáveis. Com efeito, dado,

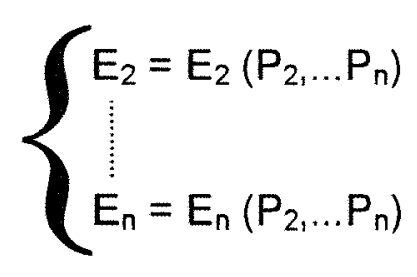


e diferenciando totalmente cada função excesso da demanda com respeito a $P_{2}$ (todos os preços que não $\mathrm{P}_{2}$ mantidos constantes) obtém-se

$$
\left\{\begin{array}{l}
\frac{d E_{2}}{d P_{2}}=\frac{\partial E_{2}}{\partial P_{2}} \cdot \frac{d P_{2}}{d P_{2}}+\cdots+\frac{\partial E_{2}}{\partial P_{n}} \cdot \frac{d P_{n}}{d P_{2}} \\
\frac{d E_{n}}{d P_{2}}=\frac{\partial E_{n}}{\partial P_{2}} \cdot \frac{d P_{2}}{d P_{2}}+\cdots+\frac{\partial E_{n}}{\partial P_{n}} \cdot \frac{d P_{n}}{d P_{2}}
\end{array}\right.
$$

ou na forma matricial

$$
\left[\begin{array}{c}
\frac{d E_{2}}{d P_{2}} \\
\vdots \\
\frac{d E_{n}}{d P_{2}}
\end{array}\right]=\left[\begin{array}{ccc}
\frac{\partial E_{2}}{\partial P_{2}} & \cdots \cdots \cdots \cdots & \frac{\partial E_{2}}{\partial P_{n}} \\
\frac{\partial E_{n}}{\partial P_{2}} & \cdots \cdots \cdots & \frac{\partial E_{n}}{\partial P_{n}}
\end{array}\right] \cdot\left[\begin{array}{c}
\frac{d P_{2}}{d P_{2}} \\
\vdots \\
\frac{d P_{n}}{d P_{2}}
\end{array}\right]
$$

onde cada derivada parcial está sendo avaliada no conjunto dos preços de equilíbrio

$$
\begin{aligned}
& \frac{d P_{i}}{d P_{2}}=0 \quad \text { se } \quad \frac{d E_{i}}{d P_{2}} \neq 0 \\
& \frac{d E_{i}}{d P_{2}}=0 \quad \text { se } \quad \frac{d P_{i}}{d P_{2}} \neq 0
\end{aligned}
$$

para $i \in\{2, \ldots, n\}$. Significa dizer que ignora-se os efeitos sobre todos os outros preços de uma mudança em $P_{2}$. Assim sendo,

$$
\frac{d E_{2}}{d P_{2}}=E_{22}
$$


e de acordo com condição de estabilidade perfeita tem-se

$$
\frac{\mathrm{dE}_{2}}{\mathrm{dP}_{2}}<0
$$

0 que implica $E_{22}<0$. Reenumerando as mercadorias, conclui-se que estabilidade perfeita exige que $E_{i i}<0, \forall_{i}$. Significa dizer geometricamente que a curva agregada de excesso da demanda para cada mercadoria deve ser decrescente. Veja a Figura 23 :

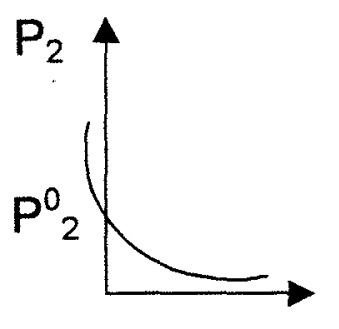

$\mathrm{E}_{1}$

\section{$E_{n}$}
a) $E_{22}<0$
b) $\ldots E_{n n}<0$

Figura 23 - Funções excesso da demanda

Dando seqüência ao procedimento acima é estabelecido o resultado fundamental:

Teorema 1 - O sistema econômico é considerado perfeitamente estável se e somente se os menores principais da matriz [ $E_{i r}$ ] alternam em sinal (apresenta-se abaixo as condições referentes a uma economia com três mercadorias, onde uma delas é o numerário: sistema normalizado).

$$
\mathrm{b}_{22}=\frac{\partial \mathrm{E}_{2}}{\partial \mathrm{P}_{2}}<0
$$

$$
\mathrm{b}_{33}=\frac{\partial \mathrm{E}_{3}}{\partial \mathrm{P}_{3}}<0
$$




$$
\left|\begin{array}{ll}
\frac{\partial \mathrm{E}_{2}}{\partial \mathrm{P}_{2}} & \frac{\partial \mathrm{E}_{2}}{\partial \mathrm{P}_{3}} \\
\frac{\partial \mathrm{E}_{3}}{\partial \mathrm{P}_{2}} & \frac{\partial \mathrm{E}_{3}}{\partial \mathrm{P}_{3}}
\end{array}\right|>0
$$

Um exercício numérico é ilustrado em detalhe para servir como material de apoio à compreensão do resultado estabelecido. Suponha uma economia que possui funções excesso da demanda descritas:

$$
\begin{gathered}
\left\{\begin{array}{l}
E_{2}=-3 P_{2}+4 P_{3}-5 \\
E_{3}=4 P_{2}-6 P_{3}+4
\end{array}\right. \\
E=\left[\begin{array}{rr}
-3 & 4 \\
4 & -6
\end{array}\right] \\
b_{22}=-3<0 \\
\left|\begin{array}{cc}
-3 & 4 \\
4 & -6
\end{array}\right|=18-16=2>0
\end{gathered}
$$

e, conclui-se que o sistema é perfeitamente estável.

Para Professor Hicks, no sistema econômico abstrato a única fonte possivel de instabilidade no mecanismo competitivo é a ocorrência do efeitorenda assimétrico. Com efeito, prova o teorema seguinte: 
Teorema 2 - Os menores principais da matriz $\left[E_{i r}\right] i, r \in\{1, \ldots, n\}$ alternam em sinal se efeitos-renda são simétricos em relação aos consumidores.

O trabalho do Professor Hicks sobre a estabilidade do equilíbrio competitivo fornece valiosas contribuições ao conteúdo analítico, destacando-se a integração da teoria dinâmica com o método da estática comparativa, o que significa dizer que estática comparativa não tem significância em teoria econômica a menos que o sistema econômico seja dinamicamente estável. Por conseguinte, a inovação fundamental devida ao Professor Hicks consiste na derivação das propriedades do sistema de equilíbrio a partir das condições de estabilidade de um sistema dinâmico correspondente. Primeiro, as condições de estabilidade Hicksiana fornecem um conjunto de condições de estabilidade que são independentes da velocidade de resposta dos preços individuais a diferenças entre oferta e demanda. Segundo, em uma certa classe de sistemas de mercados, estabilidade perfeita Hicksiana é a condição necessária e suficiente para estabilidade dinâmica verdadeira, ou seja, estabilidade dinâmica de primeira espécie. llustra-se o resultado através de um exercício numérico. Suponha uma economia constituída por funções excesso da demanda para três mercadorias

$$
\begin{gathered}
\left\{\begin{array}{l}
E_{2}=-4 P_{2}-6 P_{3}-24 \\
E_{3}=8 P_{2}-16 P_{3}-64
\end{array}\right. \\
1 \quad \begin{array}{l}
b_{22}=-4<0 \\
b_{33}=-16<0
\end{array}
\end{gathered}
$$$$
2\left|\begin{array}{cc}
-4 & -6 \\
8 & -16
\end{array}\right|=112>0
$$

Satisfeitas as duas condições para estabilidade perfeita Hicksiana, afirma-se que o sistema possui estabilidade dinâmica verdadeira. 
Os principais trabalhos escritos de Hicks sobre equilibrio geral (1934, 1939) se referem principalmente a uma avaliação da obra Elements of Pure Economics de Walras (1934), e seu livro Value and Capital (1939) que nos Capítulos de IV a VIII discute sobre o problema do equilíbrio dando ênfase ao problema da estabilidade do equilíbrio competitivo criando alguns conceitos: estabilidade perfeita e imperfeita para uma economia em mercados múltiplos. Realizando sua exposição através da linguagem geométrica bidimensional e no apêndice, traduz todo material descritivo em formalismo matemático. Apesar de sua formação universitária na graduação ter sido em matemática, Hicks não usa os conhecimentos avançados para elaborar uma teoria estruturada sobre o problema da estabilidade do equilibrio geral, pois tal realização exige conhecimento além daqueles encontrados em Value and Capital. Contudo, Hicks detinha os conhecimentos básicos em teoria das matrizes, determinantes e o cálculo diferencial e integral de funções reais a várias variáveis reais, o que facilitou a sua leitura do livro de Walras assim como para construir o modelo para mercados múltiplos. Porém, não usa o conhecimento de sistemas dinâmicos, pois acreditava no seu poder de argumentação descritiva em detrimento da análise matemática formal, conforme patente em seu prefácio de Value and Capital (1939), necessário para avançar na elaboração de uma teoria do equilibrio geral onde o problema da estabilidade teria tido melhor avaliação, teórica e aplicada, como o fizeram Samuelson, $(1941,1942,1947)$ Lange (1944) e Metzler (1945), na década de 40.

\subsubsection{Paul Anthony Samuelson}

A contribuição ao estudo da teoria da estabilidade do equilibrio competitivo devida ao Professor Samuelson, repousa na idéia fundamental de que existe uma relação de dependência formal intima entre estática comparativa e dinâmica. A esta relação de dependência ele denomina princípio de correspondência. Significa dizer que: 
"A investigação da estabilidade dinâmica de um sistema pode fornecer teoremas fecundos para a análise estática, como é possível utilizarmos propriedades conhecidas de um sistema estático comparativo para se obter informações a respeito das propriedades dinâmicas de um sistema" (1947, p.7).

Samuelson interfere no problema relativo a estabilidade do equilíbrio competitivo exposto pelo Professor Hicks estabelecendo duas proposições fundamentais.

Proposição 1 - Um sistema pode ser estável mas, não ser perfeita nem imperfeitamente estável.

Para verificar a aplicação da assertiva apresenta-se um exemplo que é desenvolvido analiticamente. Suponha uma economia cujo sistema dinâmico representativo é:

$$
\left\{\begin{array}{l}
E_{2}=-2 P_{2}+4 P_{3} \\
E_{3}=-P_{2}+P_{3}
\end{array}\right.
$$

e estuda-se o problema da estabilidade, estabilidade perfeita e imperfeita.

1 condição de estabilidade

$$
\left[\begin{array}{l}
E_{2} \\
E_{3}
\end{array}\right]=\left[\begin{array}{ll}
-2 & 4 \\
-1 & 1
\end{array}\right]\left[\begin{array}{l}
P_{2} \\
P_{3}
\end{array}\right] \quad \Delta=\left[\begin{array}{ll}
-2 & 4 \\
-1 & 1
\end{array}\right]
$$

a $\operatorname{Tr} \Delta=-1<0$

$\underline{\mathrm{b}}|\Delta|=\left|\begin{array}{cc}-2 & 4 \\ -1 & 1\end{array}\right|=-2-(-4)=-2+4=2>0$

Conclusão: O sistema é estavél. 
2 condição de estabilidade perfeita

$$
\begin{array}{ll}
\frac{\partial \mathrm{E}_{2}}{\partial \mathrm{P}_{2}}=-2<0 & 1^{\text {aa }} \text { condição } \rightarrow \text { satisfeita } \\
\frac{\partial \mathrm{E}_{3}}{\partial \mathrm{P}_{3}}=1>0 & 2^{\text {a }} \text { condição } \rightarrow \text { não satisfeita }
\end{array}
$$

Conclusão: O sistema não é perfeitamente estável.

$\underline{3}$ condição de estabilidade imperfeita

$$
\begin{aligned}
& \frac{\mathrm{dE}_{2}}{\mathrm{dP}_{2}}=\frac{\left|\begin{array}{cc}
-2 & 4 \\
-1 & 1
\end{array}\right|}{1}=\frac{-2+4}{1}=2>0 \quad 1^{\text {a }} \text { condição } \rightarrow \text { não satisfeita } \\
& \frac{\mathrm{dE}_{3}}{\mathrm{dP}_{3}}=\frac{\left|\begin{array}{cc}
-2 & 4 \\
-1 & 1
\end{array}\right|}{(-2)}=\frac{-2+4}{(-2)}=-1<0 \quad 2^{\text {a }} \text { condição } \rightarrow \text { satisfeita }
\end{aligned}
$$

Conclusão: O sistema não é imperfeitamente estável.

Proposição 2 - Um sistema é imperfeitamente estável, mas se afasta cada vez mais do equilibrio.

$$
\left\{\begin{array}{l}
E_{1}=P_{1}+P_{2} \\
E_{2}=2 P_{1}+P_{2}
\end{array}\right.
$$


1 condição de estabilidade

$$
A=\left[\begin{array}{ll}
1 & 1 \\
2 & 1
\end{array}\right]
$$

a $\operatorname{tr} A=1+1=2>0$

não satisfeita

b $|A|=\left|\begin{array}{ll}1 & 1 \\ 2 & 1\end{array}\right|=1-2=-1<0 \quad$ não satisfeita

2 imperfeitamente estável

a $\frac{\mathrm{dE}_{2}}{\mathrm{dP}_{2}}=\frac{\left|\begin{array}{ll}1 & 1 \\ 2 & 1\end{array}\right|}{1}=\frac{(-1)}{1}=-1<0$

$\underline{\mathrm{b}} \frac{\mathrm{dE_{3 }}}{\mathrm{dP}}=\frac{\left|\begin{array}{ll}1 & 1 \\ 2 & 1\end{array}\right|}{1}=\frac{(-1)}{1}=-1<0$

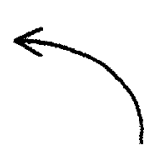

Satisfeitas

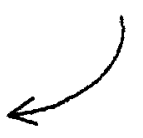

Diferentemente de Leon Walras e John Hicks, Samuelson tem uma formação cultural e acadêmica mais abrangente, principalmente, no que se refere à matemática universitária superior avançada: cálculo diferencial e integral de funçōes reais de uma variável real, de funçōes reais de duas ou mais variáveis reais, cálculo vetorial, cálculo matricial, teoria qualitativa das equações diferenciais ordinárias e parciais, sistemas dinâmicos e equações a diferenças, geometria métrica plana e espacial, geometria analítica plana e espacial, trigonometria plana e esférica. Portanto, Samuelson conhece todos os 
instrumentos necessários para realizar com autoridade os dois artigos (1941, 1942) e sua inclusão no livro Foundations of Economics Analysis (1947) em capítulos que tratam exclusivamente sobre a teoria da estabilidade na configuração do equilíbrio geral e tópicos paralelos (teoria Keynesiana, teoria malthusiana e ciclo de negócios). Sua formação sobre equações diferenciais e sistemas dinâmicos está diretamente ligada aos textos clássicos de Emile Picard (1856-1941) em Cours d'Analyse e David G. Birkoff (1844-1944) em Dynamical Systems, além de sua afinidade de estudos com E. B. Wilson (18791964) e Gilberto Bliss, matemáticos a quem ele referenciava. Ambos considerados eminentes matemáticos na década de 40 . Porém, Samuelson não deu seguimento ao estudo sobre a teoria da estabilidade do equilíbrio competitivo ou mesmo sobre teorias paralelas. Uma forte razão para tal fato é a enorme inquietação que Samuelson demonstra para rapidamente absorver novos elementos em economia, influência de seus eminentes professores tais como Alvin Hansen, Wassily Leontief, Joseph Schumpeter, Jacob Viner e Aaron Director, e matemática. E a partir daí elaborar novas teorias econômicas ou reformulando algumas já conhecidas em todas as áreas da economia: teoria da troca no comércio internacional, teorema da equalização dos preços dos fatores, teorema de Stolper \& Samuelson, que usa intensivamente geometria métrica, analítica e álgebra; teoria do comportamento do consumidor e da firma, que usa conhecimentos de cálculo diferencial e integral elementar; e outras áreas importantes da teoria econômica pura.

Hoje, Paul Anthony Samuelson é Institute Professor Emeritus of Economics no Massachusetts Institute of Tecnology, sob os louros de seus inúmeros prêmios acadêmicos nacional e internacional, inclusive tendo sido o primeiro americano a receber o Prêmio Nobel de Economia em 1970. 


\subsubsection{Oskar Lange}

Com o propósito de ampliar e modificar o domínio de ação estabelecido por Hicks (1939) na teoria da estabilidade do equilíbrio num mercado competitivo, Lange (1944) introduz o conceito de estabilidade parcial de ordem e posto diferentes. Estabelece que o sistema admite ser parcialmente estável de ordem $m(m \leq n)$ se as condições Hicksianas são satisfeitas quando somente $\underline{m}$ outros preços são ajustados e os preços restantes mantidos constantes. Formalmente, a condição de estabilidade parcial de ordem $\mathrm{m}$ pode ser estabilidade como segue:

$\left|\frac{d E_{r}}{d P_{r}}\right|_{n-m}=\frac{J_{n n}, \ldots \cdot n-m}{J_{n m}, \cdots \cdot n-m, r}<0$

$r=1,2, \ldots . m$.

onde o numerador é o cofator de $\underline{\mathrm{J}}$ de ordem $\underline{\mathrm{m}}$ e o denominador é o cofator de $\mathrm{J}$ de ordem $(\mathrm{m}-1)$. O determinante $\mathrm{J}$ é definido,

$$
J=\left|\begin{array}{ccc}
\frac{\partial E_{1}}{\partial P_{1}} & \cdots \cdots \cdots . . . & \frac{\partial E_{1}}{\partial P_{n}} \\
\vdots & \vdots \\
\frac{\partial E_{n}}{\partial P_{1}} & \cdots \cdots \cdots \cdot \frac{\partial E_{n}}{\partial P_{n}}
\end{array}\right|
$$

Se o sistema é parcialmente estável de ordem $\underline{n}$, onde é o número de bens inclusive o numerário, diz-se que ele é totalmente estável. Assim as condições de Lange se reduzem às condições Hicksianas. 
Lange define, também, que o sistema é dito estável de posto $\underline{m}$ se ele é parcialmente estável de ordem m porém não atende para ordem superior a $\mathrm{m}$. $O$ posto de estabilidade do sistema corresponde a mais alta ordem de estabilidade que o sistema possui. Um sistema é dito totalmente estável se possui estabilidade de posto $\underline{\underline{n}}$.

Inicialmente, definições supra elaboradas por Lange, não usa termos da literatura Hicksiana. Porém, as definições que seguem compreendem extensões da literatura propriamente Hicksiana. Estabelece que um sistema possui estabilidade parcial perfeita de ordem $\underline{m}$ quando o sistema possui estabilidade parcial para todas as ordens menores referentes a quaisquer preços assegurado constante. Caso contrário está definido a estabilidade parcial imperfeita de ordem $\underline{m}$. Formalmente, a condição para estabilidade perfeita de ordem $\underline{m}$ é escrita como segue:

$$
a_{11}<0, \quad\left|\begin{array}{ll}
a_{11} & a_{12} \\
a_{21} & a_{22}
\end{array}\right|>0
$$

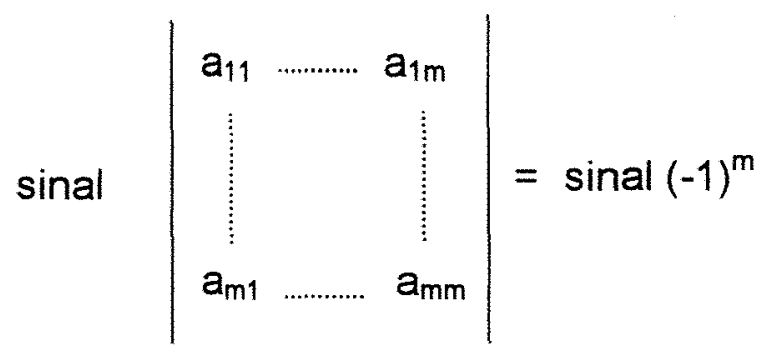

Como produto de sua síntese analítica sobre a teoria da estabilidade do equilíbrio competitivo, Lange enuncia um resultado fundamental: 
Proposição 3: As condições Hicksianas para estabilidade perfeita são equivalentes às condições de estabilidade dinâmica quando o determinante característico de ordem $\underline{m}$ é simétrico.

Como material de apoio à compreensão da proposição supra-enunciada cabe imaginar a existência de uma economia abstrata que possui três mercadorias sendo uma delas o numerário, cuja representação está descrita abaixo:

$$
\left\{\begin{array}{l}
E_{2}=-P_{2}+P_{3}-1 \\
E_{3}=P_{2}-P_{3}+1
\end{array}\right.
$$

cujo desenvolvimento é estabelecido como segue:

$\mathrm{n}=3 \rightarrow$ número total de mercadorias

$\mathrm{m}=2 \rightarrow$ número de mercadorias exclusive o numerário

$\left[\begin{array}{l}E_{2} \\ E_{3}\end{array}\right]=\left[\begin{array}{rr}-1 & 1 \\ 1 & -1\end{array}\right] \cdot\left[\begin{array}{l}P_{2} \\ P_{3}\end{array}\right]+\left[\begin{array}{c}-1 \\ 1\end{array}\right] \quad \begin{aligned} & b_{22}=-1<0 \\ & b_{33}=-1<0\end{aligned}$
$\left|\begin{array}{ll}-1-\lambda & 1 \\ 1 & -1-\lambda\end{array}\right|=0 \rightarrow$ determinante característico de ordem 2

Lange transparece que seu trabalho contém: (1) somente discussão técnica sobre a teoria da estabilidade do equilibrio competitivo, (2) não realiza qualquer discussão empírica $e,(3)$ não efetua qualquer exemplo numérico.

Uma avaliação de sua obra é realizada sob cinco pontos. Primeiro, nota-se que Lange detém pleno conhecimento dos fundamentos Walrasiano do equilibrio geral, pois realiza um resumo do ponto central discutido no livro de Walras sobre estabilidade: função excesso da demanda e condição da estabilidade estática Walrasiana. Segundo, Lange demonstra domínio da teoria 
da estabilidade traçada por Hicks, pois traça uma linha de análise onde contribui com novas definições e ampliando algumas já existentes. Terceiro, nota-se seu pleno conhecimento das idéias principais sobre estabilidade dinâmica desenvolvida por Samuelson $(1941,1942)$. Quarto, Lange demonstra que possui largo domínio sobre os elementos de matemática relativo a equações diferenciais ordinárias, matrizes e determinantes, manipulando-os de forma a realizar com clareza o tratamento analítico de suas proposições, além de ser um economista de formação cultural vasta, incluindo trabalhos publicados sobre economia socialista (polonês de nascimento). Quinto, a questão da interpretação do Tâtonnement está traduzido numa versão normativa.

\subsubsection{Lloyd Metzler}

O Professor Metzler contribui significativamente à obra Hicksiana estabelecendo dois teoremas fundamentais que melhor esclarecem os pontos de vista do pesquisador no que se refere à teoria da estabilidade do equilíbrio competitivo:

Teorema 3 - Estabilidade perfeita Hicksiana é condição necessária para estabilidade de primeira espécie se o sistema de mercado tende a ser estável para todos os conjuntos de velocidades de ajustamento

$$
\left(k_{i}\right), i \in\{1,2, \ldots, n\}
$$

Suponha uma economia cujo sistema representativo é

$$
\left\{\begin{array}{l}
D_{t}=-P_{t}+200 \\
S_{t}=-0,2 P_{t}+100
\end{array} \quad K=12\right. \text { velocidade de ajustamento }
$$


1 Determinação do preço de equilíbrio

$$
P_{t}=P_{e}
$$

$$
\begin{gathered}
-P_{e}+200=-0,2 P_{e}+100 \\
-P_{e}+0,2 P_{e}=100-200 \\
-0,8 P_{e}=-100 \\
P_{e}=\frac{100}{0,8} \\
P_{e}=125
\end{gathered}
$$

2 Determinação da função excesso da demanda defasada de um período

$$
\begin{aligned}
& E\left(P_{t-1}\right)=D\left(P_{t-1}\right)-S\left(P_{t-1}\right) \\
& E\left(P_{t-1}\right)=-P_{t-1}+200-\left(-0,2 P_{t-1}+100\right) \\
& E\left(P_{t-1}\right)=-0,8 P_{t-1}+100
\end{aligned}
$$

$\underline{3}$ Determinação da equação de comportamento do modelo

$$
\begin{aligned}
& P_{t}-P_{t}=K E\left(P_{t-1}\right) \\
& P_{t}-P_{t-1}=12\left(-0,8 P_{t-1}+100\right) \\
& P_{t}=P_{t-1}+\left(-9,6 P_{t-1}+1200\right) \\
& P_{t}=-8,6 P_{t-1}+1200 \quad \text { para } P(0)=P_{0}
\end{aligned}
$$

4 Solução

$$
\begin{aligned}
& P_{t}=\left(P_{0}-P_{e}\right)[1+K(a-A)]^{t}+P_{e} \\
& P_{t}=\left(P_{0}-125\right)[-0,86]^{t}+125
\end{aligned}
$$

$\underline{5}$ Condição de estabilidade $\quad-1<1+K(a-A)<1$

$1+12(-1+0,2)+1+12 \cdot(-0,8)=1-9,6=-8,6$

$-8,6<-1$ 
Conclui-se que o mercado não é estável e portanto exibirá oscilações explosivas.

Duas considerações relativas ao significado econômico do teorema melhor esclarecem seu valor aplicacional à teoria do equilíbrio, mais especificamente, a estabilidade do equilíbrio competitivo.

Primeira, o grau ao qual a estabilidade de um grupo de mercados depende das velocidades de ajustamento. Dois casos se apresentam: aquele no qual a inflexibilidade de certos preços é considerado um fator estabilizador e; (2) aquele no qual os mercados são estáveis mesmo se todos os preços forem respostas para diferenças entre oferta e demanda. Como denominador comum de ambos os casos, à medida que as condições de estabilidade perfeita Hicksiana não são satisfeitas, a estabilidade do sistema depende de uma inflexibilidade relativa de certos preços.

Segunda, as condições que comandam as respostas de preços são muito menos claras que as condiçōes de demanda e oferta em mercados individuais. Significa dizer que enquanto velocidade de ajustamento são resultantes de fatores institucionais tais como disponibilidade ou habilidade de compradores ou vendedores no sentido de manter ou reduzir estoques; as condições estáticas de demanda e oferta em mercados individuais dependem das condições de maximização de lucros de produtores e consumidores. Consequentemente, os economistas matemáticos acreditam com mais propriedade em seu conhecimento acerca das condições de demanda e oferta do que seu conhecimento sobre tais fatores dinâmicos como velocidade de ajustamento do ponto de vista analítico sistemas de mercado que sejam despidos de velocidade de ajustamentos.

O passo seguinte contributivo à estabilidade de equilibrio competitivo devido ao Professor Metzler consiste na prova de que em uma certa classe de sistemas de mercado, estabilidade perfeita Hicksiana é condição necessária e suficiente para estabilidade dinâmica de primeira espécie, definição estabelecida por Samuelson $(1941,1942)$. Contudo, ele desenvolve todo o seu 
esquema supondo que todas as mercadorias existentes naquele sistema de mercado são substitutos brutos (demanda Marshalliana) diferentemente do que fizera Hicks (1939) que utilizou o conceito de substituto líquido (demanda Hicksiana). Procedeu-se à definição: todas as mercadorias são substitutos brutos quanto um aumento no preço da i-ésima mercadoria mantido inalterado todos os outros preços, reduz-se o excesso da demanda para aquela mercadoria e aumenta o excesso da demanda para as demais. Formalmente,

$$
\frac{\partial \mathrm{E}_{\mathrm{j}}}{\partial \mathrm{P}_{\mathrm{k}}}>0, \quad \forall \mathrm{P}, \mathrm{j} \neq \mathrm{k}
$$

Exemplifica-se a definição acima através de um exercício numérico:

$$
\begin{aligned}
& \left\{\begin{array}{l}
E_{1}=-2 P_{1}+3 P_{2} \\
E_{2}=P_{1}-P_{2}
\end{array}\right. \\
& \frac{\partial E_{1}}{\partial P_{2}}=3>0 \\
& \frac{\partial E_{2}}{\partial P_{1}}=1>0
\end{aligned}
$$

Após a definição de substituto bruto o Professor Metzler conduz a sua análise através da prova do teorema fundamental:

Teorema 4 - Se todas as mercadorias num sistema de mercado são substitutos brutos, as condições para estabilidade dinâmica de primeira espécie são idênticas às condições para estabilidade perfeita Hicksiana.

O valor aplicacional do teorema 4 é visualizado num exemplo numérico estabelecido como elemento de apoio à compreensão teórica. Suponha uma economia constituída por 2 mercadorias, cujas funções excesso da demanda 
estão descritas abaixo:

$$
\left\{\begin{array}{l}
E_{2}=-2 P_{2}+P_{3}+4 \\
E_{3}=3 P_{2}-3 P_{3}-3
\end{array}\right.
$$

cujo vetor de preços de equilíbrio é $P=(1,3,2)$. Descreve-se:

1 a condição de substitutos brutos

$$
\begin{array}{lll}
\frac{\partial \mathrm{E}_{2}}{\partial \mathrm{P}_{2}}=-2<0 & \text { e } & \frac{\partial \mathrm{E}_{2}}{\partial \mathrm{P}_{3}}=+1>0 \\
\frac{\partial \mathrm{E}_{3}}{\partial \mathrm{P}_{3}}=-2<0 & \frac{\partial \mathrm{E}_{3}}{\partial \mathrm{P}_{2}}=+3>0
\end{array}
$$

$\underline{2}$ a condição para estabilidade

$$
E=\left[\begin{array}{ll}
-2 & +1 \\
+3 & -3
\end{array}\right]
$$

a $\operatorname{Tr} E=-2-3 \quad \therefore \operatorname{Tr} E=-5<0$

$\underline{b}|E|=\left|\begin{array}{rr}-2 & 1 \\ 3 & -3\end{array}\right| \quad \therefore|E|=6-3 \quad \therefore|E|=3>0$

$\underline{3}$ a condição para estabilidade perfeita Hicksiana

$$
\frac{\partial E_{2}}{\partial P_{2}}=\frac{\left|\begin{array}{rr}
-2 & 1 \\
3 & -3
\end{array}\right|}{(-3)} \quad \therefore \quad \frac{\partial E_{2}}{\partial P_{2}}=-1<0
$$


$\frac{\partial E_{3}}{\partial P_{3}}=\frac{\left|\begin{array}{rr}-2 & 1 \\ 3 & -3\end{array}\right|}{(-2)} \quad \therefore \quad \frac{\partial E_{3}}{\partial P_{3}}=-1,5<0$

donde se conclui que todas as condições do teorema são satisfeitas.

\subsubsection{O modelo de expectativas adaptativas}

$\mathrm{O}$ artigo "A Theorem on Expectations and the Stability of Equilibrium" (1956) cujos autores são Arrow \& Enthoven constitui no primeiro passo, do ponto de vista do rigor científico, na busca da relação entre estabilidade dinâmica e expectativa singular um sistema dinâmico estável pode absorver efeitos de alguma extrapolação de movimeintos de preços e, ainda assim permanecer estável.

Face à linha de raciocínio sugerida naquele artigo, e numa maneira de estender e intensificar o estudo sobre a tema, Arrow \& Nerlove (1956) estabeleceram a relação entre estabillidade dinâmica e uma função expectativa melhor elaborada sugerida pela definição de expectativas apresentada pelo professor Hicks em seu livro Value and Capital (1939).

Uma hipótese básica de trabalho consiste em que mudanças no preço esperado da i-ésima mercadoria em face das alterações nos preços correntes são comandadas pela relação.

$P_{i}^{\prime}=P_{i}+n_{i} \dot{P}_{i} \quad P_{i}>0$

onde

$\mathrm{P}_{\mathrm{i}} \rightarrow$ preço corrente da i-ésima mercadoria. 
$\mathrm{P}_{\mathrm{i}} \rightarrow$ preço esperado futuro da i-ésima mercadoria.

$\dot{\mathrm{P}}_{\mathrm{i}} \rightarrow$ derivada do preço corrente da i-ésima marcadoria com respeito ao tempo.

$n_{i} \rightarrow$ elasticidade de expectativas.

$$
\begin{gathered}
P_{i}^{\prime}-P_{i}=0 \quad \frac{d P_{i}}{d t} \quad \therefore \quad \frac{d P_{i}}{d t}=\frac{P_{i}^{\prime}-P_{i}}{n_{i}} \\
\frac{d P_{i}}{d t}-\frac{P_{i}^{\prime}-P_{i}}{n_{i}}=0 \quad \therefore \quad \frac{d P_{i}}{d t}-\frac{P_{i}^{\prime}}{n_{i}}+\frac{P_{i}}{n_{i}}=0 \\
\frac{d P_{i}}{d t}+\frac{1}{n_{i}} \cdot P_{i}=\frac{P_{i}^{\prime}}{n_{i}} \quad \text { eq. (8) }
\end{gathered}
$$

A expressão eq. (8) é uma equação diferencial linerar de primeira ordem e primeiro grau cuja solução é estabelecida como segue:

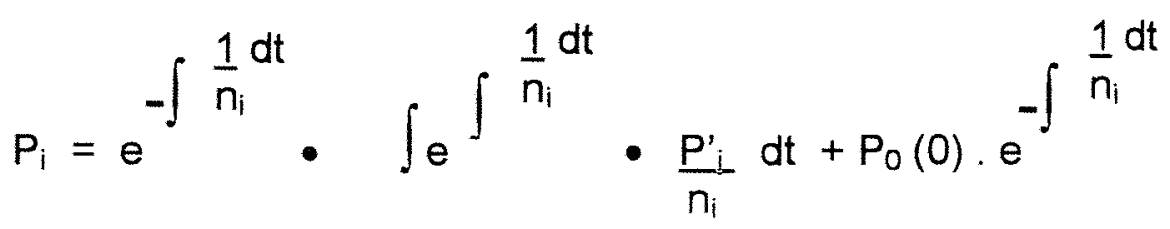

$$
P_{i}=e^{\frac{-1}{n_{i}}} \cdot \int e^{\frac{1}{n_{i}}} \cdot \frac{P^{\prime} i}{n_{i}} d t+P_{0}(0) \cdot e^{\frac{-1}{n_{i}} t}
$$

$$
P_{i}=e^{\frac{-1}{n_{i}} \cdot t} \cdot P_{i}^{\prime} e^{\frac{1}{n_{i}} \cdot t}+P_{0}(0) \cdot e^{\frac{-1}{n_{i}}}
$$

$$
P_{i}=P_{i}^{\prime}+P_{0}(0) \cdot e^{\frac{-1}{n_{i}} \cdot t}
$$


Algumas considerações são realizadas a respeito das informações disponiveis concernentes à eq. (9) quando utilizado a valoração de $n_{i}$. Significa dizer que:

1 para $n_{i}=0$, os preços correntes são esperados persistir, e deste modo afirmase que as expectativas são estáticas,

$n_{i}=0 \rightarrow P_{i}=P_{i}^{\prime}$

$\underline{2}$ para $n_{i}>0$, algum múltiplo da mudança em preços foi adicionada ao preço corrente de modo a atingir o preço esperado futuro e, por conseguinte, afirmase que as expectativas são extrapolativas,

$n_{i}=2 \rightarrow P_{i}=P_{i}^{\prime}+P_{0}(0) \cdot e^{\frac{-1}{2} t}$

$\underline{3}$ para $n_{i}<0$, os preços esperados não mudam tanto como os preços correntes.

$n_{i}=-1 \rightarrow P_{i}=P_{i}^{\prime}+P_{0}(0) \cdot e^{+t}$

Analíticamente considera-se não a idéia de expectativas de preços futuros particulares, mas expectativas do nivel médio sobre o qual preços futuros são esperados flutuar. Com efeito, o nível médio sobre o qual preços futuros são esperados denominam-se preço esperado normal.

Em vista do parágrafo anterior, acredita-se que a influência de preços mais recentes sobre expectativas deve ser maior do que a influência de preços menos recentes, ou seja, $P_{t-1}$ exerce maior influência sobre o preço esperado futuro do que $P_{t-5}$. Significa dizer que o preço esperado normal é uma média ponderada dos preços passados, onde os pesos declinam à medida que 0 tempo passado é mais remoto. 
Cumpre, neste momento consagrar-se aquilo que Hicks chama de elasticidade de expectativas: É o coeficiente que mede a variação no preço futuro resultante de variação no preço corrente de determinada mercadoria. 0 campo de definição plausível para a elasticidade de expectativa é o intervalo $(0,1)$. Isto significa que um preço particular passado pode ter alguma influência contudo não significa que quanto mais remoto o preço considerado implica em levar as pessoas a pensar que o preço normal prevalecerá. Com efeito, expressa o preço corrente como um desvio do preço normal, ou seja aquele preço prévio esperado pelos indivíduos e não como desvio de preços passados. Portanto, expressa de forma matemática a elasticidade de expectativa como segue:

$\frac{P i(t)-P i(t-1)}{P i(t-1)-P i(t-1)}=\beta_{i}$

quando assume que a variável tempo é descontinua. Neste caso os preços são expressos em logarítmos e $\beta_{i}$ é a elastlicidade de expectativa do preço da iésima mercadoria, a qual é admitida constante. Considerações são feitas para retirar as informações disponiveis na eq. (10):

1 para $\beta_{i}=0$, alterações no preço corrente não produziriam efeito sobre o preço esperado normal;

$\underline{2}$ para $\beta_{\mathrm{i}}=1$, o preço corrente foi projetado em direção as expectativas do nivel de preços futuros pensado (idealizado) pelos indivíduos.

Quando utilizado a variável tempo em termos contínuos a eq. (10) torna-se,

$$
\begin{aligned}
& \dot{P}_{i}^{\prime}=\beta_{i}\left(P_{i}-P_{i}^{\prime}\right) \quad \beta_{i} \geq 0 \\
& \dot{\mathrm{P}}_{\mathrm{i}}^{\prime}=\beta_{\mathrm{i}} \mathrm{P}_{\mathrm{i}}-\beta_{\mathrm{i}} \mathrm{P}_{\mathrm{i}}^{\prime} \quad \therefore \dot{\mathrm{P}}_{\mathrm{i}}^{\prime}+\beta_{\mathrm{i}} \mathrm{P}_{\mathrm{i}}^{\prime}=\beta_{\mathrm{i}} \mathrm{P}_{\mathrm{i}} \quad \therefore
\end{aligned}
$$




$$
\frac{d P_{i}^{\prime}}{d t}+\beta_{i} P_{i}^{\prime}=\beta_{i} P_{i}
$$

A expressão eq. (12) é uma equação diferencial linear de primeira ordem e primeiro grau cuja solução é estabelecida como segue:

$$
\begin{aligned}
& P_{i}^{\prime}(t)=e^{-\int \beta i d t} \cdot \int e^{\int \beta i d t} \cdot\left(\beta_{i} P_{i}\right) d t+P_{i}^{\prime}(0) \cdot e^{-\int \beta i d t} \\
& P_{i}^{\prime}(t)=e^{-\beta i t} \cdot \int e^{\beta i t} \cdot \beta_{i} P_{i} d t+P_{i}^{\prime}(0) \cdot e^{-\beta i t} \\
& P_{i}^{\prime}(t)=e^{-\beta i t}\left(P_{i} \cdot e^{\beta i t}\right)+P_{i}^{\prime}(0) \cdot e^{-\beta i t} \\
& P_{i}^{\prime}(t)=P_{i}(t)+P_{i}^{\prime}(0) \cdot e^{-\beta_{i} t}
\end{aligned}
$$

onde

$P_{i}(0)$ é o valor inicial do preço esperado normal.

Considerações feitas em eq. (13) produzem:

1 para $\beta_{i}=0$, alterações em preço corrente não afeta o preço esperado normal;

$\beta_{i}=0 \rightarrow P_{i}^{\prime}(t)=P_{i}(t)+P_{i}^{\prime}(0) \therefore P_{i}^{\prime}(t)-P_{i}^{\prime}(0)=P_{i}(t)$

$\underline{2}$ para $\beta \mathrm{i}=+\infty$, preços correntes são esperados a persistir e, diz-se que as expectativas são estáticas.

$\beta i=+\infty \rightarrow P_{i}^{\prime}(t)=P_{i}(t)$

O modelo de formação de expectativas sugerido pela definição de elasticidade de expectativas de Hicks fornece uma representação razoável do 
preço esperado normal em termos de preços passados. Isto se confirma em vista das considerações levadas a efeito a partir da eq. (7), pois os resultados finais obtidos em eq. (11) são compativeis com aqueles gerados por eq. (7). Ademais, as expectativas geradas pela equação eq. (11) são chamadas expectativas adaptativas. 


\section{A TEORIA DA ESTABILIDADE DO EQUILÍBRIO COMPETITIVO EM MERCADO MÚLTIPLO BASEADA NUMA ECONOMIA ARROW \& DEBREU.}

\subsection{Ambiente econômico e cenário analítico}

O período que compreende do término da Segunda Grande Guerra até 1958 é considerado de arrancada para a prosperidade por causa da necessidade de reconstrução das economias, a descolonização e o acesso das regiōes menos desenvolvidas, Ásia, África e América Latina aos padrōes de vida moderna, os quais geram uma demanda crescente em seus mercados. $O$ continente europeu ocidental aspira à fase da sociedade de consumo. A guerra fria travada entre o mundo ocidental e a cortina de ferro, países do leste europeu, não prejudica o carreamento de recursos para investimentos na área de pesquisa científica gerada de tecnologias, o que gerou grandes avanços na agricultura, indústria e serviços elevando o padrão de vida dos habitantes da América do Norte, Estados Unidos e Canadá, dos europeus ocidentais e do Japão no continente Asiático.

O impulso econômico impõe uma profunda transformação das estruturas. As antigas formas do capitalismo-patrimonial ou financeiro - são substituidas pelo capitalismo tecnocrático, ou seja, um sistema gerencial onde a gestão dos lucros gerados pelo processo produtivo estão nas mão dos tecnocratas - altos funcionários públicos e privados, ex-alunos das Grandes Escolas ou de Universidades privilegiadas, grandes homens de negócios, sábios de toda a espécie. Forma-se uma dualidade. As empresas 
internacionalizam-se ou nacionalizam-se, resultando deste modo que suas decisões têm repercussões políticas, diplomáticas e sociais acentuadas. As técnicas que empregam - energia atômica, informática ( $1^{\mathrm{a}}$ e $2^{\mathrm{a}}$ gerações), motores a reação - respondem a uma produção maciça. Simultaneamente, o espaço terrestre tornou-se menor porque as distâncias são percorridas em velocidade de cruzeiro cada vez maior pelo uso de aviões. A televisão emprega satélites terrestres e até os transportes são mais evoluídos: trem, carro e navio. Finalmente, as ciências econômicas e sociais e as técnicas administrativas procuram assimilar estas novas forças: a cibernética e a robótica.

Sob o manto dos fatos históricos estabelecidos, o tratamento analítico da teoria do equilíbrio geral sob conteúdo axiomático tem início nos anos 50 , mais precisamente a partir dos estudos realizados pela equipe de pesquisadores da Comissão Cowles. A conduta de pesquisa baseava-se na construção e solução de modelos econômicos puros e aplicados no campo da teoria do equilibrio geral, focalizando, a existência, unicidade e estabilidade concomitante estudos sobre problemas econométricos. O conteúdo do conhecimento matemático utilizado para construir os modelos econômicos já estavam consolidados: topologia geral, sistemas dinâmicos, programação linear e análise convexa.

Padrões da axiomática formal são estabelecidos. Primeiro, o discurso contém um conjunto de termos técnicos, tais como, elementos, relações entre os elementos, operações a serem realizadas sobre os elementos, que são deliberadamente escolhidos como termos indefinidos e são denominados os termos primitivos do discurso.

Segundo, o discurso contém um conjunto de proposições sobre os termos primitivos que são livremente escolhidas como proposições indemonstráveis e são denominadas os postulados (ou axiomas), $\mathrm{P}$, do discurso.

Terceiro, todos os outros termos técnicos do discurso são definidos por meio dos termos anteriormente introduzidos. 
Quarto, todas as outros proposições do discurso são logicamente deduzidas das proposições anteriormente aceitas ou estabelecidas e são denominadas os teoremas, $T$, do discurso.

Quinto, para cada teorema $\mathrm{Ti}$ do discurso só uma proposições correspondente, que pode ou não ser formalmente estabelecida, existe que afirma que o teorema $\mathrm{Ti}$ é logicamente derivado dos postulados $\mathrm{P}$.

Sexto, o postulado $P$ implica o teorema T. E fica estabelecido a forma de realização do edifício da teoria do equilíbrio geral, quando da passagem das economias na versão Walras - Hicks - Samuelson - Metzler - Lange, para a economia Arrow \& Debreu, a partir dos anos 50.

Estabelecido a formalização axiomática, resta realizar a discussão dos conceitos e proposições elementares relativos aos problemas de existência e unicidade, constróem a Economia Arrow \& Debreu, para em seguida tratar a teoria da estabilidade no período 1958 - 1960, até o instante do rompimento analítico produzido pelo trabalho de Scarf, descartando o Tâtonnement sob a condição principal de substitutibilidade das mercadorias presentes no sistema econômico.

Debreu (1952) escreve um artigo que trata da prova da existência de um equilibrio para um sistema mais geral composto de agentes econômicos. Dois anos mais tarde, Arrow \& Debreu (1954) escrevem um artigo mais contundente que trata da prova da existência de um equilibrio em um modelo integrado de produção e consumo.

$\mathrm{Na}$ verdade, para a prova da existência de um equilibrio geral podem ser utilizadas técnicas diversas: (1) aplicações do teorema do ponto fixo de Brower (Dierker, 1974) e teorema do ponto fixo de Kakutani (Arrow \& Debreu, 1954); (2) algoritmos combinatórios para a computação do equilíbrio geral aproximado (Scarf, 1960); (3) processos diferenciais convergindo para o equilíbrio geral denominado análise global (Smale, 1976); (4) a teoria do índice do ponto fixo de um mapeamento (Dierker, 1972).

Em equilibrio geral, preços de equilibrio podem ser interpretados como 
aqueles preços que coordenam os planos de compra e venda de todos os agentes na economia. Estabelecimento: equilíbrio único ou número finito de equilibrio. Walras (1874) estabelece apenas um tratamento superficial sobre o problema da unicidade do equilíbrio, enquanto que Wald (1936) apresenta um tratamento sistemático sobre o problema da unicidade surgerindo caminhos de prova de natureza analítica.

Com o propósito de elaborar proposições que revelam a natureza formal do problema da unicidade do equilíbrio é fundamental introduzir as propriedades da função excesso da demanda:

P.1 Homogeneidade: $E(t P)=E(P), \forall t>0, T \in R$.

P. 2 Lei de Walras: $P . E(P)=0, \forall P$.

P.3 Desejabilidade: $E_{i}(P) \rightarrow \infty$ se $P_{i}=0$.

P.4 Diferenciabilidade: E é continuamente diferenciável.

Duas proposições importantes são enunciadas e analisadas através de exercícios numéricos. Primeira, o sistema de preço é um sistema de preço de equilibrio se $E(P)=0$ llustra-se: seja uma economia que possui duas mercadorias e é representada pelo sistema

$$
\left\{\begin{array}{l}
E_{1}=-P_{1}+2 P_{2}-4 \\
E_{2}=P_{1}-P_{2}+1
\end{array}\right.
$$

cujo vetor de preço é calculado usando a Regra de Cramer:

$$
\begin{aligned}
& \left\{\begin{array}{l}
-P_{1}+2 P_{2}=+4 \\
P_{1}-P_{2}=-1
\end{array} \quad \text { onde } \quad E_{1}=0 \text { e } E_{2}=0\right. \\
& \Delta=\left|\begin{array}{rr}
-1 & 2 \\
1 & -1
\end{array}\right| \therefore \Delta=1-2 \quad \therefore \quad \Delta=-1
\end{aligned}
$$




$$
\begin{aligned}
& \Delta_{1}=\left|\begin{array}{cc}
4 & 2 \\
-1 & -1
\end{array}\right| \quad \therefore \Delta_{1}=-4+2 \quad \therefore \quad \Delta_{1}=-2 \\
& \Delta_{2}=\left|\begin{array}{rr}
1 & 4 \\
1 & -1
\end{array}\right| \quad \therefore \Delta_{2}=1-4 \quad \therefore \quad \Delta_{2}=-3 \\
& P_{1}=\frac{\Delta_{1}}{\Delta} \quad \therefore \quad P_{1}=\frac{(-2)}{(-1)} \quad \therefore \quad P_{1}=2 \\
& P_{2}=\frac{\Delta_{2}}{\Delta} \quad \therefore \quad P_{2}=\frac{(-3)}{(-1)} \quad \therefore \quad P_{2}=3
\end{aligned}
$$

Segunda, se $P \in \varepsilon$, conjunto de preços, então $t P \in \mathcal{E}, \forall t>0$, de modo que admite-se que o vetor de preço de equilíbrio $P$ seja único se $q \in \varepsilon$ implica $q$ $=\mathrm{tP}, \forall \mathrm{t}>0$. Numericamente, seja $P=(3,2)$ e estabeleça $t=2$. Daí, faça $q=(\underbrace{}_{t}(\underbrace{4)}_{p} \therefore q=2(3,2) \therefore q=t P$.

A economia é dita ser regular se $E(P)$ é de posto completo $\forall P \in \varepsilon$. Dois resultados são estabelecidos. Primeiro, economias críticas é um subconjunto nulo fechado do conjunto de todas as economias, cuja prova é realizada utilizando-se o teorema de Sard. Segundo, o número de equilibrios em uma economia regular é finito, cuja prova é realizada pelo uso do teorema do índice de Poincaré - Hopf.

Do segundo resultado derivam-se dois corolários importantes. Primeiro, o número de equilíbrios em uma economia regular é impar. Segundo, se $E(P)$ é negativo para todo $P \in \mathcal{E}$, então o equilíbrio é único.

llustra-se o segundo corolário com um exercício. Suponha que existe uma economia com duas mercadorias cuja representação é realizada através 
do sistema não-normalizado:

$$
\left\{\begin{array}{l}
E_{1}=-P_{1}+2 P_{2}-4 \\
E_{2}=P_{1}-P_{2}+1
\end{array}\right.
$$

cujo vetor de preço de equilíbrio é $P=(2,3)$ quando $E_{1}=0$ e $E_{2}=0$. Daí, calcula-se

$$
\begin{aligned}
& |E(P)|=\left|\begin{array}{cc}
\frac{\partial E_{1}}{\partial P_{1}} & \frac{\partial E_{1}}{\partial P_{2}} \\
\frac{\partial E_{2}}{\partial P_{1}} & \frac{\partial E_{2}}{\partial P_{2}}
\end{array}\right| \\
& |E(P)|=\left|\begin{array}{rr|}
-1 & 2 \\
1 & -1
\end{array}\right| \therefore \quad|E(P)|=-1<0
\end{aligned}
$$

o que implica $P=(2,3)$ é único.

Uma definição de extrema importância para o desenvolvimento da teoria da estabilidade é descrita como segue: uma economia com função excesso da demanda $E$ tem a propriedade de preferência revelada se P. $E(q)>0$ sempre que $P \in E$ e $q \notin E$. llustra-se a definição através de um exercício numérico: seja uma economia que possui duas mercadorias que é representada pelo sistema,

$$
\left\{\begin{array}{l}
E_{1}\left(q_{1}, q_{2}\right)=-q_{1}+2 q_{2}-3 \\
E_{2}\left(q_{1}, q_{2}\right)=q_{1}-q_{2}+1
\end{array}\right.
$$

e faça $q=(2,5)$ um novo conjunto de preços e que

$$
\begin{aligned}
& E_{1}=(2,5)=5 \text { e } E_{2}(2,5)=-2 \text {. Dai, P.E(q) }=(1,2) .(5,-2) \quad \therefore \\
& P . E(q)=1.5+2 .(-2) \quad \therefore \quad P . E(q)=5-4 \therefore P . E(q)=1>0
\end{aligned}
$$


Uma observação importante é que se todos os agentes são idênticos a economia tem a propriedade de preferência revelada. De fato, a razão essencial pela qual a propriedade mantém-se, se todos os agentes são idênticos é que não existe troca no equilíbrio. Este resultado é utilizado por Arrow et al em teoremas nos artigos de 1958 e 1959.

Propriedades importantes para a construção dos modelos de equilíbrio geral são estabelecidas. Primeira, uma economia com função excesso da demanda $E$ tem o propriedade de substituto bruto forte se $P_{i}>$ qi e $P_{j}=q_{j}$ para cada $i \neq j$ implica que $E_{j}(P)>E_{j}(q), \forall i \neq j$. Segundo, uma economia com função excesso da demanda $E$ tem a propriedade de substituto bruto fraco se $P_{i}>q_{i} e$ $P_{j}=q_{j}$ para cada $i \neq j$ implica que $E_{j}(P) \geq E_{j}(q), \forall i \neq j$.

Duas proposições fundamentais são derivadas das propriedades acima. Primeira, a propriedade de substitutibilidade bruta implica a propriedade de preferência revelada. Segunda, a propriedade de substitutibilidade bruta implica unicidade do equilíbrio. E salienta-se que as propriedades de preferência revelada e substitutos brutos (forte e fraco) não dependem da diferenciabilidade.

Finalmente, deve-se observar que o estudo sobre a estabilidade global do equilíbrio competitivo está diretamente ligado ao método direto de Lyapunov que depende do uso da função Lyapunov. Diz-se que $V$ é uma função Lyapunov se atende a três condições:

$$
\begin{array}{ll}
1 \mathrm{~V}(\mathrm{P})>0, & \mathrm{P} \neq \mathrm{Pe}_{\mathrm{e}} \\
\underline{2} \mathrm{~V}\left(\mathrm{P}_{\mathrm{e}}\right)=0 & \\
\underline{3} \dot{\mathrm{V}}(\mathrm{P})<0, & \mathrm{P} \neq \mathrm{Pe}_{\mathrm{e}}
\end{array}
$$

E a partir da definição da função Lyapunov é possivel estabelecer um resultado importante: se $\dot{V}>0$ sempre que $P \neq P_{e}$, o equilibrio é dito ser globalmente estável. Este resultado é amplamente utilizado na construção dos modelos de equilibrio geral quando do tratamento na teoria da estabilidade em economias com vetor de preços globalmente estável. 


\subsection{Fundamentos da teoria da estabilidade do equilíbrio competitivo - O processo de ajustamento de preços no sistema econômico: Tâtonnement.}

Tâtonnement é um mecanismo de ajustamento explícito que comanda a maneira pela qual preços e quantidades demandadas e ofertadas mudam no tempo em resposta a um perturbação do equilíbrio. Sua caracteristica principal é que a troca toma lugar somente quando um vetor de preços de equilíbrio é anunciado e a dotação inicial dos indivíduos permanecem a mesma durante o período de ajustamento do sistema econômico. Este é o mecanismo de ajustamento de preços cuja origem remonta a Walras e é utilizado por Hicks (1939), Samuelson (1941, 1942, 1947), Lange (1944), Metzler (1945) e Arrow, et al (1956, 1958, 1959, 1960), e os economistas matemáticos japoneses Uzawa e Negishi, antes da contestação realizada no início dos anos 60 por Scarf (1960) e Gale (1960).

O estudo da teoria da estabilidade do equilíbrio competitivo baseado numa estrutura da economia Arrow \& Debreu, tem seu início com os artigos de Arrow \& Hurwicks (1958), Arrow et al (1959).

No primeiro artigo (1958) priorizam o problema da estabilidade dinâmica de um mercado perfeitamente competitivo que possui um mecanismo de ajustamento de preços proporcional ao excesso da demanda. Formalmente,

$$
\frac{d P}{d t}=K_{i} E_{i}\left(P_{i}\right)
$$

Elaboram o artigo iniciando-o com a apresentação dos conceitos dinâmicos fundamentais à compreensão do problema da estabilidade dinâmica de um mercado perfeitamente competitivo: ponto de equilibrio, equações do mecanismo de ajustamento dos preços, estabilidade local e estabilidade global.

Estabelecidos os conceitos fundamentais, Arrow \& Hurwicks descrevem os processos de ajustamento de preços que são utilizados como meio para 
estudar o problema da estabilidade no mercado competitivo múltiplo: processo de ajustamento instantâneo e processo de ajustamento defasado.

Um exemplo teórico é resolvido com o intuito de ancorar os pontos supra estabelecidos:

$$
\begin{aligned}
& \frac{d P}{d t}=k \cdot E(P) \\
& \left\{\begin{array}{l}
D_{t}=a P_{t}+b \\
S_{t}=A P_{t}+B
\end{array}\right. \\
& E(P)=D(P)-S(P) \\
& E(P)=a P+b-A P-B \\
& E(P)=(a-A) P+(b-B)
\end{aligned}
$$

$P_{e}$ é dinamicamente estável pois $P \rightarrow P_{e}$ quando $t \rightarrow \infty$ se $(a-A)<0$ com funções oferta e demanda com inclinações convencionais.

Os resultados provenientes da elaboração do modelo com os elementos traçados nos conceitos fundamentais e mecanismo de ajustamento são colocados como segue. Primeiro, eles estudam situações de mercado na qual não existe troca em equilibrio: (1) caso de indivíduos idênticos, (2) caso de uma distribuição de recurso inicial Pareto-ótimo. Segundo, elaboram o caso para duas mercadorias. Terceiro, elaboram modelo que trata com o caso onde todos os bens são substitutos brutos em todos os preços. Realizam uma incursão no caso em que os bens são considerados complementares, também.

Nas três situações consideradas são realizados aperfeiçoamentos dos estudos anteriormente estabelecidos por Walras, Hicks, Samuelson, Lange, 
Metzler. O resultado fundamental derivado de todos os casos estudados é que - sistema é estável sob o processo de ajustamento em um mercado perfeitamente competitivo.

Aplicação direta das definições do parágrafo anterior é caracterizada pelos seguintes teoremas:

Teorema 6 - Em uma economia de troca pura, se não existe troca em equilibrio, então equilíbrio é localmente estável para quaisquer velocidades de ajustamento de preços.

Um exercício numérico é estabelecido como material de apoio à compreensão do enunciado do teorema.

$$
\begin{aligned}
& \left\{\begin{array}{l}
D_{t}=100-5 P_{t} \\
S_{t}=50+5 P_{t}
\end{array}\right. \\
& E(P)=100-5 P_{t}-50-5 P_{t}
\end{aligned}
$$

cuja solução é descrita abaixo

$P=\left(P_{0}-P_{e}\right) e^{k(-10 t)}+P_{e}$

e quando $t \rightarrow \infty$ implica $P \rightarrow P_{e}$, ou seja, $P_{e}$ é dinâmicamente estável.

Este teorema é aplicado nos seguintes casos: (1) economia que possui um único consumidor; (2) economia na qual todos os consumidores possuem preferências e dotações iniciais idênticas; (3) economia na qual as dotações iniciais dos consumidores são de tal maneira que um ótimo de Pareto existe no ponto de dotação inicial. 
Teorema 7 - O sistema dinâmico é localmente estável e também tem estabilidade Hicksiana se todas as mercadorias são substitutos brutos. Formalmente,

$\frac{\partial E_{i}}{\partial P_{i}}=b_{i i}<0, \quad \forall i$

$\frac{\partial E_{i}}{\partial P_{j}}=b_{i j}>0, \quad \forall i \neq j$

Suponha uma economia cujas funções excesso da demanda são as seguintes:

$$
\left\{\begin{array}{l}
E_{2}=-4 P_{2}+3 P_{3}-6 \\
E_{3}=P_{2}-P_{3}-1
\end{array}\right.
$$

1 Primeira condição: $b_{22}<0$ e $b_{33}<0$

$$
\begin{aligned}
& \frac{\partial E_{2}}{\partial P_{2}}=-4<0 \\
& \frac{\partial E_{3}}{\partial P_{3}}=-1<0
\end{aligned}
$$

2 Segunda condição: $b_{23}>0$ e $b_{32}>0$

$$
\frac{\partial E_{2}}{\partial P_{3}}=+3>0
$$

$\frac{\partial E_{3}}{\partial P_{2}}=+1>0$

Conclui-se que o sistema é localmente estável, e cujos cálculos são descritos abaixo

$J=\left|\begin{array}{cc}-4 & +3 \\ 1 & -1\end{array}\right|=4-3 \neq 0:$ condição de existência do sistema de preços 

$E_{2}=0$
$\left\{\begin{array}{l}+4 P_{2}-3 P_{3}=+6 \\ P_{2}-P_{3}=1\end{array}\right.$
$\left\{\begin{array}{l}P_{2}=3 \\ P_{3}=2\end{array}\right.$
$E_{3}=0$

O par $(3,2)$ é o vetor de preços de equilíbrio.

Teorema 8 - Um sistema que possui um equilíbrio único e satisfaz o axioma da preferência revelada no agregado é globalmente estável.

Considere uma economia cuja função excesso da demanda é não-linear

$$
\begin{aligned}
& E=\left(\frac{5}{P}-2\right) \quad \text { velocidade de ajustamento } k=4 \\
& \frac{d p}{d t}=k \cdot\left(\frac{5}{p}-2\right) \\
& V(P)=\left(P-P_{e}\right)^{2} \quad \text { função Lyapunov } \\
& \frac{d V}{d t}=2 \cdot\left(P-P_{e}\right) \frac{d P}{d t} \\
& \frac{d P}{d t}=0 \rightarrow 4 \cdot\left(\frac{5}{P}-2\right)=0 \quad \therefore \quad \frac{20}{P_{e}}-8=0 \\
& P_{e}=2,5 \quad \text { preço de equilibrio } \\
& \frac{d V}{d t}=2 \cdot(P-2,5) \cdot 4 \cdot\left(\frac{5}{P}-2\right) \\
& \frac{d V}{d t}=8 \cdot(P-2,5] \cdot\left[\frac{5}{P}-2\right]<0 \\
& \frac{d V}{d t}=8 \cdot\left(\frac{5 P}{P}-2 P-\frac{12,5}{P}+5\right)
\end{aligned}
$$


$\frac{d V}{d t}=8 \cdot\left[5-2 P-\frac{12,5}{P}+5\right]$

$\frac{d V}{d t}=8 \cdot\left[10-2 P-\frac{12,5}{P}\right]$

$\frac{d V}{d t}=4\left[20-4 P-\frac{25}{P}\right)$

$\frac{d V}{d t}=4\left(\frac{20 P-4 P^{2}-25}{P}\right)$

$\frac{d V}{d t}=\frac{-4\left(4 P^{2}-20 P+25\right)}{P}$

$\frac{d V}{d t}=\frac{-4(2 P-5)^{2}}{P}<0, \quad \forall P>0 \quad$ eq. (22)

Conclui-se que $P_{e}=2,5$ é um preço de equilibrio dito globalmente estável

No segundo artigo Arrow et al (1959) estendem os resultados do artigo de autoria de Arrow \& Hurwicks (1958) em várias direções. Primeiro, fornecem uma prova de estabilidade global na medida que consideram todos os bens como substitutos brutos. Este resultado mostra-se válido para processos onde 0 mecanismo de ajustamento de preço é preservador de sinal continuo, porém não para mecanismo de ajustamento de preço onde exista proporcionalidade em relação a função excesso da demanda. Segundo, Tratam com sistemas no qual uma das mercadorias desempenha o papel de numerário (sistema normalizado) e com sistemas no qual todas as mercadorias são tratadas simetricamente (sistema não-normalizado). Exemplo numérico é descrito:

1 Sistema normalizado (existência de numerário)

$$
P=\left(P_{1}, P_{2}, P_{3}\right)>0 \quad\left\{\begin{array}{l}
E_{2}=-2 P_{2}+P_{3}+1 \\
E_{3}=P_{2}-P_{3}+1
\end{array}\right.
$$

vetor de preços de equilíbrio $P=(1,2,3)$ 
2 Sistema não-normalizado (não-existência de numerário)

$$
P=\left(P_{1}, P_{2}, P_{3}\right) \geq 0 \quad\left\{\begin{array}{l}
E_{1}=-P_{1}+2 P_{2}-P_{3} \\
E_{2}=P_{1}-2 P_{2}+P_{3} \\
E_{3}=-P_{1}+2 P_{2}-P_{3}
\end{array}\right.
$$

vetor de preços de equilíbrio $P=(2,3,4)$.

Arrow et al (1959) descrevem os modelos estáticos e dinâmicos que são utilizados como base para construírem os principais resultados. Definem o preço não-normalizado da k-ésima mercadoria como sendo sempre nãonegativo, ou seja, nenhum preço é utilizado como numerário. Conhecido o preço estabelecem a função excesso da demanda do i-ésimo indivíduo para a k-ésima mercadoria de modo que pudessem definir a restrição orçamentária do i-ésimo indivíduo. Assim, com o intuito de generalizarem o resultado, agregam as funções excesso da demanda individual e, deste modo, estabelecem a função excesso da demanda agregada. Impõem que a função excesso da demanda atende a propriedade de ser homogênea em relação ao preço com o propósito de evitar o problema da ilusão monetária. Realizam esta propriedade para ambos os sistemas: normalizado e não normalizado.

O núcleo do artigo estabelece os elementos fundamentais referentes aos conceitos de substitutibilidade, na forma incremental e na forma diferencial. A diferença entre ambas as formas é que a segunda associada com a lei de Walras implica na positividade do vetor preço de equilibrio. Formalmente, estabelece a condição de substitutibilidade bruta na forma incremental, a condição de substitutibilidade bruta na forma diferencial, a condição de substitutibilidade bruta equivalente à condição de substitutibilidade bruta na forma incremental, e a condição de substitutibilidade bruta modificada.

As três primeiras condições são utilizadas na derivação dos principais resultados estabelecidos na Seção 3 , enquanto que a quarta condição é utilizada na derivação do teorema 1 apresentado no artigo original. 
O resultado principal sobre a estabilidade do equilíbrio competitivo sob a condição de substitutibilidade bruta é realizado. Para tornar possível a realização do resultado principal é estabelecido um roteiro:

LEMA 1: Sob as hipóteses de homogeneidade e substitutibilidade da função excesso da demanda, o vetor de preço de equilibrio é unicamente determinado até um múltiplo escalar.

LEMA 2: Sob as hipóteses de substitutibilidade bruta, homogeneidade e lei de Walras, temos:

$\sum_{j} \bar{P}_{j}\left\{E_{j}(P)-\bar{E}_{j}\right\}>0$

para qualquer $P>0, P \neq \lambda \bar{P}$ para qualquer $\lambda>0$

LEMA 3: Sob as hipóteses de substitutibilidade bruta e homogeneidade, $\forall P>0$,

$P \neq \lambda \bar{P} \quad \forall \lambda>0$

$\mathrm{P}_{\mathrm{k}^{\prime}} / \mathrm{P}_{\mathrm{k}^{\prime}}=\max _{\mathrm{k}} \mathrm{P}_{\mathrm{k}} / \overline{\mathrm{P}}_{\mathrm{k}}$

Implica que

$E_{k^{\prime}}(P)-E_{k}<0$

$E_{k^{n}}(P)-\bar{E}_{k^{n}}>0$

E os lemas 1,2 e 3 são diretamente utilizados na demonstração do resultado principal: 
Proposição 4: Sob as hipóteses de substitutibilidade bruta, homogeneidade e lei de Walras, o processo Tâtonnement é globalmente estável.

Como um aplicativo do significado da proposição desenvolve-se por completo um exercício numérico. Imagine uma economia que possui três mercadorias, uma das quais é o numerário, que é representada pelo sistema de equações a seguir:

$$
\left\{\begin{array}{l}
E_{2}=\frac{P_{3}}{P_{2}+P_{3}} \\
E_{3}=\frac{P_{2}}{P_{2}+P_{3}}
\end{array}\right.
$$

cujo desenvolvimento é estabelecido como segue:

1 condição de substitutibilidade bruta

$$
\begin{aligned}
& \frac{\partial E_{2}}{\partial P_{3}}=\frac{P_{2}}{\left(P_{2}+P_{3}\right)^{2}}>0 \\
& \frac{\partial E_{3}}{\partial P_{2}}=\frac{P_{3}}{\left(P_{2}+P_{3}\right)^{2}}>0
\end{aligned}
$$

2 condição de homogeneidade

$$
\begin{aligned}
& E_{2}\left(\lambda P_{2}, \lambda P_{3}\right)=\frac{\lambda P_{3}}{\left(\lambda P_{2}+\lambda P_{3}\right)} \quad \therefore \quad E_{2}\left(\lambda P_{2}, \lambda P_{3}\right)=E_{2}\left(P_{2}, P_{3}\right) \\
& E_{3}\left(\lambda P_{2}, \lambda P_{3}\right)=\frac{\lambda P_{2}}{\left(\lambda P_{2}+\lambda P_{3}\right)} \quad \therefore \quad E_{3}\left(\lambda P_{2}, \lambda P_{3}\right)=E_{3}\left(P_{2}, P_{3}\right)
\end{aligned}
$$

3 lei de Walras

$$
\Sigma P_{i} . E_{i}=0 \therefore E_{2} P_{2}+E_{3} P_{3}=0 \therefore \frac{2 P_{2} P_{3}}{P_{2}+P_{3}}=0
$$


Enfim, Arrow et al (1959) provam a estabilidade global do mercado competitivo para um caso especial, ou seja, para o caso no qual os bens são todos considerados substitutos. Uma caraterística importante deste resultado é a ampla generalidade do ajustamento de preços; a taxa de mudança de preço não é necessariamente proporcional ao excesso da demanda, contudo, é assumido ser unicamente uma função preservadora de sinal do excesso da demanda.

\subsection{Scarf e o ataque frontal ao Tâtonnement}

A publicação dos artigos de Scarf (1960) e Gale (1960) expõem alguns resultados que contestam aqueles estabelecidos por Arrow e outros: o sistema econômico representado pelo sistema dinâmico gerado por sistemas de equações diferenciais ou a diferenças são estáveis. Tanto Scarf (1960) quanto Gale (1960) apresentam exemplos numéricos convincentes em que o sistema econômico pode apresentar instabilidade quer sob a ótica local como global.

A questão central: é o processo Tâtonnement geralmente estável sem quaisquer restrições tal como substitutibilidade bruta? Segundo Scarf (1960) a resposta é negativa. Imagine uma economia constituída por três indivíduos e três mercadorias e, considere as funções utilidades de cada indivíduo como representada formalmente:

$U_{1}\left(q_{11}, q_{12}, q_{13}\right)=\min \left(q_{11}, q_{12}\right)$

$U_{2}\left(q_{21}, q_{22}, q_{23}\right)=\min \left(q_{22}, q_{23}\right)$

$U_{3}\left(q_{31}, q_{32}, q_{33}\right)=\min \left(q_{33}, q_{31}\right)$

com a correspondente dotação de mercadorias

$$
q_{i j}=\left\{\begin{array}{l}
1 \text { para } i=j \\
0 \text { para } i \neq j
\end{array}\right.
$$


Regra de comportamento: cada indivíduo deseja duas mercadorias que são perfeitamente complementares ou seja na razão de um a um. Graficamente, para quaisquer duas mercadorias
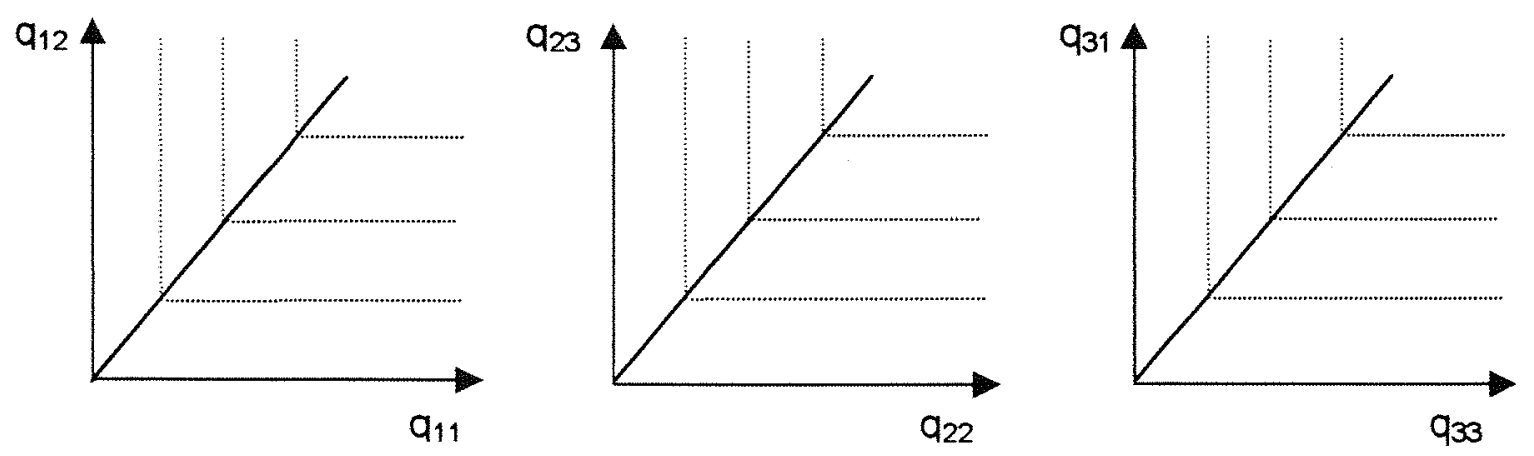

Figura 24 - Curvas de indiferenças

Tarefa principal: estabelecer as restrições orçamentarias dos três indivíduos e as funções excesso da demanda para cada mercadoria. Sejam $\mathrm{P}_{1}$, $P_{2}, P_{3}$ os preços das mercadorias 1, 2, 3 e sejam $E_{1}, E_{2}, E_{3}$ as funções excesso da demanda para cada mercadoria 1, 2 e 3 . Formalmente, $P_{1} q_{11}+P_{2} q_{12}=\bar{P}_{1} q_{11}$ : restrição orçamentária do indivíduo 1 $P_{2} q_{22}+P_{3} q_{23}=\bar{P}_{2} q_{22}$ : restrição orçamentária do indivíduo 2 $P_{3} q_{33}+P_{1} q_{33}=\bar{P}_{3} q_{33}$ : restrição orçamentária do indivíduo 3

$$
\begin{aligned}
& E_{1}=q_{1}-\bar{q}_{1} \therefore E_{1}=\left(q_{11}+q_{21}+q_{31}\right)-\left(\bar{q}_{11}+\bar{q}_{21}+\bar{q}_{31}\right) \\
& q_{11}=q_{12} \text { e } \bar{q}_{11}=1
\end{aligned}
$$$$
1 \quad P_{1} q_{11}+P_{2} q_{11}=P_{1} \cdot \bar{q}_{11}
$$$$
P_{1} \cdot\left(q_{11}-\bar{q}_{11}\right)+P_{2} q_{12}=0
$$$$
P_{1} \cdot\left(q_{11}-1\right)+P_{2} q_{11}=0 \therefore P_{1} q_{11}+P_{2} q_{11}=P_{1}
$$$$
q_{11} .\left(P_{1}+P_{2}\right)=p_{1} \therefore q_{11}=\frac{P_{1}}{P_{1}+P_{2}}
$$$$
q_{11}-\bar{q}_{11}=\frac{P_{1}}{P_{1}+P_{2}}-1 \therefore q_{11}-\bar{q}_{11}=\frac{P_{1}-P_{1}-P_{2}}{P_{1}+P_{2}}
$$$$
q_{11}-\bar{q}_{11}=-\frac{P_{2}}{P_{1}+P_{2}}
$$ 
2 $P_{1} q_{31}+P_{3} q_{33}=P_{3} \bar{q}_{33}$

$$
P_{1} q_{31}+P_{3} q_{33}=P_{3} \therefore P_{1} q_{31}+P_{3} q_{31}=P_{3}
$$

$$
q_{31}\left(P_{1}+P_{3}\right)=P_{3} \therefore q_{31}=\frac{P_{3}}{P_{1}+P_{3}}
$$

$\underline{3} \quad E_{1}=\left(q_{11}-\bar{q}_{11}\right)+q_{31}$

$$
E_{1}=-\frac{P_{2}}{P_{1}+P_{2}}+\frac{P_{3}}{P_{1}+P_{3}}
$$

Simultaneamente,

$$
\begin{aligned}
& E_{2}=-\frac{P_{3}}{P_{2}+P_{3}}+\frac{P_{1}}{P_{1}+P_{2}} \\
& E_{3}=-\frac{P_{1}}{P_{3}+P_{1}}+\frac{P_{2}}{P_{2}+P_{3}}
\end{aligned}
$$

Observa-se em seguida que a condição de substitutibilidade

$$
\frac{\partial E_{i}}{\partial P_{j}}>0
$$

é violada. E para isso é aplicado a derivada às eq. (26) à eq. (28) e tem-se:

$$
\begin{aligned}
& \frac{\partial E_{1}}{\partial P_{2}}=-\frac{\left(P_{1}+P_{2}\right) \cdot 1-P_{2}(1)}{\left(P_{1}+P_{2}\right)^{2}}=-\frac{P_{1}+P_{2}-P_{2}}{\left(P_{1}+P_{2}\right)^{2}}=-\frac{P_{1}}{\left(P_{1}+P_{2}\right)^{2}}<0 \\
& \frac{\partial E_{2}}{\partial P_{3}}=-\frac{\left(P_{2}+P_{3}\right) \cdot 1-P_{3}(1)}{\left(P_{2}+P_{3}\right)^{2}}=-\frac{P_{2}+P_{3}-P_{3}}{\left(P_{2}+P_{3}\right)^{2}}=-\frac{P_{2}}{\left(P_{2}+P_{3}\right)^{2}}<0 \\
& \frac{\partial E_{3}}{\partial P_{1}}=-\frac{\left(P_{3}+P_{1}\right) \cdot 1-P_{1}(1)}{\left(P_{3}+P_{1}\right)^{2}}=-\frac{P_{3}+P_{1}-P_{1}}{\left(P_{3}+P_{1}\right)^{2}}=-\frac{P_{3}}{\left(P_{3}+P_{1}\right)^{2}}<0
\end{aligned}
$$

que conduz a o cálculo do vetor de preço de equilíbrio

$$
E_{1}=0 \Leftrightarrow \frac{P_{2}}{P_{1}+P_{2}}=\frac{P_{3}}{P_{3}+P_{1}} \Leftrightarrow P_{2}=P_{3}, \quad P_{1}>0
$$


$E_{2}=0 \Leftrightarrow \frac{P_{3}}{P_{2}+P_{3}}=\frac{P_{1}}{P_{1}+P_{2}} \Longleftrightarrow P_{3}=P_{1}, \quad P_{2}>0$
$E_{3}=0 \Longleftrightarrow \frac{P_{1}}{P_{3}+P_{1}}=\frac{P_{2}}{P_{2}+P_{3}} \Longleftrightarrow P_{2}=P_{1}, \quad P_{3}>0$

$V\left(P_{1}, P_{2}, P_{3}\right)$ onde $P_{1}=P_{2}=P_{3}$

E conclui-se que o preço fica sobre a porção não-negativa através de $P(0)$.

A avaliação do comportamento do processo de ajustamento de preço é descrito a partir da eq. (30),

$$
\begin{aligned}
& \frac{d P(t)}{d t}=E[P(t)] \quad \text { eq. }(30) \\
& \frac{d\left[P_{1}{ }^{2}+P_{2}{ }^{2}+P_{3}{ }^{2}\right]}{d t}=2 P_{1} \frac{d P_{1}}{d t}+2 P_{2} \frac{d P_{2}}{d t}+2 P_{3} \frac{d P_{3}}{d t}=0
\end{aligned}
$$

Pela Lei de Walras

$$
\begin{aligned}
& \frac{d\left(P_{1} P_{2} P_{3}\right)}{d t}=P_{2} P_{3} \frac{d P_{1}}{d t}+P_{1} P_{3} \frac{d P_{2}}{d t}+P_{1} P_{2} \frac{d P_{3}}{d t} \\
& \frac{d\left(P_{1} P_{2} P_{3}\right)}{d t}=P_{2} P_{3} E_{1}+P_{1} P_{3} E_{2}+P_{1} P_{2} E_{3} \\
& \frac{d\left(P_{1} P_{2} P_{3}\right)}{d t}=0
\end{aligned}
$$


Geometricamente o preço fica sobre a superfície da hipérbole retangular através de $P(0)$. A interseção das superfícies é uma círculo. Preços giram em torno do circulo indefinidamente e nunca alcançam o ponto de equilíbrio que é o centro do circulo.

Resultante das eq. (23) à eq. (30) tem-se: (1) não existe efeitosubstituição, (2) a curva de indiferença não é estritamente côncava á origem, (3) a curva de indiferença tem uma quebra e portanto não é diferenciáveis, (4) existe somente efeito-renda.

\subsection{A teoria da estabilidade no sistema econômico após o ataque frontal de Scarf}

Nesta Seção a abordagem consiste dos pontos a seguir. Primeiro, apresentação e discussão detalhada dos principais mecanismos de ajustamentos de preços Non-Tâtonnement. (1) Uzawa \& Hahn (1962); (2) Hahn \& Negish (1962); (3) Green (1974). Segundo, incursão na aplicação da análise global no campo da teoria do equilibrio geral, incluindo um exercício numérico.

\subsubsection{Fundamentos do processo de ajustamento de preços no sistema econômico: Non-Tâtonnement}

Face aos resultados encontrados, Scarf (1960) e Gale (1960) alguns economistas matemáticos tratam de desenvolver um mecanismo de ajustamento explicito no qual a troca ocorre em cada valor anunciado do vetor de preço e que a dotação dos indivíduos participantes do mercado mudam continuadamente ao longo do processo de ajustamento do sistema, que denominaram Non-Tâtonnement. Dois processos de ajustamentos dos sistemas de preços na versão Non-Tâtonnement são estabelecidos e se tornam clássicos: Processo de Uzawa \& Hahn (1962), Processo de Hahn \& Negishi 
(1962) e Green (1974) .

Primeiro, o processo de ajustamento do preço Uzawa \& Hahn (1962) fundamenta-se na hipótese que cada indivíduo participa na troca á medida que a mesma incrementa a satisfação do individuo. Portanto, é admitido que a utilidade do estoque de mercadorias mantido pelos consumidores individualmente aumenta ao longo do período de tempo como um resultado das transações. Em vista da hipótese estabelecido pelo processo Uzawa \& Hahn (1962), é possível traçar algum comentário pertinente ao modelo. Primeiro, a hipótese exige grande quantidade de informação do sistema econômico, facilitando a construção de exemplos onde somente troca pareto-ótimo exige a participação de muitos agentes econômicos. Segundo, a hipótese de que troca raramente ocorrem quando participantes individualmente aumentam utilidade é somente um atrativo quando agentes econômicos são considerados ingenuamente esperar preços constantes e transações serem finalizadas.

Segundo, o processo de ajustamento de preço de Hahn \& Negishi (1962) está baseado na hipótese que se existe um excesso de oferta de uma determinada mercadoria, então todos os compradores potenciais desta mercadoria podem realizar seus desejos. Ademais, se existe um excesso da demanda para uma determinada mercadoria, então todos os vendedores potenciais podem realizar seus desejos. Contudo, se os mercados são suficientemente bem organizados não existirá excesso de qualquer ordem. Um resultado importante é derivado da hipótese do modelo:

Teorema 9 - No sistema econômico a troca ocorre somente quando o sinal do excesso da demanda para qualquer mercadoria individual é 0 mesmo como no sinal do excesso da demanda para aquela mercadoria no agregado.

Um exercício numérico facilita o entendimento do enunciado do teorema. Seja uma economia que possui duas mercadorias que é representada pelas equações, 


$$
\left\{\begin{array}{l}
E_{1}=-3 P_{1}+P_{2} \\
E_{2}=P_{1}-2 P_{2}
\end{array}\right.
$$

e calcula-se as derivadas parciais primeiras das funções excesso da demanda individuais,

$$
\frac{\partial \mathrm{E}_{1}}{\partial \mathrm{P}_{1}}=-3<0 \quad \text { e } \quad \frac{\partial \mathrm{E}_{2}}{\partial \mathrm{P}_{2}}=-2<0
$$

E, em seguida, agrega-se as funções excesso da demanda individual e obtémse

$$
\begin{aligned}
& E\left(P_{1}, P_{2}\right)=\sum_{i=1}^{2} E_{i} \therefore E\left(P_{1}, P_{2}\right)=\left(-3 P_{1}+P_{2}\right)+\left(P_{1}-2 P_{2}\right) \\
& E\left(P_{1}, P_{2}\right)=-2 P_{1}-P_{2}
\end{aligned}
$$

Derivam-se a função excesso da demanda agregada e obtêm-se

$$
\frac{\partial \mathrm{E}}{\partial \mathrm{P}_{1}}=-2<0 \quad \frac{\partial \mathrm{E}}{\partial \mathrm{P}_{2}}=-1<0
$$

que atende ao resultado esperado.

Terceiro, Green descreve o processo pelo qual a solução final é alcançada através de uma sequência de lances. Cada lance é comparado a um contra-lance que representa uma alocação viável que poderia ser utilizada para bloqueá-lo. Na verdade, nenhum bloqueio adicional é possível para que o lance final seja realizado pelos indivíduos que constituem o sistema. Nenhuma atividade de fato acontece enquanto o processo de recontratação ainda está por estabelecer-se. Com efeito, o conjunto de todas as combinações de utilidade viabilizada pelos membros da coalizão são fixados ao longo do curso da barganha. Este fato é derivado do processo Walrasiano Tâtonnement no qual os excessos da demanda são registrados pelos usos de tickets, e preços ajustam-se à medida que o excesso da demanda converge para zero - somente então a troca ocorre. Conclui-se que os resultados da teoria da estabilidade 
tradicional referente ao processo Tâtonnement estabelece que quando $\mathrm{t} \rightarrow \infty$ preços tornam-se arbitrariamente próximos dos preços de equilíbrio. Significa dizer que sob a ótica Tâtonnement, os indivíduos realizarão de fato qualquer troca desde que eles devam sempre esperar que os preços convirjam para o vetor de preços de equilíbrio. Assim sendo, o resultado obtido por Green é de natureza diferente daquele estabelecido pelo Tâtonnement. Ou seja, a probabilidade que o lance atual não esteja no core aproxima-se de zero quando t cresce. Portanto, a realização da troca de mercadorias por mercadorias, barganha, tomará lugar num período finito de tempo com certeza (probabilidade 1) o que implica o processo Tâtonnement como hipótese bem mais simples a tolerar.

\subsubsection{Análise global: Stephen Smale}

Professor Stephen Smale, matemático profissional, Medalha Field, o prêmio equivalente ao Prêmio Nobel dá uma guinada importante em sua atividade acadêmica. Passa a atuar na aplicação da matemática pura ao desenvolvimento da teoria do equilíbrio geral. Com efeito, aponta as vantagens do enfoque da análise global aplicado á teoria do equilíbrio clássico.

Primeira, as provas de existências são consideradas mais simples. $O$ teorema do ponto fixo de Kakutani, não é usado, o principal instrumento analítico é o cálculo das funções reais de várias variáveis reais.

Segunda, a estática comparativa é integrada ao modelo em uma maneira simples, as primeiras derivadas desempenham um papel fundamental.

Terceira, o enfoque do cálculo está mais próximo das tradições da teoria do equilíbrio competitivo clássico.

Quarta, oportunamente, as provas de equilibrio são construtivas. Tais provas podem ser elaboradas por um algoritmo rápido, que é o método de Newton modificado para estabelecer convergência global. Ainda as provas de existências são surpreendentemente poderosas para produzirem a 
generalidade da teoria axiomática Arrow \& Debreu.

Estabelece propriedades sobre a função excesso da demanda que são importantes na elaboração da estrutura do sistema econômico.

1 Lei de Walras: $\sum P_{i}, E_{i}=0$

2 Homogeneidade: $E(\lambda P)=E(P)$,

$\forall \lambda>0$

3 Condições de fronteira: $E_{i}(P) \geq 0$

se $P_{i}=0$

que geram resultados importantes:

1. Teorema 10 - Suponha que uma função excesso da demanda. E satisfaz a (Existência) Lei de Walras, homogeneidade e a condição de fronteira. Então existe um preço de equilibrio.

2. Teorema 11 - Se uma função $F: U \rightarrow R^{n},\left(U C R^{K}\right)$ é de classe suficientemente (Sard) diferenciável $\left(C^{r}, R^{r}>K-n, 0\right)$ então o conjunto de valores regulares de $\mathrm{F}$ tem medida completa.

3. Teorema 12 - Se $y \in R^{m}$ é um valor regular de uma função contínua (Função Inversa) $F: U \rightarrow R^{n}, U C R^{K}$, então ou $F^{-1}(y)=0$, ou é uma subvariedade de dimensão $(K-n)$.

Conhecida a estrutura matemática do sistema economico abstrato é possivel então aplicar o instrumental da análise global a uma economia de troca pura. Imagine uma economia de troca na qual existe a função utilidade $U: P \rightarrow R$ e o espaço de mercadorias $P=\left\{x \in R^{\prime} ; x>0\right\}$. Tal economia é construída sob as hipóteses clássicas: 
1 Monotonicidade: $\nabla U(x)$ tem coordenadas positivas;

2 Convexidade: $D^{2} U(x)$ é negativa definida sobre o espaço tangente em $x$ da superfície de indiferença correspondente;

3 Condição de fronteira: as superfície de indiferença são conjuntos fechados em $R^{\prime}$ (não apenas $P$ ).

De posse das hipóteses clássicas é possivel gerar o resultado principal: Teorema 13 - A função da demanda $F$ satisfaz

$1 \nabla U(F(P, W))=\lambda P$, para algum $\lambda>0$

$2 P . F(P, W)=W$

3 $F(\lambda P, W)=F(P, W), \quad \forall \lambda>0$

$4 F$ é continua

Define-se o estado de uma economia como a m-upla $\left(x_{1}, x_{2},-\cdots, x_{m}\right)$ onde $x_{i} \in P$ e $P \subset R$, é possivel enunciar duas ordens de condições de funcionamento do sistema econômico. Quais sejam,

1 Condição de viabilidade: $\sum x_{i}=\sum e_{i} \rightarrow$ dotação inicial

2 Condição de satisfação de um estado: $\forall i, x_{i}$ maximiza $U_{i}$ no conjunto orçamentário $B=\left\{y \in P: P . y=P . e_{i}\right\}$

Para a economia de troca sob as condições supra estabelecidas gerase um resultado importante:

Teorema 14 - Existe um preço de equilíbrio de toda economia de troca pura.

Constrói-se um exemplo numérico. Imagine uma economia representada pelas funções excesso da demanda:

$$
\left\{\begin{array}{l}
E_{1}=P_{1}+2 P_{2}-6 \\
E_{2}=P_{1}-P_{2}-2
\end{array}\right.
$$

cujos cálculos são estabelecidos como segue: 


$$
|E(P)|=\left|\begin{array}{ll}
\frac{\partial E_{1}}{\partial P_{1}} & \frac{\partial E_{1}}{\partial P_{2}} \\
\frac{\partial E_{2}}{\partial P_{1}} & \frac{\partial E_{2}}{\partial P_{2}}
\end{array}\right| \quad \therefore \quad|E(P)|=\left|\begin{array}{cc}
1 & 2 \\
1 & -1
\end{array}\right| \quad \therefore \quad|E(P)|=-3 \neq 0
$$

onde 0 jacobiano da transformação diferente de zero corresponde à condição de existência do vetor de preços de equilibrio em uma economia de troca pura.

E a prova de existência utilizando o método de análise global estende a demonstração estabelecida pelo teorema Arrow \& Debreu, ou seja, generaliza o resultado estabelecido na estrutura da economia Arrow \& Debreu.

Em relação ao problema da estabilidade e a análise global Professor Stephen Smale traça importantes contribuiçōes nos anos 70 , sobre a teoria da estabilidade sob o equilibrio competitivo. Os trabalhos mais importantes de Smale sobre processos dinâmicos consistem de dois artigos escritos em 1976.

O primeiro artigo contém um modelo de Non-Tâtonnement que segue a linha de pesquisa do modelo Hahn-Negishi (1962). Contudo, existem duas diferenças entre eles: (1) o modelo discute o processo de ajustamento de natureza estocástica e portanto não é descrito por uma equação diferencial ordinária; (2) a hipótese de otimização de longo prazo é evitada. Sugere hipóteses: (a) troca ocorre aos preços correntes, (b) toda troca aumenta a satisfação dos indivíduos envolvidos, (c) algum troca ocorrerá sempre, desde que consistente com todos os indivíduos envolvidos. Resultado: em um mercado de troca pura um processo de ajustamento específico converge a um vetor de preços de equilíbrio.

O segundo artigo contém um modelo Tâtonnement, que cobre uma nova linha de pesquisa no conhecimento e está ligado aos problemas de calcular o equilíbrio e à procura por um processo de ajustamento com melhores propriedades de convergência do que o Tâtonnement clássico. Resultado: 
Teorema 15 - Exceto para um conjunto de pontos de fronteira com medidas de Lebesgue zero, toda trajetória partindo da fronteira, ou mesmo de um ponto próximo da fronteira, converge em direção ao conjunto de equilibrio.

Em verdade, o desenvolvimento dos modelos de equilíbrio geral na visão da análise global é a virada de mesa na metodologia sobre a pesquisa matemática aplicada ao campo da economia pura nos anos 70 e 80 e extensivo aos anos 90 . 


\section{CONSIDERAÇÕES FINAIS}

Quando Walras publicou Elements of Pure Economics não podia imaginar a repercussão que seu trabalho acarretaria mesmo após 84 anos, 1874 à 1958. Sua intenção foi elaborar a estrutura de um modelo de economia pura que apresentasse a inter-relação entre os mercados. Contudo, foi mais além, pois descreveu uma metodologia que possibilitasse estudar as interrelações dos mercados sob a ótica qualitativa. Com efeito, acreditava Walras, que se ele apresentasse as condições gerais referente à inter-relação dos mercados, ou seja existência de solução do sistema de equações que representava o sistema econômico não haveria necessidade de calcular sua solução explícita, e assim o realizou. Eis as condições: (1) condição subjetiva, que consiste na busca de uma posição de máximo por parte de cada um dos agentes econômicos isolados, (2) condição objetiva, que consiste no equilibrio entre oferta e demanda para cada mercado que garante a posição de máximo atingida por todo agente e que é compatível com a alcança da por qualquer outro.

Traçada a estratégia de apresentar a existência de solução trata Walras em discutir se a solução do equilibrio é estável. Contudo, neste ponto (solução de equilíbrio estável) Walras não obtém o sucesso esperado que era estabelecer, uma vez mais, condições gerais para o problema da estabilidade do equilibrio competitivo. Porém este fracasso momentâneo não representa desânimo a Walras pois o mesmo provando seu caráter de homem criativo e inovador define um novo elemento para servir como base para o estudo da estabilidade do equilíbrio competitivo, denominado excesso da demanda que 
corresponde a diferença entre demanda e oferta, todas as três, função do preço. De posse do novo conceito estabelece a condição Walrasiana de equilíbrio competitivo em mercado único: um aumento de preço revela que o excesso da demanda diminui.

De certo modo é de estranhar que Walras tendo as qualidades de um cientista criativo e que tivera formação acadêmica quantitativa apresentasse dificuldades em gerar resultados mais positivos em termos analíticos no escopo da teoria do equilíbrio competitivo. Justificativas transparecem.

Primeira, diretamente ligada às suas limitações no domínio do conhecimento qualitativo das matemáticas avançadas existentes no seu periodo de atividade intelectual produtivo (1870 - 1900). Veja que o estudo da teoria qualitativa das equações diferenciais ordinárias e parciais já demonstrava seu estudo em ritmo acelerado pois tais assuntos estavam ligados diretamente ao desenvolvimento da teoria matemática propriamente dita e aos desenvolvimentos da física teórica, também.

Segunda, destaca-se que nenhum grupo de matemáticos àquela época demonstra interesse direto em realizar estudos sobre o tema elaborado por Walras, apesar de sua intensa correspondência com um dos eminentes matemáticos do último quartel do século XIX: Henri Poincaré.

Terceira, o economista de formação matemática que poderia ter ajudado Walras, teria sido Marshall, porém não o fez pois apesar de trabalhar também no campo da economia pura, tinha interesses e conteúdo temático diferentes, pois Marshall buscava influenciar um maior grupo de leitores, afastando-se assim da metodologia do equilíbrio geral, tomando como destaque a metodologia do equilíbrio parcial.

O trabalho de Marshall está diretamente ligado à ortodoxia clássica originada nos trabalhos de Adam Smith, David Ricardo, Jean Baptista Say, John Stuart Mill, o que contrastando assim com Walras, que está diretamente ligado aos economistas fundadores, como ele, da escola marginalista. E, é por causa da grande influência que Marshall exercia no âmbito da literatura 
econômica de lingua inglesa que o trabalho de Walras ficou realmente obscurecido e sem qualquer retoque ou mesmo leitura potencial, apesar de Edgeworth (1881), Pareto (1910), Cassel (1918), Bowley (1924) e Schlesinger (1932) terem traçado algum modelo de equilibrio geral no final do século XIX até aos meados dos anos 30, quando John Richard Hicks, matemático e economista inglês de primeira envergadura promove o ressuscitamento da obra de Walras ao publicar em artigo as idéias principais sobre a inter-relação dos mercados sob a ótica Walrasiana (1934).

É baseado no artigo publicado em 1934 associado à sua formação fortemente quantitativa, que Hicks publica Value and Capital (1939) no qual traça e desenvolve novas idéias sobre a teoria da estabilidade do equilíbrio competitivo. Nos três primeiros capítulos desta obra magistral, Hicks elabora sob forma geométrica o conteúdo analítico da teoria do comportamento da demanda e da oferta do consumidor que serviram como lastro para o conceito de excesso da demanda.

Linhas de pesquisas em teoria econômica proliferam nos anos 70 e 80 como resultado dos fundamentos estabelecidos no livro clássico de Hicks, Value and Capital (1939): (1) equilibrio temporário e produção devido a Grandmont, 1977; (2) expectativa em equilíbrio temporário devido a Green, 1973, e a Fuchs \& Laroque, 1976; (3) moeda em equilibrio temporário devido a Grandmont \& Yunes, 1972 e 1973; (4) equilíbrio dinâmico, ou no tempo devido a Grandmont, 1983 e (5) propriedades da estabilidade em modelos de equilíbrio temporário devido a Fuchs \& Laroque, 1976 e Grandmont, 1977; generalização do sistema de substituto bruto devido a Morishima, 1970.

$\mathrm{Na}$ década de 40, Samuelson (1941, 1942, 1947), Lange (1944), Metzler (1945) elaboram trabalhos que apresentam uma unidade metodológica: uso de equações diferenciais e a diferenças que geram sistemas dinâmicos que melhor representam a economia abstrata. Os modelos constituídos geram soluções de natureza quantitativa como qualitativa de modo a ocasionar a melhor compreensão do funcionamento do sistema econômico abstrato. 
Porém, dois destacados cientistas, Tjalling Charles Koopmans e Maurice Allais, nos anos quarenta criam modelos abstratos em economia pura de qualidade diferente daqueles supra citados.

Professor Tjalling Charles Koopmans introduz o conceito de atividade linear como átomo da tecnologia, ou seja, o elemento fundamental na elaboração de modelos econômicos de produção e alocação. Com efeito, resultados dos modelos construídos a partir de atividade elementar são mais generalizáveis em comparação aos elaborados a partir da teoria econômica tradicional, principalmente pelas decisões sobre a produção conjunta e os subprodutos.

$\mathrm{Na}$ construção dos modelos de análise econômica, Koopmans utiliza intensivamente as ferramentas de programação linear e análise convexa, mudando a ênfase que vinha sendo dada para a construção dos modelos econômicos apoiado no cálculo diferencial e integral. Com efeito, Koopmans identifica problemas econômicos dentro de quatro linhas de pesquisa, por volta do final dos anos 40: (1) programação linear e análise de atividade; (2) economia do bem-estar; (3) relações interindustriais e (4) problemas de alocações.

Estas linhas de pesquisas identificadas por Koopmans conduzem as pesquisas dos principais cérebros na década seguinte, anos 50 , a produzirem trabalhos na teoria do equilibrio geral tais como Kenneth Arrow, Gerard Debreu, Leonid Hurwics, David Gale, Uzawa como visto ao longo dos Capítulos 2, 3, 4. Tal fato revela o prestígio e a sensibilidade do Professor Koopmans na condução e solidez de suas idéias no campo da construção dos modelos econômicos abstratos e práticos. O reconhecimento final às suas contribuições garantiram-Ihe o Prêmio Nobel em Economia conferido em 1975 pela Real Academia de Ciências.

O Professor Maurice Allais, ainda nos anos 40 introduz uma análise rigorosa do modelo do equilíbrio geral de uma economia competitiva e nãomonetária em seu livro clássico denominado Traité d'Economie Pure (1943). 
Com efeito, demonstra de forma independente o primeiro e o segundo teoremas da Economia do Bem-Estar. Utiliza técnicas do calculo diferencial, ou seja, caracterização de máximo restrito via multiplicadores de Lagrange o que é considerado uma inovação metodológica importante que fora introduzida à mesma época que os dois artigos de Samuelson $(1941,1942)$ e seu livro clássico Foundations of Economic Analysis (1947).

Apesar de não oferecer qualquer análise formal da existência do equilíbrio competitivo, Professor Maurice Allais introduz uma análise da estabilidade do equilíbrio competitivo na versão original de Walras na medida que assume que os ajustamentos de preços ocorrem sucessivamente num mercado depois do outro, utilizando uma idéia equivalente à aquela da condição de substitutibilidade bruta e uso do método de estabilidade de Lyapunov e que foi utilizado por Arrow et al em artigos publicados nos anos de 1958 e 1959. Com efeito o pioneirismo de sua atuação é destacado em Negishi (1962, p.656). E como reconhecimento ao seu esforço para a construção do edifício da economia pura pelo conjunto de sua obra, Allais é agraciado com o Prêmio Nobel de 1988 pela Academia Real de Ciências da Suécia.

Nos anos 50, na esteira da linha de ação teórica sugerida por Koopmans e Allais, o Professor Kenneth Arrow, na área especifica do equilibrio geral realiza provas rigorosas de existência. Percebe, de imediato, que com o uso das técnicas tradicionais de cálculo diferencial não arrancaria em direção a provas rigorosas sobre a existência do equilibrio em uma economia competitiva. Busca novos rumos utilizando a Análise Convexa e o Teorema da Separação para efetuar as provas rigorosas que buscava sobre a existência do equilíbrio numa economia competitiva, vindo a publicá-las em 1954, em parceria com Gerard Debreu.

Arrow \& Debreu com o propósito de construir toda a estrutura da economia consideram que cada mercadoria é descritas por suas características físicas, por sua localização, sua data de disponibilidade e pelo estado do ambiente em que está disponível. Supõe-se que existe um conjunto completo 
de mercados futuros, um para cada mercadoria, que as transações são dispendiosas e que os ajustamentos são realizados somente por movimentos de preços (porém ignoram mercados de açōes e a existência de moeda). Com efeito, todos os contratos são efetuados no ínício do período de cada mercado em particular, e não existem incentivos para reabrir os mercados. Denominam esta estrutura na literatura neoclássica, de economia Arrow \& Debreu.

Introduz o conceito de incerteza nos modelos econômicos de equilíbrio geral através de dois livros importantes: Aspects of the Theory of RiskBearing (1965) e Essays in the Theory of Risk-Bearing (1970). Neste livros ele argumenta que, enfrentando um futuro incerto, as firmas e os indivíduos gostariam de garantir que as suas ofertas e demandas fossem competitivas. Assim, seria ótimo para os agentes econômicos envolvidos que se pudessem tomar decisões simultaneamente, antes de se tornar previsivel a situação vigente no futuro. São exatamente estas decisões antecipadas que possibilitam retornos de seguro via redução do risco total, não obstante ocorre que o estabelecimento desses contratos antecipados exige que as parte envolvidas possuem o mesmo grau de informações sobre os eventos futuros. Como, no entanto, nem mesmo as informações sobre eventos já ocorridos distribuem-se uniformemente pela população, e como a própria existência do seguro modifica o comportamento das pessoas numa forma desconhecidas pelos seguradores, resulta que a alocação do risco - $e$, consequentemente, de recursos - realmente não se efetua no ponto ótimo. Portanto, a dificuldade principal para a obtenção de uma boa alocação do risco reside na má distribuição de informação (assimetria da informação).

No terreno da teoria da estabilidade do equilíbrio competitivo, Arrow et al, constróem a primeira versão rigorosa de modelagem expositiva sobre 0 mecanismo de ajustamento de preço - Tâtonnement - cujo comportamento da solução esta baseada no conceito de substitutibilidade bruta $(1958,1959)$. Com referência às demonstrações das proposições da teoria da estabilidade moderna na estrutura Arrow \& Debreu cumpre destacar três pontos. Primeiro, é 
uma prova de quasi-estabilidade, ou seja, o sistema pode ter mais do que um ponto de repouso ou estacionário e, aí aplica-se, o segundo método de Lyapunov. Segundo, é um argumento de compacidade, que frequentemente, porém nem sempre, conduz a um argumento que as variáveis permaneçam limitadas. Terceiro, é ou uma prova de unicidade local de pontos estacionários ou uma prova que todos os pontos limites, partindo das mesmas condições iniciais, são os mesmos.

Nas palavras do Professor Paul Anthony Samuelson, a fama de Kenneth Arrow de "economista para economista" foi estabelecida com a publicação em 1951, da sua tese de doutorado no livro clássico Social Choice and Individual Values. Suas contribuições aos estudos do equilíbrio, crescimento, incerteza e decisões, Ihe valeram o Prêmio Nobel em 1972. São de alto rigor teórico, argumentado e escrito em linguagem matemática, tendo, contudo, implicações fundamentais na condução de políticas em setores variados, tais como seguro de saúde, investimentos públicos e controles de grandes organizações.

É conhecido que Scarf (1960) impõe uma difícil e amarga derrota momentânea ao mecanismo de ajustamento de preços - Tâtonnement - quando apresenta situações em que as hipóteses sob a qual o modelo ortodoxo se assenta, substitutos brutos ou axioma fraco da preferência revelada ou diagonais dominantes falham à medida que o sistema econômico abstrato não converge para o vetor de preços de equilíbrio. Como uma maneira de contornar esta situação foram elaborados inúmeros trabalhos que contribuiram de forma decisiva para recuperar o prestígio do processo de ajustamento ortodoxo, porém, não mais utilizando-se de hipóteses generalistas, e sim, estudos de casos. Destacam-se: Uzawa (1960, 1961, 1962); Arrow et al (1958, 1959, 1960, 1961, 1962, 1971); Quirk (1970, 1973); Hotaka (1971); Gordon (1974); Smale (1976); Tarr (1978); Kamyia (1990) e Mukherji (1973, 1995).

$\mathrm{Na}$ teoria econômica tradicional a estrutura de mercado pode ser classificada em dois segmentos: mercados em regimes de concorrência perfeita 
e mercados em regime de concorrência imperfeita.

No mercado em regime de concorrência perfeita é assumido alguns postulados fundamentais que derivam resultados importantes para o conteúdo da análise e previsão dos fenômenos que ocorrem no sistema econômico e que foram amplamente utilizados pelos teóricos da análise do equilíbrio geral desde Walras (1874). Eis os postulados principais: (1) os consumidores e produtores são tão pequeno em relação ao tamanho do mercado que não influenciam o preço de mercado; (2) o produto é considerado homogêneo, ou seja, os produtores só produzem uma única mercadoria; (3) todas as previsões com respeito aos fenômenos de mercado se realizam, ou seja, ausência de incerteza; (4) a tecnologia, como as ações de mercado dos concorrentes são conhecidas pelos demais competidores, ou seja, o mercado é viscoso.

Como conseqüência dos postulados fundamentais resulta: (1) 0 consumidor individual procura maximizar suas utilidades, ou seja, busca 0 máximo de satisfação ao consumir determinadas quantidades de mercadorias; (2) o produtor individual procura maximizar lucro como recompensa pelo esforço produtivo, ou seja, alocar recursos, pagamento por esses recursos, e vender produtos, recebendo o preço de mercado por esse produto, com a diferença entre a receita de venda e o custo dos recursos, sendo máxima.

Modelos de equilibrio geral em mercados competitivos já estabelecidos na literatura ao longo dos anos 60, 70 e 80: (1) equilíbrio geral com mercados completos e informação simétrica; (2) equilibrio geral com externalidades e bens públicos; (3) equilíbrio geral considerando a escolha sob condição de risco; (4) equilibrio geral com mercado incompleto sob expectativas racionais; (5) equilibrio geral sob condição de informação assimétrica e destruição dos mercados; (6) estabilidade de mercado competitivo sob condição de substitutibilidade bruta fraca em mecanismo de ajustamento de preço não linear e expectativas adaptativas; (7) estabilidade em mercado competitivo sob condição de substitutibilidade bruta fazendo uso do enfoque da distância euclideana. Linhas de pesquisas sobre modelos de equilíbrio geral em 
desenvolvimento ao longo dos anos 90 destacam-se: (1) equilibrio geral com mercados incompletos; (2) o papel da moeda nos modelos de equilíbrio geral com informação assimétrica; (3) equilibrio geral sob completamento de mercados com ativos financeiros; (4) equilíbrio geral sob escolha envolvendo risco; (5) equilibrio geral sob condição de seleção adversa.

Os modelos de mercado em regime de concorrência imperfeita essencialmente estabelecidos por Cournot (1938) e aperfeiçoado na década dos 30, por Joan Robison (1933), Stalkelberg (1934) e Edward Chamberlain (1933) não possuem postulados fundamentais reais, pois tal estrutura de mercado diferencia-se ou seja, temos vários regimes de concorrência e, mesmo ausência dela. Veja-se: (1) monopólio: estrutura de mercado na qual existe um único produtor de determinada mercadoria para o qual não existe substituto próximo; (2) concorrência monopolística: estrutura de mercado na qual existem muitos vendedores que diferenciam-se no mercado apenas pela embalagem, tamanho e marca do produto. Por exemplo, pasta de dente; (3) oligopólio: estrutura de mercado na qual existe um pequeno número de vendedores de produto homogêneo ou diferenciado.

Define-se equilibrio Cournot-Nash (Nash, 1950) genericamente como uma n-upla de números reais positivos (quantidade de mercadorias) que se localiza sobre as superfícies de reação das firmas. Genericamente, no equilíbrio Cournot-Nash, cada firma estabelecida no mercado comporta-se otimamente conhecida as ações das outras firmas Com efeito, a solução preconizada no equilibrio Cournot-Nash coincide perfeitamente com o comportamento postulado na análise de mercado em concorrência perfeita e concorrência monopolística. 
Ilustra-se em duas dimensões o equilibrio Cournot-Nash:

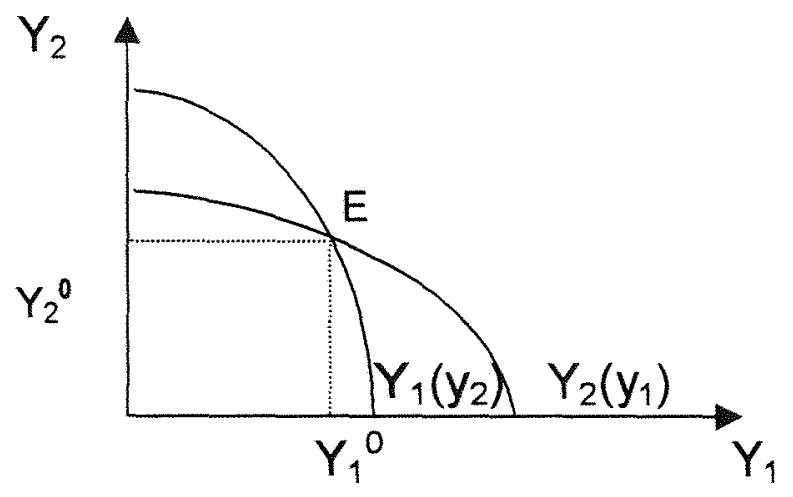

Figura 25 - Equilíbrio Cournot-Nash

e visualiza-se a Figura 25 através da seguinte composição: (1) o ponto E é único e portanto preenche a condição de estabilidade e representa o equilíbrio Cournot-Nash; (2) $Y_{1}\left(y_{2}\right)$ representa a curva de reação do competidor 1 enquanto que $Y_{2}\left(y_{1}\right)$ representa a curva de reação do competidor 2; (3) $Y_{1}$ e $Y_{2}$ correspondem a produção dos competidores 1 e 2 respectivamente; (4) a curva de reação para o competidor 2 mostra a quantidade que ele oferecerá, se o competidor 1 oferecer qualquer quantidade dada enquanto que, a curva de reação para o competidor 1 mostra a quantidade que ele oferecerá se 0 competidor 2 oferecer qualquer quantidade dada.

lluminado pelos trabalhos desenvolvidos pelos cientistas responsáveis pela advocacia dos modelos de concorrência imperfeita associado ao conceito de equilíbrio Cournot-Nash fica estabelecido ao longo dos anos 80 , artigos que buscam a explicação do comportamento das empresas em sua interação na economia de mercado. Destacam-se aqui dois artigos os quais lançam luz sobre linhas de pesquisas futuras.

O Professor David Furth (1986) da Universidade de Amsterdam descreve um modelo representativo da estrutura oligopolistica em que se encaixa precisamente o conceito de equilibrio Cournot-Nash. Destaca que para 
oligopólios regulares que é admitida a hipótese de produto homogêneo o equilibrio Cournot-Nash local possui pontos críticos em um campo de vetores Morse-Smale, que esteja definido sobre a região factível de preços e produtos não negativos. Quando considera-se a fronteira da região factivel do campo de vetores internos (interiores), segue da desigualdade de Morse que existe ao menos um ponto de equilíbrio estável na estrutura oligopolística. Por outro lado, quando ocorre existência de um equilíbrio interior não-estável, necessariamente o campo de vetores encontra-se em algum lugar ao longo da fronteira da região factivel. Este fato levanta a possibilidade da existência do equilibrio na fronteira.

O campo de vetores representativo do sistema econômico abstrato é:

$\phi\left(\phi_{1}, \ldots, \phi_{n}\right): V \rightarrow R^{n}$, para oligopólio homogêneo

$\varphi\left(\varphi_{1}, \ldots, \varphi_{n}\right): V\left(f_{1}, \ldots, f_{n}\right) \rightarrow R^{n}$, para oligopólio heterogêneo

onde

$\phi_{1}, \ldots, \phi_{\mathbf{n}}$ lucro marginal para oligopólio homogêneo

$\varphi_{1}, \ldots, \varphi_{\mathrm{n}}$ : lucro marginal para oligopólio heterogêneo

$V\left(f_{1}, \ldots, f_{n}\right)=\left\{\underline{P} \varepsilon[0, M]^{n}: \forall_{i}, f_{i}(P) \geq 0\right\}$ : oligopólio heterogêneo

$V=\left\{\underline{x} \varepsilon R^{n}: \forall_{i} \varepsilon\{1, \ldots, n\}, x_{1} \varepsilon[0, M]\right\}:$ oligopólio homogêneo

$x_{1}, \ldots . ., x_{n}:$ quantidade de produto

$P_{1}, \ldots, P_{n}:$ preços dos produtos

Os resultados fundamentais do modelo proposto pelo Professor Furth são classificados: oligopólio homogêneo, e oligopólio heterogêneo.

Teorema 16 - Quando $\phi$ internaliza pontos na fronteira de V:

1 existe ao menos um ponto de equilibrio estável;

2 o número de pontos de equilíbrio é impar;

3 se $\forall_{x 1} \varepsilon V$, sinal $\frac{\partial\left(\phi_{1}, \ldots, \phi_{n}\right)}{\partial\left(x_{1}, \ldots \ldots, x_{n}\right)}=(-1)$, existe um único ponto de equilíbrio estável. 
Teorema 17 - Quando $\varphi$ internaliza pontos na fronteira de $V\left(f_{1}, \ldots ., f_{n}\right)$

1 existe ao menos um ponto de equilibrio estável;

2 o número de pontos de equilíbrio é impar;

$\underline{3}$ se sinal $\frac{\partial\left(\varphi_{1}, \ldots, \varphi_{n}\right)}{\partial\left(P_{1}, \ldots, P_{n}\right)}=(-1), \forall \underline{p} \varepsilon V\left(f_{1}, \ldots, f_{n}\right)$ existe um único ponto de equilibrio estável

A Professora Gabrielle Demange (1986) conduz seu trabalho de pesquisa em direção a uma estrutura oligopolistica onde o produto é considerado homogêneo, aplica, também, o conceito de equilíbrio CournotNash. Com efeito, destaca a importância de dois tipos particulares de propriedades da estabilidade de um equilibrio Cournot-Nash: estabilidade interna e estabilidade relativa à entrada.

Primeira, diz-se que a estrutura oligopolística possui estabilidade de um processo de ajustamento contínuo de quantidade com um número fixo de firmas se, para equilibrio, alguma firma desvia-se (diverge) de produzir o produto de equilibrio.

Segunda, diz-se que um equilíbrio é de livre entrada se nenhuma firma ausente do mercado pode obter lucro na produção, assumindo que as outras firmas participantes do mercado não reagirão.

Enquanto que a estabilidade interna trata com firmas conhecidas no início da formação do mercado, a condição de livre entrada considera os participantes potencial, ou seja, aqueles que podem adentrar ao mercado. Em suma, a relevância empírica dos modelos oligopolísticos desenvolvidos consiste em sua aplicação às indústrias oligopolísticas como um todo ou a setores especificos daquelas indústrias.

Baseado em conceito fundamental do equilíbrio Cournot-Nash revelado no regime da concorrência imperfeita, oligopólio, é possível aprofundar-se no estudo sobre a teoria da estabilidade nas linhas de pesquisas que são desenvolvidas ao longo dos anos 90 e inicio do novo milênio em alguns problemas chaves: (1) conhecimentos limitados da demanda e equilíbrio no 
oligopólio. Significa indagar que efeitos tem sobre o equilibrio na estrutura oligopolistica quando o pesquisador tem um conhecimento restrito sobre a demanda de mercado por seu produto e reação dos concorrentes; (2) desenvolvimento das condições de estabilidade na solução de oligopólio imerso num mercado dinâmico quando ocorre que as funções demanda de mercado $e$ - nivel de produção dos rivais são desconhecidos; (3) relacionamento "funcional" entre expectativa adaptativa e estabilidade na estrutura de mercado oligopolística; (4) efeitos da velocidade de ajustamento e custos marginais crescentes sobre o problema da estabilidade na solução Cournot-Nash.

Enfim, as estruturas econômicas desenvolvidas pelos economistas ao longo dos anos 90 , e início do próximo milênio direcionam seus trabalhos em teoria dos jogos, especificamente estabilidade do equilíbrio estratégico e jogos sinalizados de equilibrio estável (Baldani, 1996; Mascolel, 1995), caos (Moon, 1992; Hilborn, 1994; Lorenz, 1996; Arfken \& Weber, 1997), nas teorias do crescimento econômico e ciclos de negócios vários problemas concentram a atenção dos pesquisadores: (1) estabilidade assintótica global e (local) de sistemas de controle ótimo aplicados à teoria do crescimento econômico; (2) procura da existência de solução para sistemas dinâmicos Hamiltonianos de crescimento econômico ótimo; (3) relacionamento entre crescimento balanceado e eficiência intertemporal na acumulação de capital; (4) descrição da estrutura e estabilidade de sistemas dinâmicos competitivos. Com efeito, fica evidenciado que a depender da estrutura de mercado que se está trabalhando e associado às hipóteses de comportamento dos agentes econômicos individuais, observa-se resultados referentes à estabilidade do equilíbrio competitivo de maneira diversa. 


\section{REFERÊNCIAS BIBLIOGRÁFICAS}

ALLAIS, M. Traité d'Economie Pure. Paris: Atelliers Industria, 1943. 852p.

ARAÚJO, A. P. Gerard Debreu. Literatura Econômica, v. 7, n.1 , p.177-126, 1985.

ARAÚJO, C. A. V. História do pensamento econômico. São Paulo: Editora Atlas, 1988. 158p.

ARFKEN, G. B. Mathematical Methods for Physicists. New York: Academic Press, 1997.

ARNOLD, V. I. Teoria da catástrofe. Campinas: Editora da UNICAMP, $1989.154 \mathrm{p}$.

ARROW, K. J. Aspects of the Theory of Risk - Bearing. Helsinki: Yrjö Janhnsson, 1965. 61p.

ARROW, K. J.; BLOCK, H. D.; HURWICZ, L. On the Stability of the Competitive, part.2. Econometrica, v.27, p 87-109, 1959.

ARROW, K. J.; DEBREU, G. Existence of an Equilibrium for a Competitive Economy. Econometrica, v. 22, p. 265-290, 1954.

ARROW, K. J.; ENTHOVEN, A. C. A Theorem on Expectations and the Stability of Equilibrium. Econometrica, v.24, p. 288- 293, 1956.

ARROW, K. J. Essays in the Theory of Risk - Bearing. Amsterdam: NorthHolland, 1970. 278p.

ARROW, K. J.; HURWICZ, L. Competitive Stability under Weak Gross Substitutibility: The Euclidean Distance Approach. International Economic Review, p. 38-49, 1960. 
ARROW, K. J.; HURWICZ, L. Competitive Stability under Weak Gross Substitutibility: Non - linear Price Adjustment and Adaptive Expectations. International Economic Review, v.3, n.2, p. 233-255, May 1962.

ARROW, K. J.; HURWICS, L. Some Remarks on the Equilibria of Economic Systems. Econometrica, v. 28, p.640-646, 1960.

ARROW, K. J.; HURWICS, L. On the Stability of the Competitive Equilibrium, part.1. Econometrica, v.26, p. 522-552,1958.

ARROW, K. J.; HAHN, F. H. General Competitive Analysis. San Francisco: Holden-Day, 1971.

ARROW, K. J.; MACMANUS, M. A Note on Dynamic Stability. Econometrica, v.26, p.297-305, 1958.

ARROW, K J.; NERLOVE, M. A Note on Expectation and Stability. Econometrica, v.26, p.297-305, 1958.

ARROW, K. J. Social Choice and Individual Values. New York: J. Wiley, 1951. 99p.

BALDANI, J.; ET AL. Mathematical Economics. New York: The Dryden Press, 1996.443p.

BERTRAND, J. Thèorie des Richesses. Journal des Savants, p. $449-508$, 1883.

BLAUG, M. História do pensamento econômico. Lisboa: Dom Quixote,.. 1984. 2v.

BLUME, L.; SIMON, C. P. Mathematics for Economist. New York: W. W. Norton, 1994.930p.

BOYER, C. História da matemática. São Paulo: Editora Edgard Blücher LTDA, 1996.496p.

CHAMBERLIN, E. H. The Theory of Monopolistic Competition. Cambridge, Mass: Harvard University Press, 1933.

CORNWALL, R. Introduction to the use of General Equilibrium Analysis. Amsterdan: North Holland, 1984.722p. 
COURNOT, A. Researches into the Mathematical Principles of the Theory of Wealth. New York: Kelly, 1838.

COUTINHO, P. C. Expectativas racionais com informação assimétrica: uma introdução. Revista de Econometria, v.13, n.1, p. 79-104, abril 1993.

CUNYNGHAME, H. Geometrical Political Economy. s.l; s.ed, 1904. 1 v

DAAL, J. V.; JOLINK, A. The Equilibrium Economics of Leon Walras. New York: Routledge, 1990.531p.

DEBREU, G. Theory of Value: An Axiomatic Analysis of Economic Equilibrium. New York: Wiley, 1959.114p.

DEBREU, G. Economic Theory in the Mathematical Mode. The American Economic Review, v.74, n.3, p. 267-278,1984.

DEBREU, G. The Aplication to Economics of Differential Topology and Global Analysis. The Americam Economic Review, v.66,n.2. p.281-287, 1976.

DEMANGE, G. Free Entry and Stability in a Cournot Model. Journal of Economic Theory, v.40,n.2, p.283-303, 1986.

EATWELL, J.; MILGATE, M.; NEWMAN, P. General Equilibrium. New York: W.W. Norton, 1990.346p.

EDGEWORTH, F. Y. Mathematical Psychics London: Routledge Kegan Paul , 1881.

EVES, H. Foundations and Fundamental Concepts of Mathematics. New Your: Dover Publications, 1990

EVES, H. Introdução à história da matemática. Campinas: Editora da UNICAMP, 1997.843p.

FARREL, M. J. The Convexity Assumption in the Theory of Competitive Markets. Journal of Political Economy, v.67, n.4, p.377-391, August. 1959.

FISHER, F. M. A Non-Tâtonnement Model with Production and Consumption. Econometrica, v.44, p. 907-938, September 1976.

FISHER, F. M. The Hahn Process with Firms but no Production. Econometrica, v.42, p.471-486, 1974. 
FISHER, F. M. Disequilibrium Foundations of Equilibrium Economics. Econometric Society Monographs in Pure Theory, 1990.363 p.

FUCHS, G.; LAROQUE, G. Dynamics of Temporary Equilibria and Expectations. Laboratoire d' Econométrie, Ecole Polytechinique, Paris, 1975.

FURTH, D. Stability and Instability in Oligopoly. Journal of Economic Theory, v.40, n.2, p.197-228,1986.

GALE, DAVID. A Note on Global Instability of Competitive Equilibrium. Office of Naval Research, 1960.

GANEM, A. Teoria neoclássica: a face econômica da razão positiva. Literatura Econômica, v.11,n.2, p.267-279, junho 1989.

GÄRDING, L. Encontro com a matemática. Brasília: Editora da Universidade de Brasília, 1981.323p.

GORDON, R. H. Negative Quasi-Definiteness and the Global Stability of General Equilibrium. Econometrica, v.42, n.1, p.197-198, January 1974.

GRANDMONT, J. M. Relatório sobre o trabalho científico de Maurice Allais. Literatura Econômica, v.11,n.3, p.561-600,outubro 1989.

GRANDMONT, J. M.; YOUNES, Y. On the Role of Money and the Existence of a Monetary Equilibrium. Review of Economic Studies, v.39, p.355-372, 1972.

GRANDMONT, J. M.; YOUNÉS, Y. On the Efficiency of a Monetary Equilibrium. Review of Economic Studies, v.40, p.149-165, 1973.

GRANDMONT, J. M. Temporary General Theory. Econometrica, v.45, n.3, p.535-572, April, 1977.

GREEN, J. R. The Stability of Edgeworth's Recontracting Process. Econometrica, v.42,n.1, p.21-34, January 1974.

GREEN, J. R. Temporary General Equilibrium in a Sequential Trading Model with Spot and Future Transactions. Econometrica, v.41, p.1103-1123, 1973.

HABIBAGAHI, H.; QUIRK, J. Hicksiany Stability and Walras's Law. Review of Economic. Studies, v.49, n.2, p. 249-258, April, 1973. 
HAHN, F. H. A Stable Adjustment Process for a Competitive Economy.

Review of Economic Studies, v.29, p.62-65, October, 1961.

HAHN, F. H. Equilibriium and Macroeconomics. New York: Themit Press, 1985. 314p.

HAHN, F. H. Gross Substitutes and the Dynamic Stability of General Equilibrium. Econometrica, v.26, p.169-170, 1958.

HAHN, F. H. On The Stability of Pure Exchange Equilibrium. International Economic Review, v.3, p.206-214, May 1962.

HAHN, F. H.; NEGISHI, T. A Theorem on Non - Tâtonnement Stability. Econometrica, v.30, p.463-469, July 1962.

HICKS, J. R. Value and Capital. Oxford: Clarendon, 1939.276p.

HICKS, J. R. Léon Walras. Econometrica, v.2, n.4, p. 338-348, October 1934.

HILBORN, R. C. Chaos and Nonlinear Dynamics. New York: Oxford University Press, 1994.

HOTAKA, R. Some Basic Problems on Excess Demand Functions. Econometrica, v.39,n.2, p.305-307, March 1971.

HUNT, E. K. História do pensamento econômico. Rio de Janeiro: Editora Campus, $1980.541 \mathrm{p}$.

INGRAO, B.; ISRAEL, G. The Invisible Hand. Cambridge: The Mit Press, 1990.491p.

KAMYIA, K. A Globally Stable Price Adjustament Process. Econometrica, v. 58, p.11481-1486, 1990.

LANGE, O. Price Flexibility and Employment. Bloomington: The Principia Press, 1944.150p.

LAROQUE, G.; GRANDMONT, J. M. Stability of Cycles and Expectations. Journal of Economic Theory, v.40, p.138-151, 1986.

LAUNHARDT, $W$. Mathematsche Begründung der Volkswirthschaftslehre. s.l; s.ed; 1885. $1 \mathrm{v}$ 
LORENZ, E. N. A essência do caos. Brasilia: Editora da Universidade de Brasilia, 1996.278p.

MASCOLEL, A.; WHINSTON, M. D.; GREEN, J. Microeconomic Theory. Oxford: Student Edition, 1995.981p.

MARSHALL, A. Principles of Economics. London: Macmillan, 1920.

MCKENZIE, L. W. On Existence of General Equilibrium for a Competitive Market. Econometrica, v.27, p. 54-71, 1959.

MCKENZIE, L. W. Stability of Equilibrium and the Value of Positive Excess Demand. Econometrica, v.28, n.3, p.606-617, 1960.

MENEZES, F. M. Equilibrium Theory in Infinite Dimensional Spaces. Revista de Econometria, v.13, n.1, p. 105-111, abril 1993.

MEROZ, A. Tjalling Koopmans. Literatura Econômica, v.5 n.1, p.17-24, 1983.

MEROZ, A. Kenneth Arrow. Literatura Econômica,v.4,n.2, p.153-170,1982.

MEROZ, A. John Hicks. Literatura Econômica v.3, n.6 p.527-546, 1981.

MEROZ, A. Wassily Leontief. Literatura Econômica, v.4, n.3, p.309-322, 1982.

MEROZ, A. Friedrich von Hayek. Literatura Econômica, v.4, n.5, p.603-616,1982.

MEROZ, A. Paul Anthony Samuelson. Literatura Econômica, v.3, n.4, p. 221-268, 1981.

MEROZ ,A. Leonid Kantorovich. Literatura Econômica, v.4, n.6, p. 743-748, 1982.

METZLER, L. A .The Stability of Multiple Markets: The Hicks Conditions. Econometrica, v.13, p. 277-292, 1945.

MOON, F.C. Chaotic and Fractal Dynamics. New York: Wiley, 1992.

MORET, J. Emploi des Mathématiques en Economie Politique Paris: Giard-Brière, 1915. $1 \mathrm{v}$ 
MORGENSTERN, O. Abraham Wald: 1902-1950. Econometrica, v.19, n.4, p.361-367, October 1951.

MORISHIMA, M. A. Generalization of the Gross Substitute System. Review of Economic Studies, v.37, n.2, p. 177-186, April 1970.

MORISHIMA, M. A. The Stability of Exchange Equilibrium: An Alternative Approach. International Economic Review, v.3, n.2, May 1962.

MUKHERJI, A. A. Locally Stable Adjustment Process. Econometrica, v.63, n.3, p. $441-448,1995$.

MUKHERJI, A. On the Sensitivity of Stability Results to the Choice of the Numeraire. Review of Economic Studies, v.40, n.3, p. 427-433, July 1973.

NAGEL, E. Assumption in Economic Theory. American Economic Review, v.43, n.3, p. 211-219, May 1953.

NEGISHI, T. General Equilibrium Theory and International Trade. Amsterdan: North-Holland, 1972.412p.

NEGISHI , T. On the Formation of Prices. International Economic Review, v.2,n.1,p. 123-126, January 1961.

NEGISHI, T. The Stability of a Competitive Economy: A Survey Article. Econometrica, v.30, p. 635-669, 1962.

NEGISHI, T. A Note on the Stability of an Economy where All Goods Are Gross Substitutes . Econometrica, v.26, p.445-447, 1958.

NIKAIDÔ, H.; UZAWA, $H$. Stability Non-Negativity in a Walrasian Tâtonnement Process. International Economic Review, v.1, n.1, p.50-59, January 1960.

PRADO , E. F. S. A Constelação Pós - Walrasiana. Revista de Economia Política, v.14, n.4, out-dez 1994.

QUIRK, J. P. Complementary and Stability of Equilibrium. The American Economic Review, v.60, n.3, p. 358-363, June 1970.

ROBINSON, J. The Economics of Imperfect Competition. London: Macmillan, 1933. 
SAAVEDRA-RIVANO, $\mathrm{N}$. Novos métodos matemáticos em economia dinâmica: uma resenha bibliográfica. Literatura Econômica, v.11, n.3, p. 637-644, outubro 1989.

SAMUELSON, P. A . Journal of Economic Literature, September, 1998.

SAMUELSON, P. A. The Foundations of Economic Analysis. Cambrigde: Harvard University Press, 1947. 380p.

SAMUELSON, P. A. The Stability of Equilibrium: Comparative Statics and Dynamics. Econometrica, v.9,p. 97-120, April 1941.

SAMUELSON, P. A. The Stability of Equilibrium: Linear and Non - Linear Systems. Econometrica, v.10, n.1, p.1-25, January 1942.

SAPOSNIK, R.; QUIRK, J. Introduction to General Equilibrium Theory and Welfare Economics. New York: Mcgraw-Hill, 1968. 221p.

SCARF, H. Some Examples of Global Instability of the Competitive Equilibrium. International Economic Review, v.1, p.157-172, September 1960.

SCHUMPETER, J. A. Dez grandes economistas. Editora Civilização Fronteira, 1958.70p.

SCHUMPTER, J. A. História da análise econômica. Editora Fundo de Cultura ,1964.1009p. 3v.

SHEPARD, R. W. Theory of Cost and Production Functions. New Jersey: Princeton University Press, 1970. 343p.

SILK, L. Os economistas. Rio de Janeiro: Zahar editores, 1980.

SMALE, S. A Convergent Process of Price Adjustment and Global Newton Methods. Journal of Mathematical Economics, v. 3, p.107-120, 1976.

SMALE, S. Dynamics in General Equilibrium Theory. American Economic Association, v.66,n.2, p.288-294, 1976.

SPIVAK, M. Calculus. Houston: Publish or Perish, 1994.670p.

STACKELBERG, $H$. von. Marketform and Gleichgewicht. Vienna and Berlin:Julius Springer, 1934. 
STRUIK, D. J. História concisa da matemática. Portugal: Gradiva Lisboa, 1997.395p.

SYDSAETER, K.; HAMMOND, P.J. Mathematics for Economic Analysis. New Jersey: Prentice-Hall, 1995. 982p.

TAAR, DAVID G. Expectations and Stability with Gross Complements. Review of Economics Studies, v.45(3), n.171, October, 1978.

TAKAYAMA, A. Mathematical Economics. Cambridge: Cambridge University Press, 1996. 737p.

TOLIPAN, R. A necessidade da história do pensamento econômico. Literatura Econômica, v.4, n.6, p.729-742,1982.

UZAWA, H. On the Stability of Edgeworth's Barter Process. International Economic Review, v.3,p.218-232, May 1962.

UZAWA, $H$. The Stability of Dynamic Process. Econometrica, v.29, n.4, p.617-631, October 1961.

VARIAN, H. Microeconomic. New York: W. W. Norton Company, 1992. 348p.

VARIAN, H. Microeconomia: Princípios Básicos. Rio de Janeiro: Editora Campus, 1994. 710p.

YAMANE, T. Matemática para economistas. São Paulo: Editora Atlas S.A., 1970.656p.

WALD , A. On Some Systems of Equations of Mathematical Economics. Econometrica, v.19, p.368-403, 1952.

WALKER, D. A. Walras' Theories of Tâtonnement. Journal of Political Economy, v.95,n.4,p.758-774,1987.

WALRAS, L. Compêndios dos elementos de economia política pura. São Paulo: Nova Cultural, 1996.352p. Coleção Os Economistas.

WALRAS, L. Elements of Pure Economics. Translated by William Jaffé(1954). Homewood,Irwm, 1926.

WEINTRAUB, E. R. On the Existence of a Competitive Equilibrium: 1930-1954. Journal of Economic Literature, v.21, p.1-39,1983. 


\section{BIBLIOGRAFIA RECOMENDADA}

APOSTOL, T. M. Calculus. New York: Blaisdell Publishing Company, 1966.666p. $2 \mathrm{v}$.

BARTLE, R. G.; SHERBERT, D. R. Introduction to Real Analysis. New York: Wiley, 1992.404p.

BEAVIS, B.; DOBBS, I. Optimization and Stability Theory for Economic Analysis. Cambridge: Cambridge University Press, 1990. 330p.

BOYCE, W. E.; DIPRIMA, R. Equações diferenciais elementares e problemas de valores de contorno. Rio de Janeiro: L.T.C, 1994. $531 p$.

BRONSON, R. Moderna introdução às equações diferenciais. São Paulo: Mc Graw-Hill do Brasil, 1977. 387p.

COURANT, R. Cálculo diferencial e integral. São Paulo: Editora Globo, 1965. 616p.

CYSNE, R.P.; MOREIRA, H. A. Curso de matemática para economistas. São Paulo: Editora Atlas, 1997. 282p.

DEBREU, G. On A Theorem of Scarf. Review of Economic Studies, v.30, p.177-180, 1963.

DEBREU, G. A Social Equilibrium Theorem. Proceedings of The National Academy of Science, v.38, p. 886-893, 1952.

DEBREU, G. Market Equilibrium. Proceedings of The National Academy of Sciences, v.42, p. 876-878, 1956. 
DEBREU, G. New Concepts and Techniques for Equilibrium Analysis. International Economic Review, v.3, p. 257-273, 1962.

DEBREU, G.; SCARF, H. A Limit Theorem on the Core of an Economy. International Economic Review, v. 4, p. 235-246, 1963.

DEBREU, G. The Coefficient of Resource Utilization. Econometrica, v. 19, p. 273-292, 1951.

DEBREU, G. Valuation Equilibrium and Pareto Optimum. Procedings of The National Academy of Sciences, v. 40, p. 267-278, 1954.

DOMINGUES, H. H. Espaços métricos e introdução à topologia. São Paulo: EDUSP, 1982. 183p.

FARIAS, T. A. Estabilidade de equilíbrio competitivo: A relação entre estabilidade dinâmica e expectativa adaptativa. Recife, 1987. 119p. Dissertação ( M.S. ) - Universidade Federal de Pernambuco.

FIGUEIREDO, D. G.; NEVES, A. F. Equações diferenciais aplicadas. Rio de Janeiro: IMPA, 1997. 301p.

GANDOLFO, G. Mathematical Methods and Models in Economic Dynamics. Amsterdan: North-Holland, 1971. 511p.

GANTMACHER, F. R. The Theory of Matrices. New York: Chelsea Publishing Co, 1974. 220p.

GUILLEMIN, V.; POLLACK, A. Differential Topology. New York: Prentice-Hall, 1974. 220p.

HAHN, F. H. Non-Walrasian Equilibria. Review of Economic Studies, p. 1-17, February 1978.

HAUSMAN, D. M. The Inexact and Separate Science of Economics. Cambridge: Cambridge University Press, 1994. 372p.

HEY, J. D. Current, Issues in Microeconomics. New York: Macmillan, 1986. $325 p$.

KEMENY, J. G. Finite Mathematical Structures. New York: Prentice-Hall, 1959. 525p.

KEMP, M.; KIMURA, $Y$. Introduction to Mathematical Economics. Germany: Springer-Verlag, 1978. 352p. 
KLEIN, E. Mathematical Methods in Theorical Economics: Topological and Vector Space Foundations of Equilibrium Analysis. New York: Academic Press, 1973. 334p.

KOGIKU, K C. Microeconomic Models. New York: Harper-Row, 1971. 309p.

KOUTSOYIANNIS A. Modern Microeconomics. New York: Macmillan, 1992. 581p.

KREIDER, D. L. Equações diferenciais. São Paulo: EDUSP, 1972. 485p.

KUELKAMP, N. Introdução à topologia geral. Florianópolis: Editora da UFSC, 1988. 202p.

LANGE, S. Linear Algebra. New York: Addison-Wesley, 1969. 294p.

LEIGHTON, W. Equações diferenciais ordinárias. Rio de Janeiro: L. T. C, 1978. 294p.

MILGROM, P.; ROBERTS, J. Comparing Equilibrium. The American Economic Review, v. 84, n. 3, p. 441-459, June 1994.

MORGENSTERN O. Thirteen Critical Points in Contemporary Economic Theory: An Interpretation. Journal of Economic Literature, v. 21, n. 2, p. $40-60,1983$.

MURATA, Y. Mathematics for Stability and Optimization of Economic System. New York: Academic Press, 1977. 360p.

NIKAIDO, $\mathrm{H}$. Introduction to Sets and Mappings in Modern Economics. Amsterdan: Nort-Holland, 1975. 335p.

PENNEY, D.; EDWARDS, C. H. Equações diferenciais elementares com problemas de contorno. Rio de Janeiro: Prentice-Hall do Brasil, 1995. $643 p$.

PHLIPS, I. Applied Consumption Analysis. Amsterdan: North- Holland, 1990. 331p.

PINDYCK, R.; RUBINFELD, D. Microeconomia. São Paulo: Makron Book, 1994. $968 p$. 
REICHLIN, P. Equilibruim Cycles in a Overlapping Generations Economy with Production. Journal of Economic Theory, v. 40, p. 89-102, 1986.

SAMUELSON, P. A. The Collected Scientific Papers of Paul Anthony Samuelson. New York: Editor By Joseph e. Stiglitz, 1966. 3v.

SMALE, S.; HIRSCH, H.W. Differential Equations, Dynamical Systems and Linear Algebra. New York: Academic Press, 1974. 359p.

VALENTINE, F. Convex Sets. New York: Mcgraw-Hill, 1964. 184p.

VARIAN, H. Non-Walrasian Equilibria. Econometrica, v. 45, n. 3 , p. 573-590, April 1977.

WOODS, J. E. Mathematical Economics. New York: Longman, 1978. 382p. 